PUBLISHED BY THE AMERICAN MUSEUM OF NATURAL HISTORY CENTRAL PARK WEST AT 79TH STREET, NEW YORK, NY 10024 Number 3317, 50 pp., 32 figures, 6 tables January 30, 2001

\title{
On Tsaganomyidae (Rodentia, Mammalia) of Asia
}

\author{
BANYUE WANG ${ }^{1}$
}

\begin{abstract}
The taxa within the family Tsaganomyidae are systematically redefined. Cyclomylus lohensis is a valid taxon. It is generically different from Tsaganomys in both tooth and skull morphology, including having lower crowned cheek teeth with closed roots, more prominent lophs and cusps on occlusal surfaces, a reduced dentine part, different microstructure of the incisor enamel, as well as other features. Two new species, $C$. intermedius and $C$. biforatus, are included in the genus Cyclomylus, mainly based on differences in crown height and root number. The strongly hypsodont tsaganomyids can be separated into two genera: Tsaganomys and a new genus, Coelodontomys, based on differences in cheek tooth morphology and relations of cheek teeth with incisors. As a result, Tsaganomyidae includes three genera and five species: Tsaganomys altaicus, Cyclomylus lohensis, C. intermedius, C. biforatus and Coelodontomys asiaticus. Tsaganomys is the sister group to Cyclomylus plus Coelodontomys.

Cyclomylus lohensis, the most primitive species, made its first appearance in early early Oligocene; C. intermedius also then but slightly later. Cyclomylus biforatus and Coelodontomys asiaticus are restricted to late early Oligocene. Tsaganomys altaicus made its first occurrence in late early Oligocene and survived to early late Oligocene (or possibly earliest Miocene), by which time Cyclomylus and Coelodontomys had already become extinct.

The Tsaganomyidae differ from Hystricognathi and Ctenodactyloidea in lacking the derived features of the two latter groups, such as hystricomorphous skull, large and deep pterygoid fossa, well-developed lower masseteric crest, fused malleus and incus, large and anteriorly expanded malleus head, proximal fusion of tibia and fibula, and large hypocone on upper cheek teeth. The autapomorphic features of the Tsaganomyidae are extremely enlarged temporal fossa, prominent sagittal and occipital crests, robust and strongly laterally convex zygomatic arch with welldeveloped jugal meeting premaxilla, high ascending ramus with high coronoid process, and triangularly convex surface of condyloid process. The angular process in the tsaganomyids is large and strongly flared, which is so different from the typical hystricognathous lower jaw that
\end{abstract}

\footnotetext{
${ }^{1}$ Professor, Institute of Vertebrate Paleontology and Paleoanthropology, Chinese Academy of Sciences, Beijing 100044, China.
} 
it is called tsaganomys-type hystricognathous mandible in this paper. The Tsaganomyidae presumably have unelongated masseter and pterygoid muscles but well-developed temporal muscle and steplike occlusal surface of the cheek tooth row. These features may be associated with crushing and transverse chewing. Obviously, the Tsaganomyidae evolved in a direction fairly distinct from both the Ctenodactyloidea and Hystricognathi.

\section{INTRODUCTION}

The Tsaganomyidae are a group of Oligocene rodents endemic to Asia. They are fossorial rodents with a protrogomorphous skull, derived hystricognathous lower jaw, strong incisors, and cylindrical, unilaterally hypsodont cheek teeth, in which the occlusal pattern is lost early in wear. Their fossils are widely found and have been considered highly instructive in geological age determination (Teilhard de Chardin, 1926; Bohlin, 1937; Kowalski, 1974; Wang et al., 1981; Bryant and McKenna, 1995). However, because the taxa within the family remain so far inadequately defined, their classification is in a rather chaotic state, and, consequently, their geological distribution is poorly understood.

Matthew and Granger (1923) described two genera and species, Tsaganomys altaicus and Cyclomylus lohensis, based on the material from the Hsanda Gol Formation of Mongolia. Later the two taxa were reported from Nei Mongol, Gansu, and Ningxia provinces of China (Teilhard de Chardin, 1926; Bohlin, 1937; Young and Chow, 1956). Vinogradov and Gambaryan (1952) described two new species of a new genus: Pseudotsaganomys turgaicus and P. mongolicus from Mongolia and Kazakhstan. Shevyreva (1972) established two new taxa: $S e$ pulkomys eboretus and Beatomus bisus from Mongolia. Kowalski (1974) considered Shevyreva's two taxa as synonyms of Cyclomylus lohensis and Tsaganomys altaicus respectively. Meanwhile Kowalski created a new species of Cyclomylus, C. minutus, which was relocated to Tsaganomys by Huang (1993). Shevyreva (1994) added two new species, Beatomus gloriadei and Cyclomylus mashkovae from Kazakhstan. Recently Bryant and McKenna (1995) lumped all the above- mentioned genera and species into a single genus and species, Tsaganomys altaicus.

A careful comparison of the material of the Tsaganomyidae from the Hsanda Gol
Formation, Mongolia, in the collection of the American Museum of Natural History (AMNH), with that from China, housed in the Institute of Vertebrate Paleontology and Paleoanthropology, Chinese Academy of Sciences (IVPP), especially the holotypes of Tsaganomys altaicus and Cyclomylus lohensis, shows that Cyclomylus can be readily distinguished from Tsaganomys in tooth morphology and relations of cheek teeth to incisors. Cyclomylus is not only a valid genus but also includes three species, $C$. lohensis and two new species: $C$. biforatus and $C$. intermedius. Among the strongly hypsodont forms, there are two taxa: Tsaganomys and a new genus, Coelodontomys. Altogether the Tsaganomyidae comprise three genera and five species. The geological distribution of these taxa is clarified. A detailed analysis of the characters of the skull and lower jaw reveals that the Tsaganomyidae represent an independent lineage, having no clear affinity to Hystricognathi, Ctenodactyloidea, or $\mathrm{Cy}-$ lindrodontidae.

\section{MATERIALS AND METHODS}

The materials studied here include (1) specimens from Saint Jacques of Hanggin Qi, Qianlishan District and other localities of Otog Qi, and Alex Zuoqi of Nei Mongol, Haiyuan and Guyuan of Ningxia, and Lanzhou and Danghe of Gansu, all in China, collected by the Sino-Soviet Expedition (1959) and other teams from IVPP in 1977-1997; (2) specimens collected from the Hsanda Gol Formation, Mongolia, by the Asiatic Expedition in 1922 and 1925, housed in AMNH and IVPP; and (3) specimens described by Bohlin (1937), Young and Chow (1956) and Huang (1993) and a cast of the skull with mandible described by Teilhard de Chardin (1926). Because the differences among the species of Cyclomylus are mainly based on root number, and I was not able to examine every specimen of the large collection in the AMNH during my stay there, only a few 

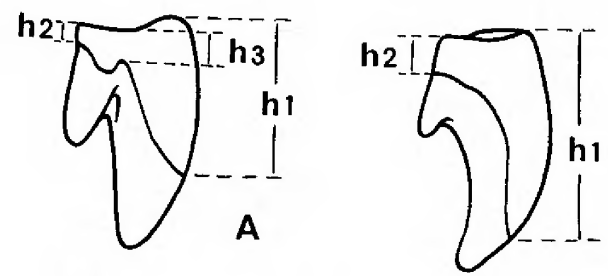

B

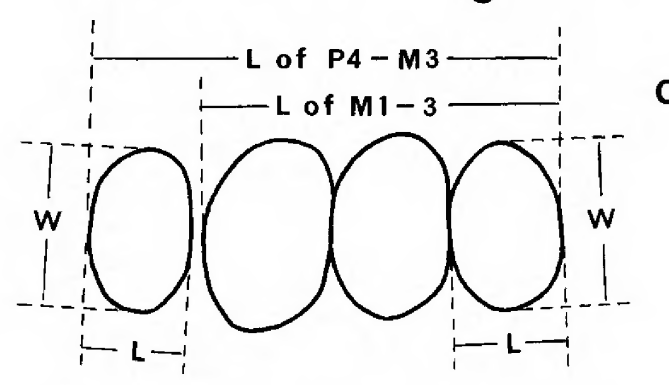

C
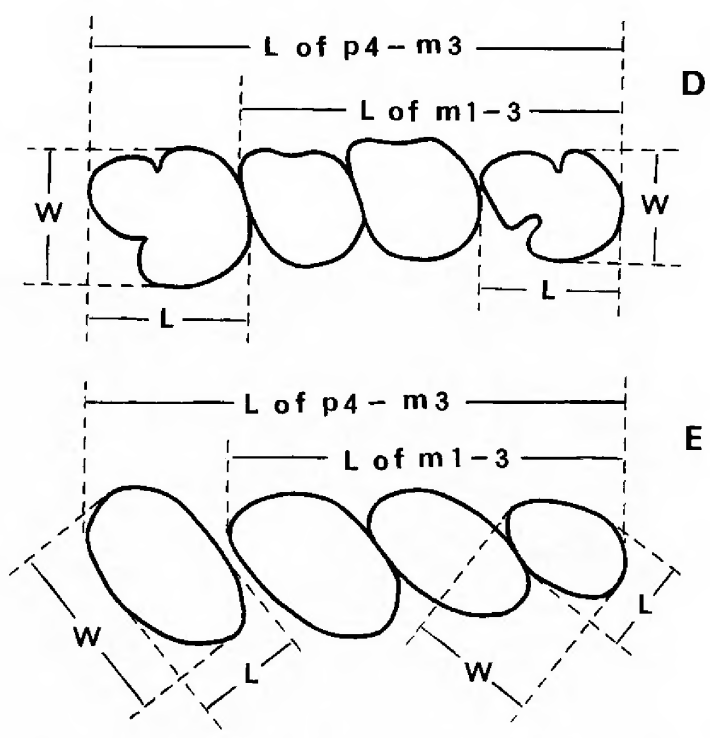

Fig. 1. Tsaganomyid cheek teeth showing reference points for measurements, A, B. Lateral view of cheek teeth. A. p4. B. Other cheek teeth except p4. C-E. Occlusal view of cheek teeth. C. Upper cheek teeth. D, E. Lower cheek teeth. D. Less worn. E. More worn. Abbreviations are: h, enamel height; h1, enamel height on lingual side of upper teeth (buccal side of lower teeth); $\mathbf{h} \mathbf{2}$, on buccal side of upper teeth (lingual side of lower teeth); h3 , enamel height between two roots on anterobuccal side on p4; $\mathbf{L}$, Length; and $\mathbf{W}$, width.

specimens, in which the roots are exposed, are discussed in this paper. Remarks on fossils from other parts of Asia are based on the literature. Because the differences among the genera and species of the Tsaganomyidae are mainly in the tooth structure and roots, and it is sometimes hard to identify these differences based on the figures and simple description, in some cases I refrain from commenting on the specimens in the literature.
Only the cheek teeth for which the position in the jaw was known were measured with calipers, and their statistics were calculated. Of the large collection of Coelodontomys housed in the AMNH, only a few specimens were measured in this paper. The measurements taken are illustrated in figure 1.

The terminology of the cusps and lophs used in this study mainly follows Wood and Wilson (1936) and that of the masseteric 
muscles follows Woods (1972). The biostratigraphic zonation of the Oligocene proposed by Wang $(1997 a, 1997 b)$ is adopted here.

\section{AbBreviations}

\section{Repositories or Localities}

AMNH American Museum of Natural History, New York

GL Prefix to localities of Gansu Museum, Lanzhou

IVPP Institute of Vertebrate of Paleontology and Paleoanthropology, Chinese Academy of Sciences, Beijing

IVPP Prefix to localities of Institute of Verte-

Loc. brate of Paleontology and Paleoanthropology, Chinese Academy of Sciences, Beijing

IVPP V Prefix to catalog number of vertebrate fossils of Institute of Vertebrate of Paleontology and Paleoanthropology, Chinese Academy of Sciences, Beijing

K Institute of Zoology, National Academy of Sciences of the Republic of Kazakhstan, Almaty

LDV Vertebrate Section, Department of Geology, Lanzhou University, Lanzhou

MNHN Museum National de Histoire Naturelle, Paris

PIN Paleontological Institute, Academy of Sciences of former USSR, Moscow

Sh Shargaltein Gol, Gansu

W Wu-tao-ya-yu, Gansu

\section{Microstructure of the Incisor Enamel}

$\begin{array}{ll}\text { HSB } & \text { Hunter-Schreger band } \\ \text { PE } & \text { portio externa } \\ \text { PI } & \text { portio interna } \\ \text { EDJ } & \text { enamel-dental junction }\end{array}$

Tables of measurements of the dentition (mm)

L length

W width

h1 enamel height on lingual side of upper cheek teeth (buccal side of lower cheek teeth)

h2 enamel height on buccal side of upper cheek teeth (lingual side of lower cheek teeth)

h3 shortest enamel height between two roots on anterobuccal side of $\mathrm{p} 4$

H1 height difference between buccal and lingual enamels of a tooth $(=\mathrm{h} 1-\mathrm{h} 2)$
$\mathrm{H} 2$ height difference between the buccal enamel (h1) and shortest enamel between two roots $(\mathrm{h} 3)$ on $\mathrm{p} 4$

\section{Statistical Treatment}

$\begin{array}{ll}\mathrm{N} & \text { number of specimens } \\ \text { Min } & \text { minimum } \\ \text { Max } & \text { maximum } \\ \text { Aver } & \text { average } \\ \mathrm{S} & \text { standard derivation } \\ \mathrm{V} & \text { variance }\end{array}$

\section{SYSTEMATICS}

Tsaganomyidae Matthew and Granger, 1923

TyPE GenUs: Tsaganomys Matthew and Granger, 1923.

INCLUDED GENERA: Cyclomylus Matthew and Granger, 1923, and Coelodontomys, new genus.

RANGE: Oligocene and possible earliest Miocene of China, Mongolia, and Kazakhstan.

Emended Diagnosis: Fossorial rodents close to Marmota in size; skull protrogomorphous, massive and low; sagittal and occipital crests prominent; orbit very small; temporal fossa very large; occiput sloping forward, very wide; braincase nearly triangular in shape, with narrow postorbital constriction; strong zygomatic arches almost forming a circle; anterior end of zygoma formed by broad vertical maxillary and jugal; small oval infraorbital foramen; jugal extending mediodorsally to meet the premaxillary; bulla flattened anteriorly, heavily septate; malleus and incus not fused; internal carotid artery system absent; mandible hystricognathous with large, flared angular process and high coronoid process; mental foramen anterior to p4; dental formula 1013/1013; incisors procumbent, with flat labial surface; upper incisor extending back into orbit, with posterior end of alveolus forming a bulge on side wall of maxillae, ending laterodorsal to M1-2; lower incisor extending back to and beneath condyle; incisor enamel multiserial; cheek teeth cylindrical, unilaterally hypsodont, four crested without hypocone; occlusal surface of cheek tooth row steplike; occlusal pattern lost very early in wear, becoming a concave surface bordered by higher margins. 
Discussion: The tsaganomyids were first named as a subfamily, Tsaganomyinae, of Bathyergidae, by Matthew and Granger (1923) to include two genera and species, Tsaganomys altaicus and Cyclomylus lohensis, which was followed by Teilhard de Chardin and Leroy (1942). Landry (1957) arranged the tsaganomyids in the subfamily Bathyerginae of the Bathyergidae. However, Teilhard de Chardin (1926) thought they represented a special family, a viewpoint neglected for a long time. Patterson and Wood (1982) formally raised the tsaganomyids to a family rank to include Tsaganomys, Cyclomylus, and perhaps Pseudotsaganomys, Sepulkomys, and Beatomus. Other authors considered them cylindrodonts (Wood, 1937, 1955, 1974; Wilson, 1949; Simpson, 1945; Schaub, 1958, Vinogradov and Gambaryan, 1952; Mellett, 1968; Shevyreva, 1972, 1974a, 1974b, 1994; Kowalski, 1974; Huang, 1993). I agree with Teilhard de Chardin (1926) and Patterson and Wood (1982) that the Tsaganomyidae warrant family rank.

\section{Tsaganomys Matthew and Granger, 1923}

Tsaganomys Matthew and Granger, 1923 (partim): 2. Bryant and McKenna, 1995 (partim): 5-16. McKenna and Bell, 1997 (partim): 191.

Beatomus Shevyreva, 1972: 143.

TyPe SPECIES: Tsaganomys altaicus Matthew and Granger, 1923.

GeOlogical Range: Late early Oligocene to early late Oligocene, possible early Miocene.

Geographic Distribution: Nei Mongol, Gansu, Ningxia provinces of China; Valley of Lakes of Mongolia; and Kazakhstan.

EMENDED Diagnosis: Medium- to largesized tsaganomyids; nasal-frontal suture more anterior in position than is premaxillary-frontal suture; left and right antepremolar crests curved and uniting before reaching incisive foramen; premaxillary-maxillary suture intersecting merged antepremolar crest; infraorbital foramen oval, with major axis nearly horizontal, almost parallel with anterior margin of ventral surface of anterior zygomatic root; angle between dorsal margin of posterior part of upper incisor alveolus and occlusal surface of cheek teeth near $40^{\circ}$; nearly straight P4 extending medially to up- per incisor; molars extending high into orbit, passing by medially to upper incisor; lower cheek teeth concave anterolingually and extending buccally to lower incisor; cheek teeth strongly unilaterally hypsodont, having short conic pulp cavity with pointed apex, ratio of dentine part to pulp cavity high, enamel on occlusal surface very thin, cusps and lophs very low and weak, no core present after being worn; lower cheek teeth with nearly transversely stretched external valley; nearly square p4 with low metalophid I, long metalophid II, subequal metaconid and protoconid; incisor enamel having thin PE with no inclined prisms and PI with $20-30^{\circ}$ inclined HSB of 5-7 prisms.

\section{Tsaganomys altaicus Matthew and Granger, 1923}

Figures 2-12, 13A, 14; table 1

Tsaganomys altaicus Matthew and Granger, 1923 (partim): 2-4, figs. 1 (partim), 2 (partim). Teilhard de Chardin, 1926: 29, 30, fig. 16C; pl. IV, figs. 4-6. Bohlin, 1937: 46-48, figs. 110-123. Vinogradov and Gambaryan, 1952 (partim): 23, 24. Mellett, 1968 (partim): 6, 10. Qiu and Gu, 1988: 207, 212. Huang, 1993: 38-39, pl. II, figs. 1, 2. Bryant and McKenna, 1995 (partim): 5-16, fig. 9.

Cyclomylus lohensis Matthew and Granger, 1923 (partim): 5. Kowalski, 1974 (partim): 158.

Tsaganomys sp. Teilhard de Chardin 1926: 30, figs. 16A, B; p1. IV, fig. 7. Wang et al., 1981: 27-30. Emry et al., 1998 (partim): 308-310, fig. 8A.

Beatomus bisus Shevyreva, 1972: 143, 144, fig. 6; 1974a: 51-53, figs. 1d, e, 2, 3.

Tsaganomys minutus: Huang, 1993: 39-42, pl. II, figs. 3-5.

Beatomus gloriadei Shevyreva, 1994: 112, figs. 1a, b. NEW SYNONYMY.

HolotyPE: A skull and lower jaw (AMNH 19019) from the Hsanda Gol Formation, red strata, Loh, Tsagan Nor basin, Mongolia. Figured by Matthew and Granger, 1923: figs. 1 (partim) and 2 (partim).

PARATYPES: AMNH 19020 and 19037.

REFERRED SPECIMENS: IVPP V 10410.118, V 10411, V 10411.1-9, V 11388-V 11426, V 11539-11542, V 11825, V 11826; LDV 860911.1-14; Sh 1; W 25; MNHN 1924-4; AMNH 19039, 19097, 21634, $26185,56650,81223 \mathrm{~A}, 81249,81261$, 

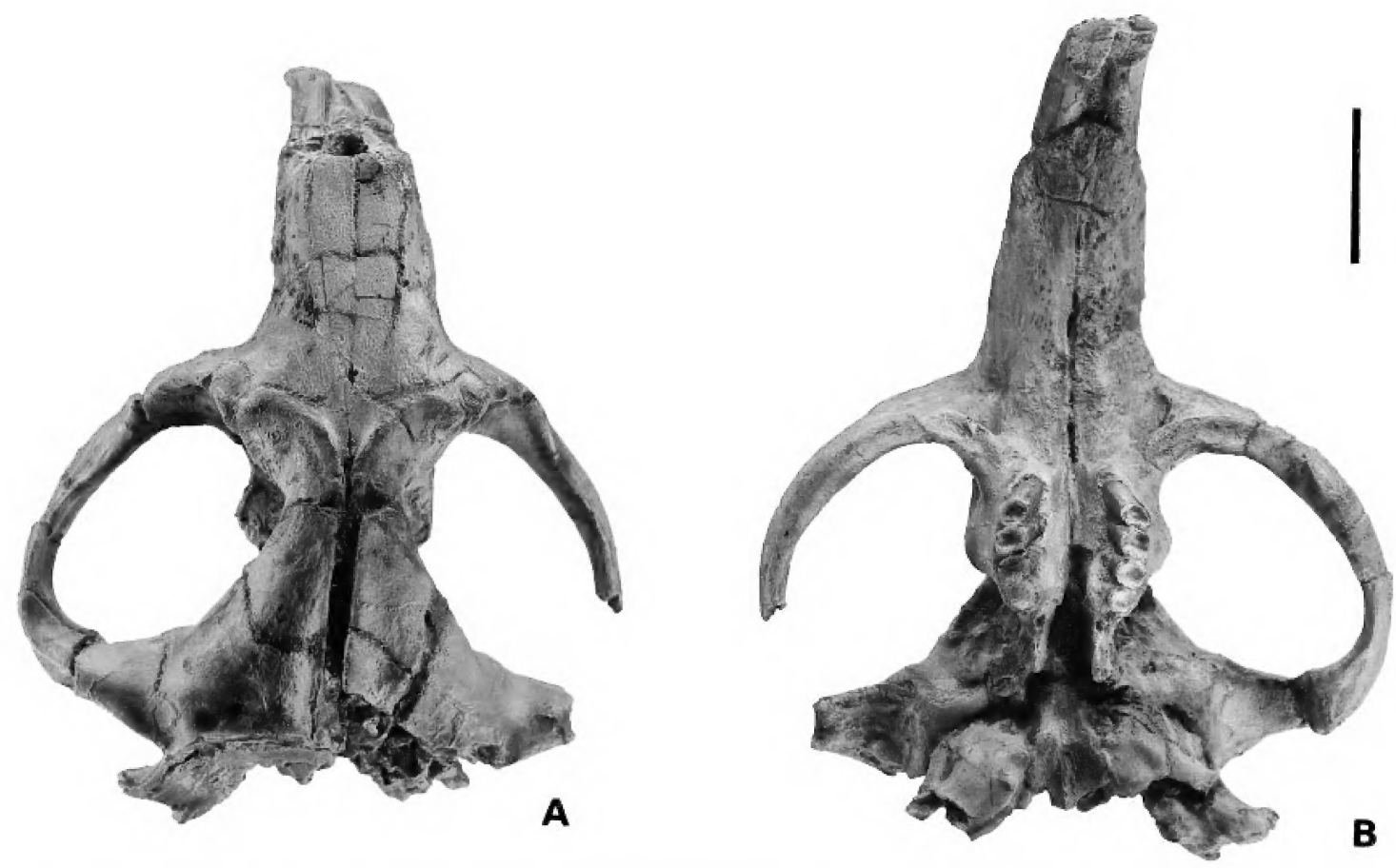

Fig. 2. Skull of Tsaganomys altaicus (IVPP V 11390). A. Dorsal view. B. Ventral view. Scale $=3$ $\mathrm{cm}$.

$81269,81356,81357,81360,81364,81390$, $81392,81464,81465,81474,81480,81483$, 81486-81490, 81991, 82126, 82178, 82262, $82265,82273,82289,82292,83510,83516$, $83519,83520,83522,83525-83528,83533$, $83535,83539,83540,83555,83558,83566$, $83571,83573,83574,83576,83584,83586$, $83590,84328,84332,84352,84513,84517$, 85184, 85191-85193, 85195-85204, 85234$85238,85240,85250,85251,85253,85257$, $85258,85261,85264,85265,85271,85273$, $85275,85276,85282,85283,85285,85286$, $85291,85302,85309,85541,85784,85786$, $85787,85789-85791,85793-85800 ;$ PIN $475 / 1899,475 / 1980,475 / 115,475 / 553,475 /$ 363, 2979/909, and K35(15)/424.

GeOLOGICAL RANGE: Late early Oligocene (upper member of Wulanbulage Formation, upper part of Ulantatal Formation, Qingshuiying Formation, Hsanda Gol Formation, yellow sandstone and lower part of red mudstone of lower member of Xianshuihe Formation, and Buran Formation), early late Oligocene and early Miocene (?) (red mudstone in Gaolanshan).

GeOgraphic Distribution: Saint Jacques
(IVPP Locs. 77045 [V 11388], 77046 [V 11389], 77046 [red bed II, V11390], 77046.2 [V 11391], 77046 [white bed II, V 11392], 77046.3 [V 11393], 77046.5 [V 11394], 77047 [V 11395], 77048.2 [V 11396], 77049.2 [V 11397], 77049.8 [V 11398], 78020 [V 11399], and other localities [V 11400-11403]) of Hanggin Qi; Tuolimiao (V 11404) of Bulunmiao and Qianlishan District (IVPP Locs. near 78016 [V 11405], 78018 [upper part, V 11406], 78018 [V 11407], 78018 [79] [V 11408] 78019 [V 11409], 79015 [V 11410]) of Otog Qi; and Ulantatal (V 10410, V 10411, V 11411-11414) and Huhetaolegai (IVPP Locs. 94003 [V 11415], 94003-2 [V 11416]) of Alxa Zuoqi in Nei Mongol; Yuanjiawowo (IVPP Locs. 920121A [V 11421], 92013-1 [V 11422], 92013-2 [V 11423]) of Haiyuan, and Sikouzi (V 11424) of Guyuan, Ningxia; Lanzhou (GL Locs. 9005 [V 11417], 9006 [V 11418], 9016 [V 11419], 9016B [V 11420], 9707A [V 11539], 9707C [V 11540], 9707D [V 11541], 9711 [V 11542], 9712 [V 11825], 9715 [V 11826]; the Gaolanshan [LDV 860911]); Shargaltein Gol (Sh 1) and Wu- 


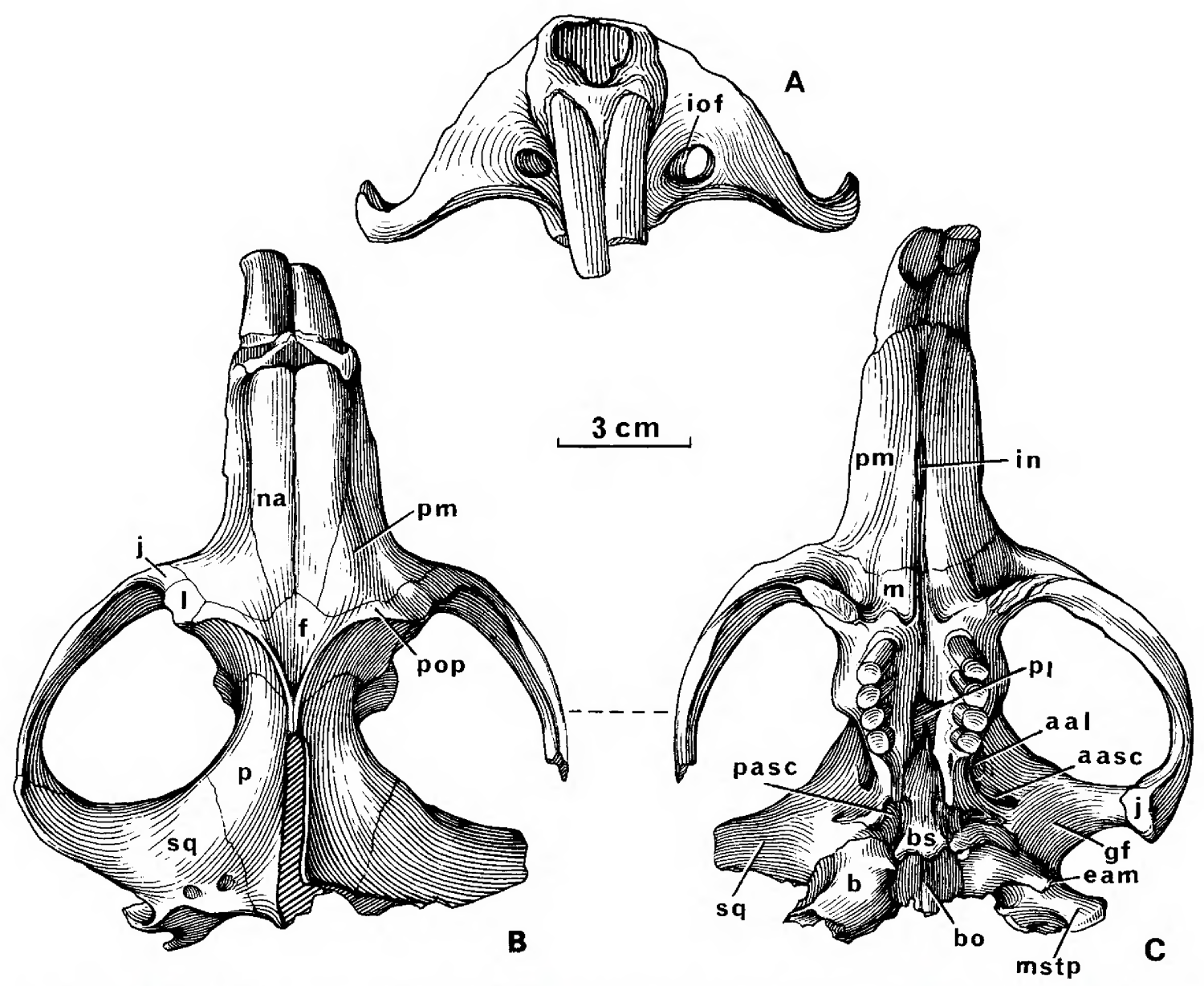

Fig. 3. Skull of Tsaganomys altaicus (IVPP V 11390). A. Anterior view. B. Dorsal view. C. Ventral view. Abbreviations are: aal, anterior alar fissure; aasc, anterior opening of the alisphenoid canal; $\mathbf{b}$, bulla; bo, basioccipital; bs, basisphenoid; eam, external auditory meatus; $\mathbf{f}$, frontal; gf, glenoid fossa of squamosal; in, incisive foramen; iof, infraorbital foramen; $\mathbf{j}$, jugal; l, lachrymal; m, maxillary; mstp, mastoid process; na, nasal; p, parietal; pasc, posterior opening of the alisphenoid canal; pl, palatine; pm, premaxillary; pop, postorbital process; sq, squamosal.

tao-ya-yu (W 25) of Danhe in Gansu; and other locality (V 11426) of China; Hsanda Gol, Loh of Tsagan Nor Basin, Mongolia (V 11425, PIN 475/1899, 475/1980, 475/115, $475 / 553,475 / 363$, and other specimens in AMNH); and Chaybulak-Dzhamangora watershed (PIN 2979/909) and K15, Podorozhinik, Zaysan Basin, Kazakhstan (K35[15]/ 424).

EMENDED DiAgnosis: As for the genus.

DESCRIPTION: The skull was described by Bryant and McKenna (1995). However, the description was based on the specimens representing Tsaganomys, Cyclomylus, and Coe- lodontomys. The complementary description given below deals mainly with the differences of Tsaganomys from the other two genera and some additional characters, mainly based on the holotype (AMNH 19019), IVPP V 10411 and V 11390, and MNHN 1924-4.

In general the shape of the skull is much like those of fossorial rodents in having a low lateral profile, narrow rostrum, broad cranial region, and an occiput sloping anteriorly. The rostrum is about two-fifths of the total length of the skull.

DORSAL VIEW: The skull is triangular in shape with a narrow anterior end. The ros- 
trum is slightly reduced anteriorly in width. The long nasals taper posteriorly in their posterior part and meet the frontal at about the level of the anterior margin of the orbit. The nasal-frontal suture is concave posteriorly. The dorsal process of the premaxillary is wide and extends more posteriorly than does the nasal. The premaxillary-frontal suture is slightly more posteriorly located than is the nasal-frontal suture and is almost parallel to the anterior part of the sagittal crest. The dorsal part of the lachrymal is large, round, with a narrow posterior process, and inserts among the jugal, premaxillary, and frontal. The very small orbit is posterior to the jugal and lateral to the lachrymal. The narrowest part of the skull is across the postorbital constriction rather than the interorbital constriction as described by Bryant and McKenna (1995). The dorsal part of the frontal is very short and wide. The parietals are long, as long as the combined length of the nasal and frontal, and roughly hexagonal in outline, with an M-shaped frontal-parietal suture. The temporal surface of the squamosal is large, with a well-developed zygomatic process uniting with the jugal. One of the particular features is that the temporal fossae are tremendous. The prominent sagittal crest starts from a pronounced anterior process on the anterolateral corner of the frontal and extends posteromedially as a curved crest. Near the frontal-parietal suture the two crests unite with each other to form a single longitudinal crest that joins with a strong occipital crest. The anterior process of the sagittal crest (the antorbital crest of Bryant and McKenna, 1995) is, in fact, located dorsomedial to the orbit, rather than anterior to it. Like the supraorbital swelling in Paramys, the anterior process of the sagittal crest appears to be homologous to the postorbital process of the Sciuridae, as suggested by Wood (1962: 16). The well-developed zygomatic arches are strongly convex outwards.

Ventral VIEW: The diastema between incisor and P4 is very long, nearly half the basal length of the skull. The incisive foramen is very small and narrow and located near the midpoint of the diastema. The crest, running from the alveolus of $\mathrm{P} 4$ to the incisive foramen, is called antepremolar crest here and may mark the lateral margin of the palate. It is concave laterally and well developed, and it sometimes forms high bony plates. Left and right antepremolar crests merge into one longitudinal crest near the midpoint between $\mathrm{P} 4$ and incisive foramen. The premaxillary-maxillary suture crosses the merged crest. There are distinct fossae lateral to the crests. The zygomatic process of the maxillary extends laterally anterior to P4 and forms the lower branch of the anterior root of the zygomatic arch. On the ventral surface there are wide rough areas for anchoring the masseter muscles. The two cheek tooth rows are very short in comparison with the skull and parallel to each other. The palate between them is concave transversely, with a longitudinal crest extending along the palatine suture to separate the palate into two longitudinal grooves. The posterior palatine foramina are opposite M2. The maxillarypalatine sutures are nearly $\mathrm{M}$-shaped, with a $\mathrm{V}$-shaped anterior part at the posterior end of the posterior palatine foramina and two lateral parts running along the lingual side of M2-3 and then turning laterally behind M3. There is a pair of distinct posterior maxillary foramina posteromedial to M3. The choana opens at the level of posterior border of M3. The very small, shallow pterygoid fossa is not perforated; it is situated far behind the anterior border of the choana. The bulla is oval in shape and slightly inflated, with ossified external auditory meatus extending laterally. The blunt mastoid process protrudes posterolaterally. The broad, short glenoid fossa consists of the zygomatic processes of squamosal and jugal. The postglenoid foramen is large.

ANTERIOR VIEW: The nostril is very small. The infraorbital foramen is small, oval, facing anteriorly and slightly ventrally, and with no evidence of passage for the masseter onto the rostrum. The major axis of the infraorbital foramen is strongly inclined and usually nearly horizontal, almost parallel to the anterior margin of the ventral surface of the maxillary. As described by Bryant and McKenna, the anterior zygomatic root is expanded to a wide, thin plate and consists of zygomatic processes of maxillary and jugal. The anterior part of the jugal expands to meet the lachrymal and premaxillary, ex- 

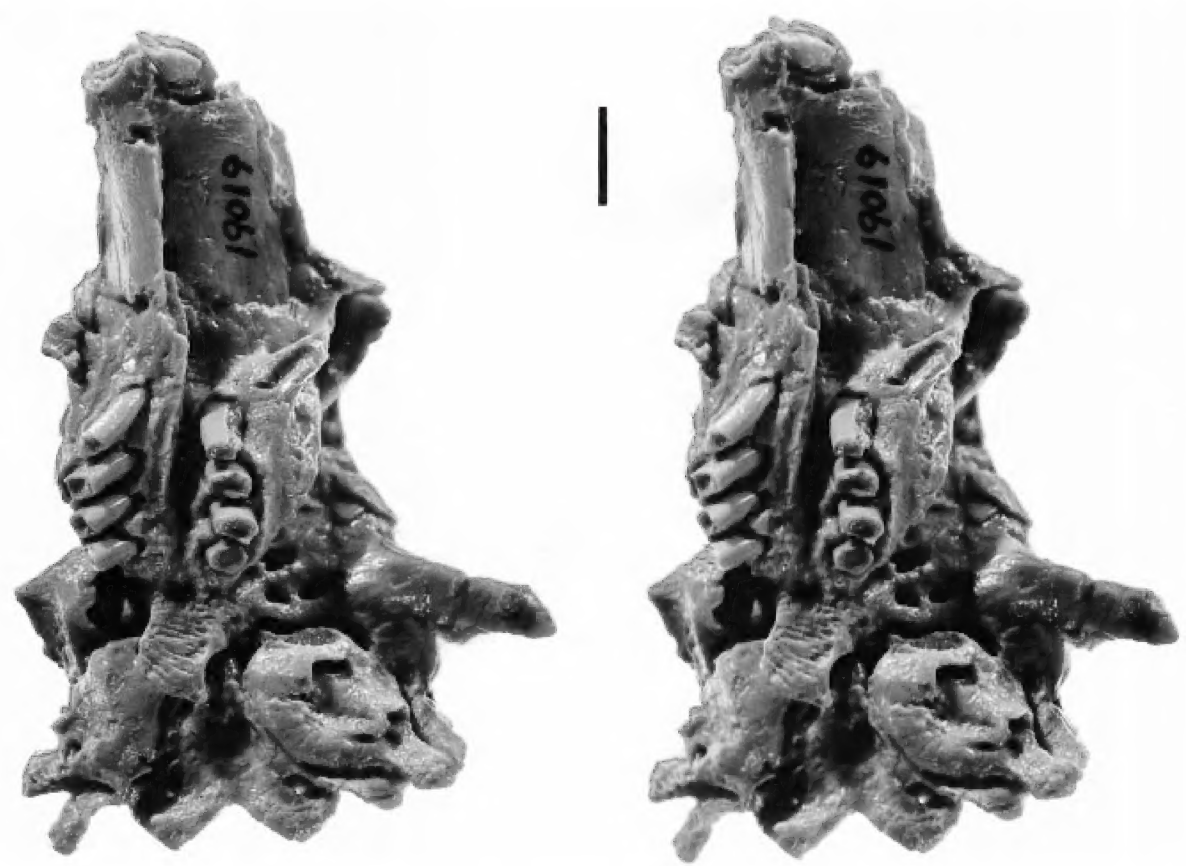

Fig. 4. Ventral view of skull of Tsaganomys altaicus (AMNH 19019, holotype) (in stereo). Scale $=1 \mathrm{~cm}$.

cluding the contact between the maxillary and the lachrymal.

LATERAL VIEW: The nostril is retracted. The anterior ends of the nasals are much more posteriorly located than those of the premaxillae. The anterior process of the temporal crest is anterior to the $\mathrm{P} 4$. The pocket formed by jugal, lachrymal, and maxillary is here interpreted as the eye socket rather than the origin of the masseter muscle (as suggested by Bryant and McKenna, 1995) because there is no scar for any muscle, and, to the contrary, there is a nasolachrymal foramen in it. As so interpreted, the orbit must be very small, and the orbital crest is formed by the jugal and lachrymal. In the orbit the orbital wing of the lachrymal extends rather widely. Just behind the orbital crest there is a crest extending posteroventally to the ethmoid foramen. It may form the anteroventral margin of the temporal fossa. The very strong upper incisor is procumbent, extends back into orbital area, forming a bulge on the lateral side of maxillary, and ends lateral to M1-2. The angle between the dorsal surface of the posterior part of the upper incisor alveolus and the occlusal surface of the upper cheek teeth is near $40^{\circ}$. The occlusal surface of the cheek tooth row is steplike: the posterior edge of the preceding tooth is slightly lower than the anterior edge of the succeeding one.

As described by Bryant and McKenna (1995), the upper molar alveoli extend into the orbital area medial to the upper incisor. However, the alveolus of $\mathrm{P} 4$ reaches the medial side of the upper incisor only and does not extend into the orbital area.

MANDIBLE: The mandible has been described by Bryant and McKenna (1995) in detail. A few additions are given below. The diastema is long, and the mental foramen is located anterior to $\mathrm{P} 4$. The coronoid process is high. The condyloid process is well developed, with a wide, triangularly convex articular surface, and without postcondyle expansion. The masseteric fossa is large and deep, with more or less distinct masseteric crests. There is a small fossa situated below m1-2 and anterior to the masseteric fossa. On the lingual side of the ascending ramus no distinct mandibular foramen is visible. The medial surface of the angular process is separated by a longitudinal crest into two 

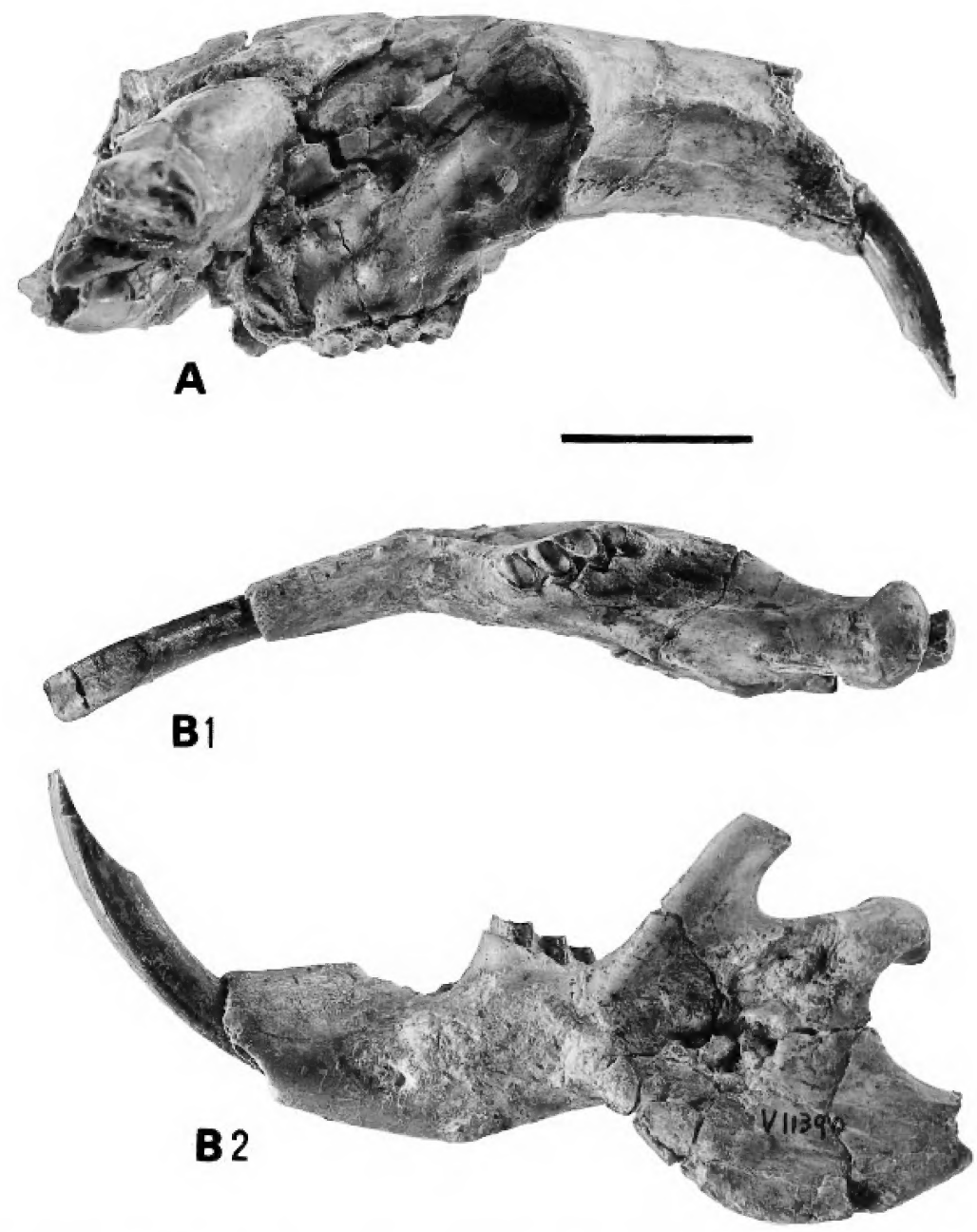

Fig. 5. Skull and lower jaw of Tsaganomys altaicus (IVPP V 11390). A. Right lateral view of skull. B. Left lower jaw. B1. Occlusal view. B2. Buccal view. Scale $=3 \mathrm{~cm}$.

parts: a large fossa above and a narrow flat one along the lower margin. The upper fossa may be for the insertion of the internal pterygoid muscle and the lower plate for the superficial masseter muscle, pars reflexus. The lower cheek teeth are concave anterolingually and extend buccal to the lower incisor alveolus. As in the upper cheek teeth, the occlusal surface of the lower cheek teeth row is also steplike, but the posterior edge of the preceding tooth is higher than the anterior edge of the succeeding one.

DENTITION: The cheek teeth are all cylindrical in form, strongly unilaterally hypsodont, and with an open root. The occlusal surface is covered by very thin enamel when unworn. The occlusal pattern is only very weakly expressed and is lost very early with wear. Then the occlusal surface becomes smooth, concave with higher margin, but without core on it. The enamel covers the anterior and lingual walls on the uppers and the buccal and posterior walls on the lowers. The uncovered part of the tooth may represent part of the root. The dentine between the occlusal surface and the top of the pulp cavity is called the dentine part here. It is high and probably grows continuously during the lifetime. The pulp cavity is relatively short and has a pointed apex. The ratio of the dentine part to the pulp cavity is high.

I have not yet seen any upper cheek tooth 

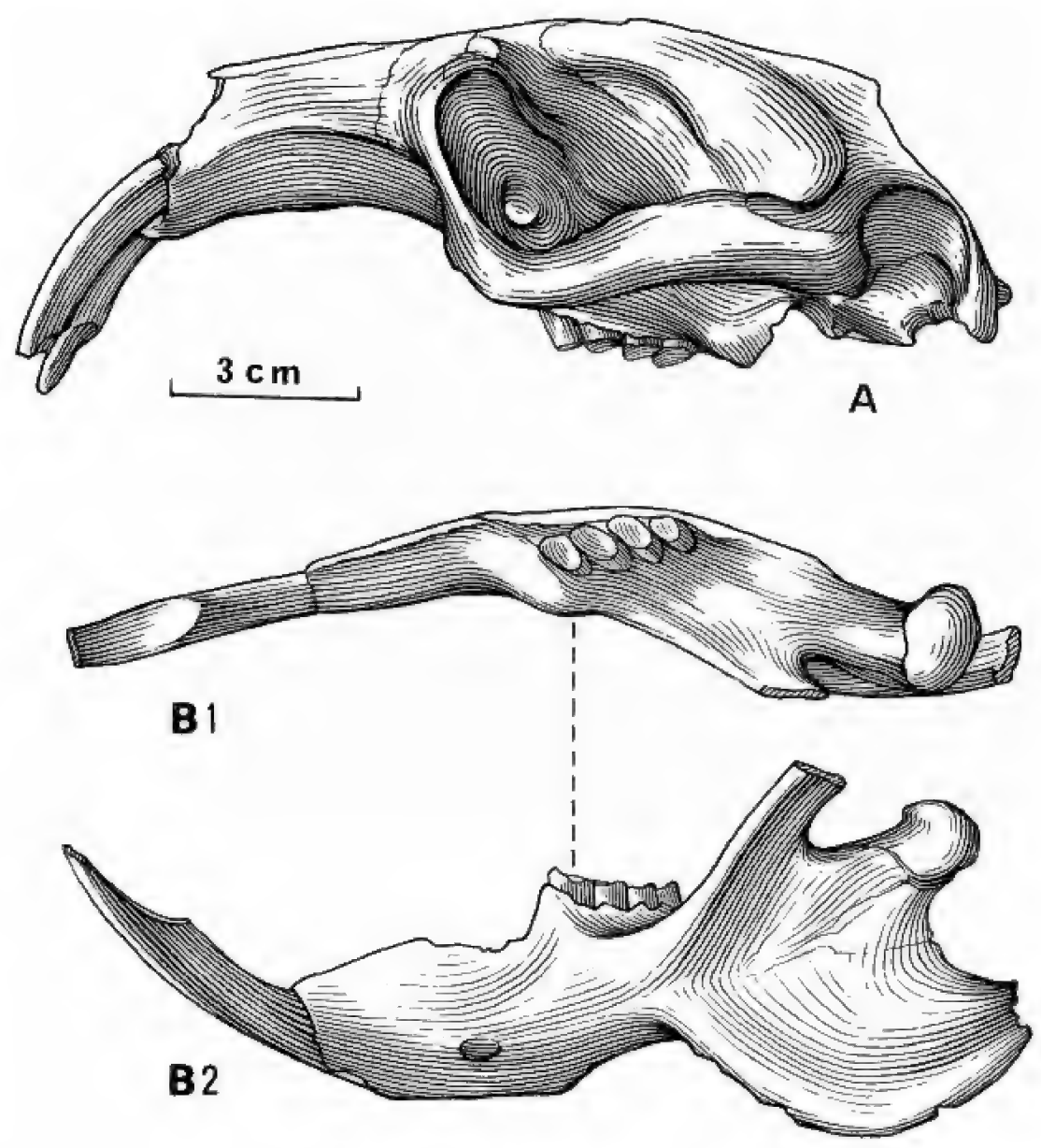

Fig. 6. Skull and lower jaw of Tsaganomys altaicus (IVPP V 11390). A. Left lateral view at skull. B. Left lower jaw. B1. Occlusal view. B2. Buccal view.

with the occlusal pattern well preserved, but I have found some unworn lower cheek teeth. AMNH 82289 preserves a slightly worn p4. In AMNH 83510 an erupting p4 was found under dp4, which was removed (figs. 11, 12). The unworn $\mathrm{p} 4$ is nearly square in occlusal view and its trigonid is slightly narrower and higher than the talonid. Very thin enamel covers the occlusal surface and all side walls but extends only a short distance downward on the anterolingual wall. The occlusal pattern is very shallow, with very weak cusps and lophids. The nearly equal protoconid and metaconid are separated by relatively long metalophid II. The metalophid I is low and weak. Behind the metaconid there is a crest or cusp, which may be the metastylid. No distinct hypolophid is seen; there is a string of tiny cusps instead. The posterolophid is complete and reaches the metastylid to close the talonid basin. No distinct entoconid and hypoconulid are visible. The prominent, but not hypertrophied, hypoconid extends anterobuccally. The ectolophid is straight. The hypoflexid (= external valley) is shallow and slightly oblique in posterolingual direction. On IVPP V 11402 the $\mathrm{m} 3$ is erupting. It is oval in occlusal view. As in $\mathrm{p} 4$ the protoconid, metaconid, and metalophid II are distinct, but the metalophid I is weaker. The entoconid is developed. The hypolophid is complete and low and joins the hypoconid. The hypoconid is close to the protoconid in position, and the hypoflexid is shallower and more anteriorly located. 


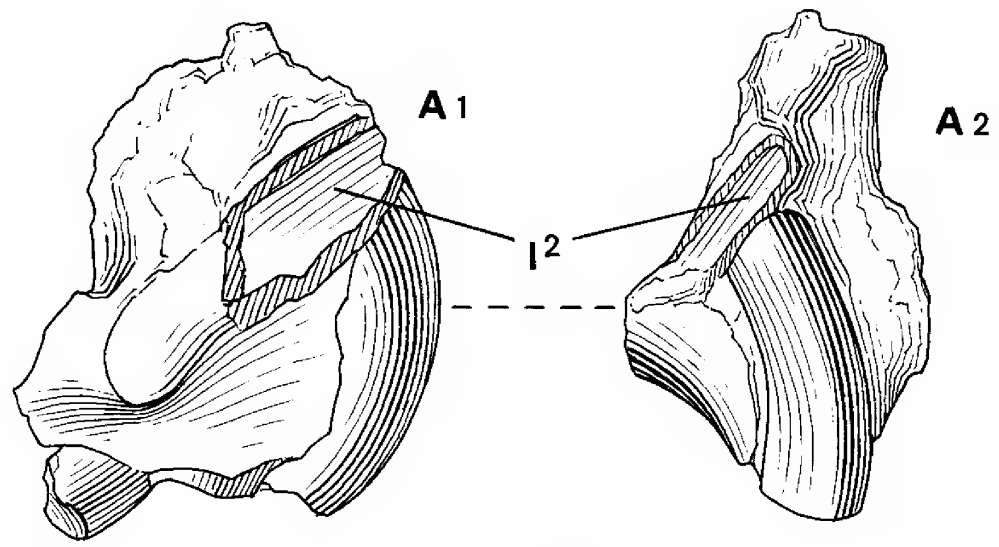

$8 \mathrm{~m} \mathrm{~m}$

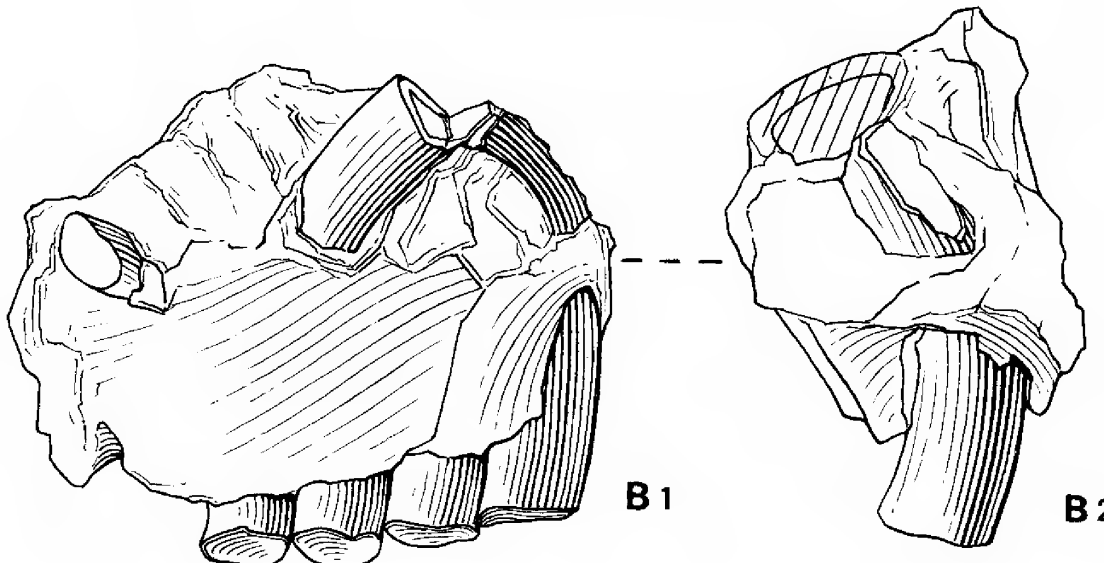

B 2

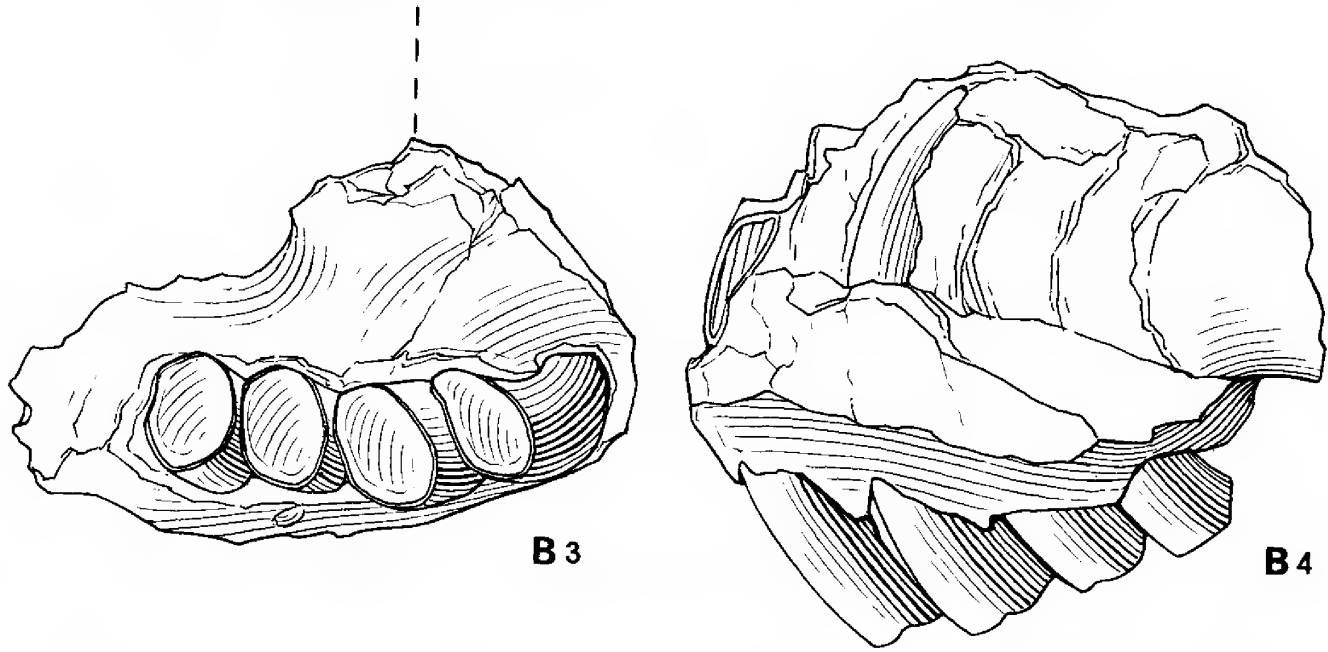

Fig. 7. Upper jaws of Tsaganomys altaicus showing the relation between I2 and upper cheek teeth. A. Right upper jaw with part of I2 and P4-M2 (IVPP V 11415). A1. Buccal view. A2. Anterior view. B. Right upper jaw with I2 and P4-M3 (AMNH 85273). B1. Buccal view. B2. Anterior view. B3. Occlusal view. B4. Lingual view. 

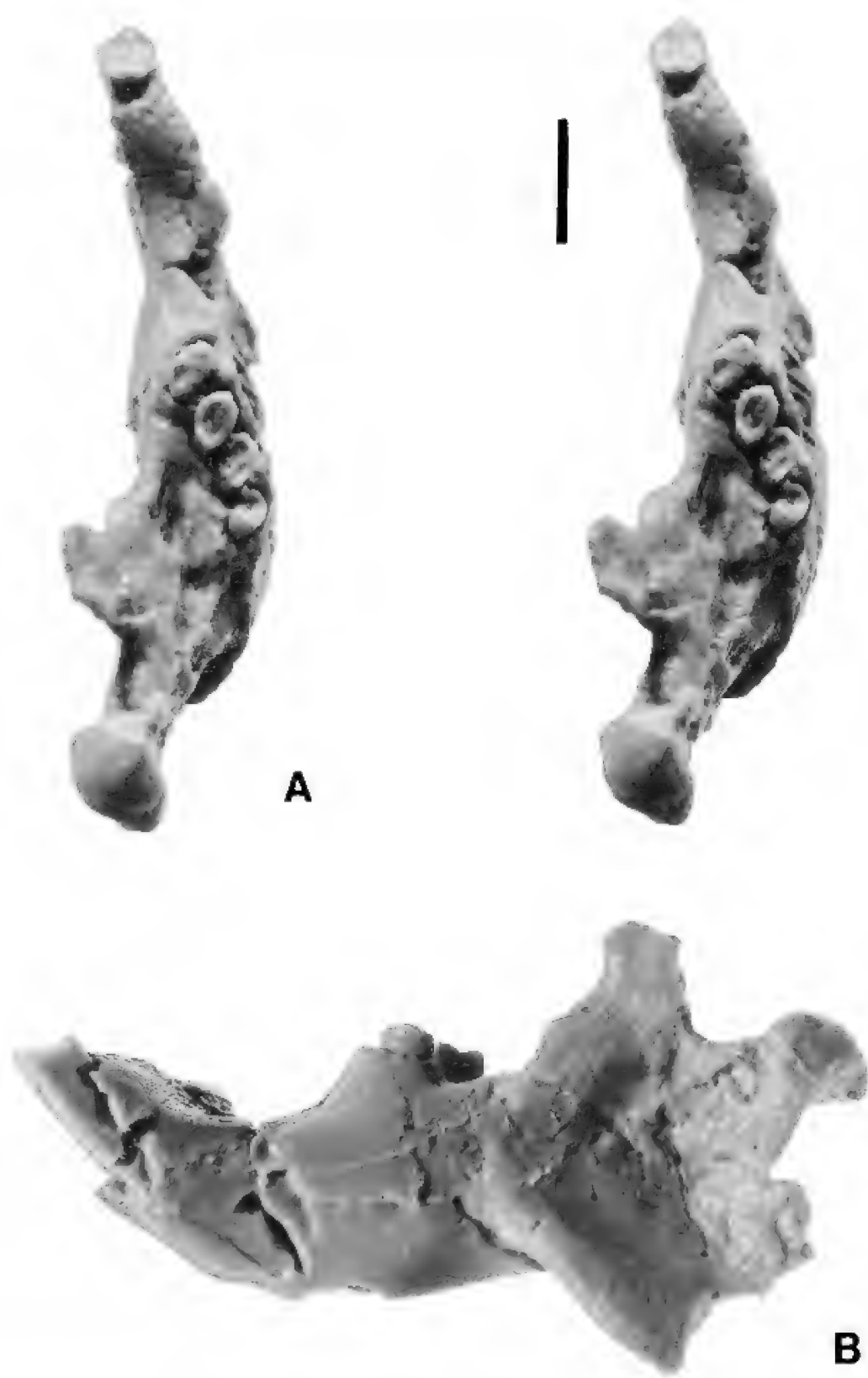

Fig. 8. Left lower jaw of Tsaganomys altaicus (AMNH 19019, holotype). A. Occlusal view (in stereo). B. Lateral view. Scale $=1 \mathrm{~cm}$.

The incisors are approximately triangular in cross section, with a round lingual top, an almost right buccomedial angle, and a flat or slightly convex labial side. The enamel covers the labial side and nearly one-fourth of the medial and external sides. On the surface of the enamel of the labial side, the longi- tudinal ridges are usually distinct but sometimes weak or even absent. The upper incisor is slightly thinner in labiolingual direction then is the lower one. The enamel has multiserial microstructure. In the lower incisor, the PE is very thin, about $10 \%$ of the total thickness of the enamel $(170-185 \mu \mathrm{m})$. The 


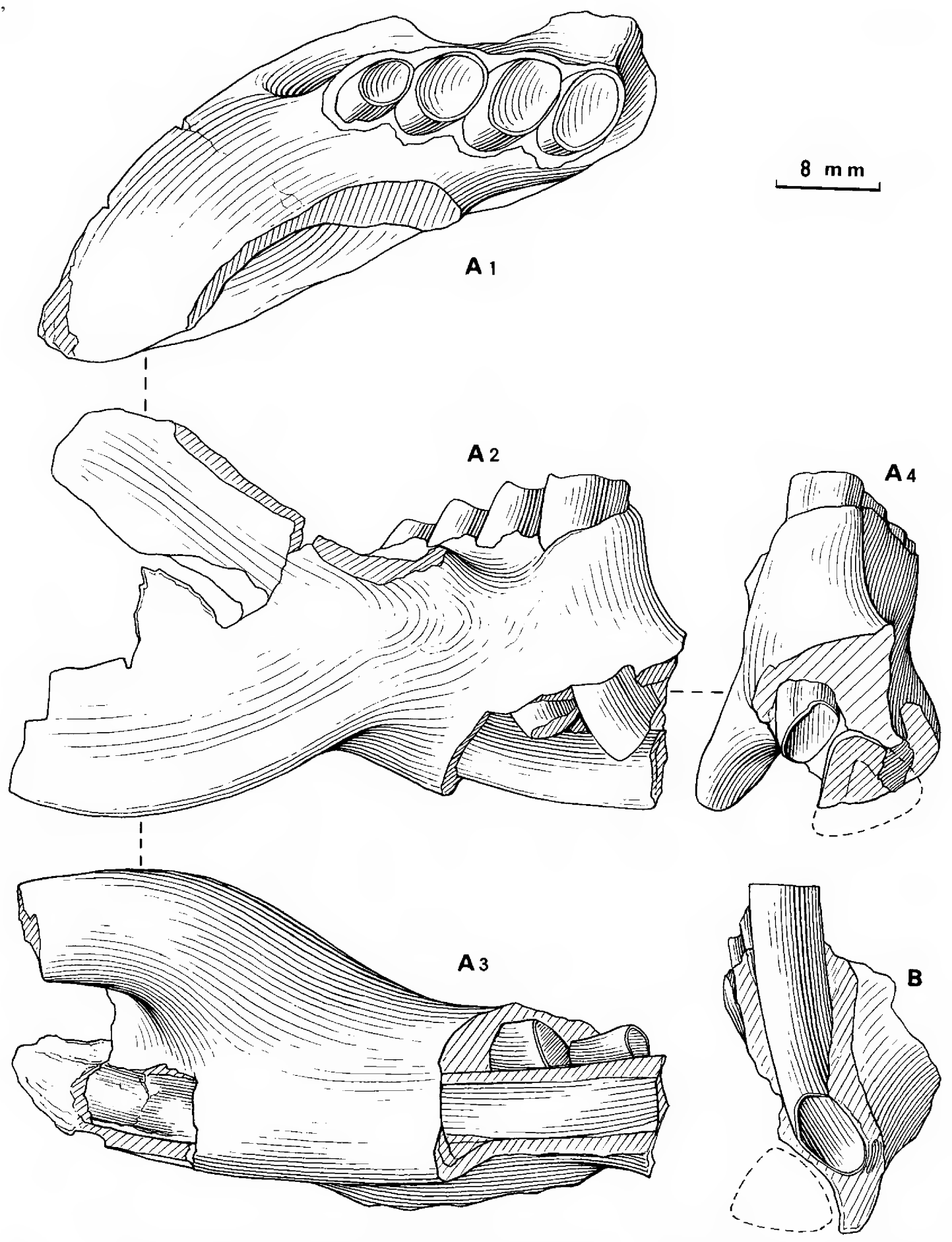

Fig. 9. Lower jaws of Tsaganomys altaicus showing the relation between i2 and lower cheek teeth. A. Right lower jaw with i2 and p4-m3 (IVPP V 11417.1). A1. Occlusal view. A2. Buccal view. A3. Ventral view. A4. Anterior view. B. Anterior view of left lower jaw with p4-m2 (AMNH 82273). 


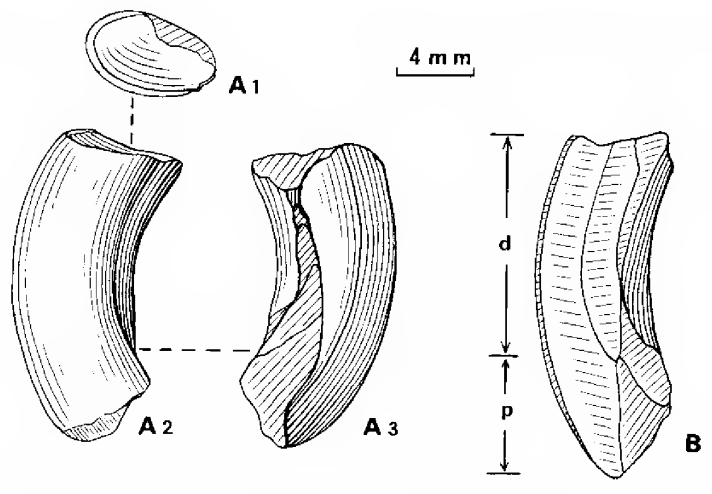

Fig. 10. Cheek teeth of Tsaganomys altaicus A. Cheek tooth of IVPP V 11389.3. A1. Occlusal view. A2. Anterobuccal view. A3. Posterolingual view. B. Longitudinal section of cheek tooth (IVPP V 11409.1) showing dentine part (d) and pulp cavity (p).

prisms of the $\mathrm{PE}$ are almost vertical to the surface of the enamel. The HSB of the PI is composed of 5-7 prisms and has about 20$30^{\circ}$ inclination.

Dimensions: See table 1.

Discussion: Based on holotypes, Matthew and Granger (1923) rightly distin-

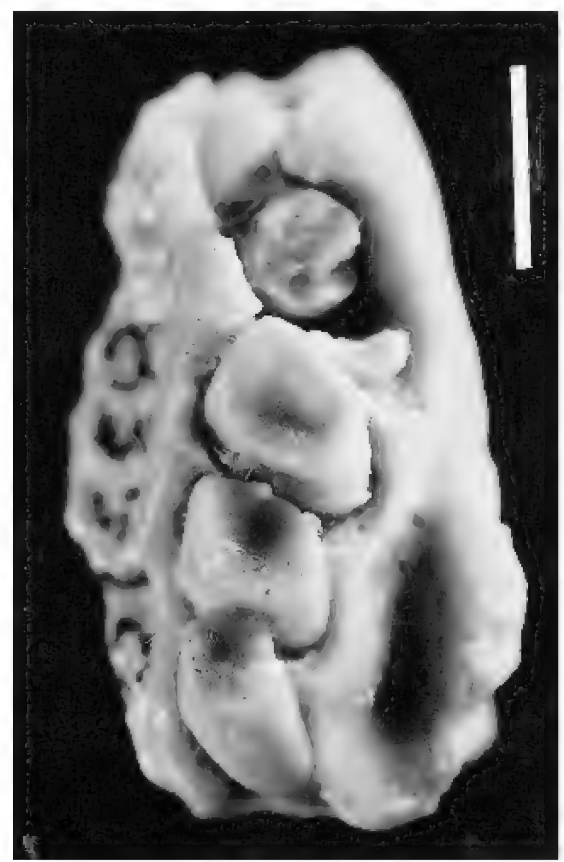

guished Tsaganomys altaicus from Cyclomylus lohensis. However, they misidentified the other specimens. The paratypes designated by them include, in fact, two different genera: Tsaganomys and a new genus, Coelodontomys (see below). Their line drawings illustrating the reconstructed skull of $T$. altaicus were based on specimens belonging to different genera (Matthew and Granger, 1923: figs. 1-3). This may be one of the factors that led to great confusion in the later classification of the Tsaganomyidae.

One of the main problems confounding classification is cheek tooth morphology. Because the enamel is very thin on the occlusal surface of the cheek teeth and the cusps and lophs are very weakly expressed, the occlusal pattern is easily worn away. When worn the cheek teeth become cylindrical and unilaterally hypsodont, and have smooth, concave occlusal surfaces. Superficially there seems to be no difference among the teeth. Careful observation reveals that among the paratypes listed by Matthew and Granger (1923) there are two different kinds of hypsodont teeth: one has a well-developed den-

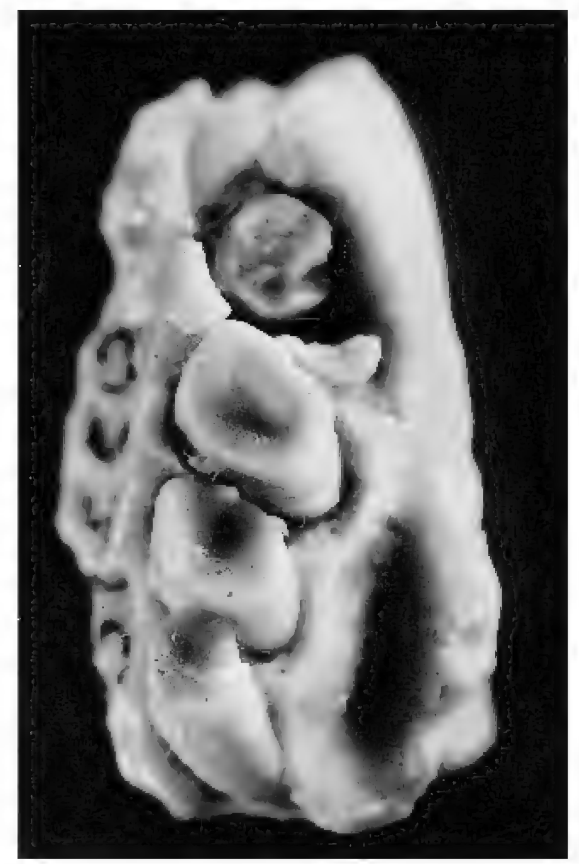

Fig. 11. Occlusal view of right lower jaw with $\mathrm{p} 4-\mathrm{m} 3$ of Tsaganomys altaicus (AMNH 83510) (in stereo); Scale $=5 \mathrm{~mm}$. 

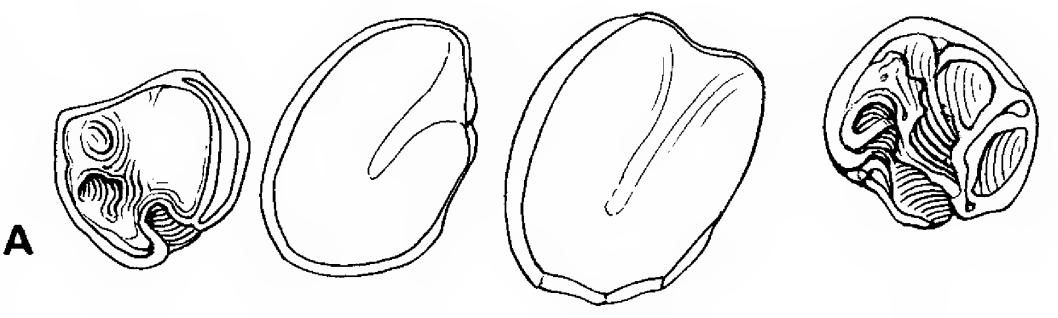

\section{$2 \mathrm{~m} \mathrm{~m}$}

B

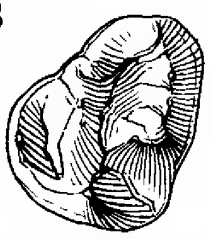

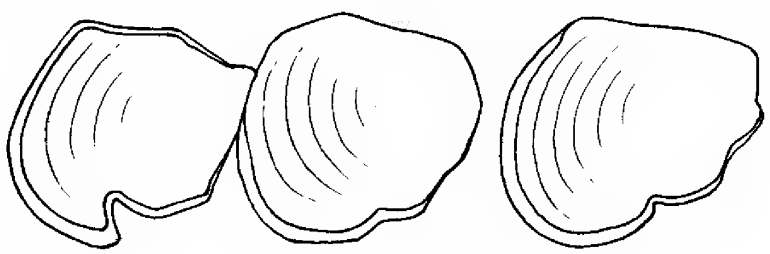

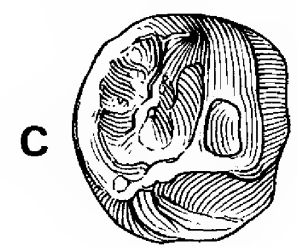

Fig. 12. Occlusal view of cheek teeth of Tsaganomys altaicus. A. Right p4-m3 of AMNH 83510. B. Right dp4-m3 of IVPP V 11402. C. Right p4 of AMNH 82289.

tine part composed of primary dentine, a short conical pulp cavity with pointed apex, and a high ratio of dentine part to pulp cavity; the other one shows opposite trends. In addition, the skulls that bear these two kinds of teeth differ in morphology (see table 6). The former is typical of Tsaganomys, but the latter represents a new taxon (Coelodontomys). Shevyreva (1972) rightly distinguished two kinds of teeth among the strongly hypsodont cheek teeth. Unfortunately, however, she referred them incorrectly and named a new genus and species, Beatomus bisus, without figuring the holotype. According to her description and figures of the other specimens (Shevyreva, 1972: fig. 6; 1974a: figs. 1d, e, 2, 3). Beatomus bisus shows typical Tsaganomys tooth morphology. On the other hand, her Tsaganomys is quite different from the holotype of Tsaganomys altaicus but similar to Coelodontomys. It seems that Beatomus bisus is a junior synonym of Tsaganomys altaicus.

Kowalski (1974) described Cyclomylus minutus from Khatan Khayrkhan, Mongolia. Huang (1993) relocated this species into Tsaganomys. Bryant and McKenna (1995) considered $T$. minutus as a synonym of $T$. altai- cus. I have not seen Kowalski's holotype, and I am not certain whether it is a Tsaganomys. However, I observed Huang's specimens from Ulantatal area, Nei Mongol, China. They are typical of Tsaganomys. The measurements of the Ulantatal specimens indicate that they are within the range of Tsaganomys altaicus. The measurements of the cheek teeth of Tsaganomys show no obvious size groupings among the specimens (fig. 14). The available material indicated that young individuals are small and some cheek teeth show a size increase from top to base. I agree with Bryant and McKenna (1995) that $T$. minutus of Hung (1993) is a junior synonym of $T$. altaicus. The cheek teeth of $T$. altaicus all have open roots at all stages of wear.

Tsaganomys sp. of Teilhard de Chardin (1926) from Saint Jacques, Nei Mongol, China, referred to Cyclomylus lohensis by Kowalski (1974: 158) is T. altaicus, as well.

Among the specimens of "Tsaganomys and/or Cyclomylus" from the Buran Formation in Zaysan Basin, Kazakhstan, listed by Emry et al. (1998), only K35(15)/424 belongs to T. altaicus (Emry et al., 1998: fig. 8A).

Emry and Korth (1996) considered Mo- 

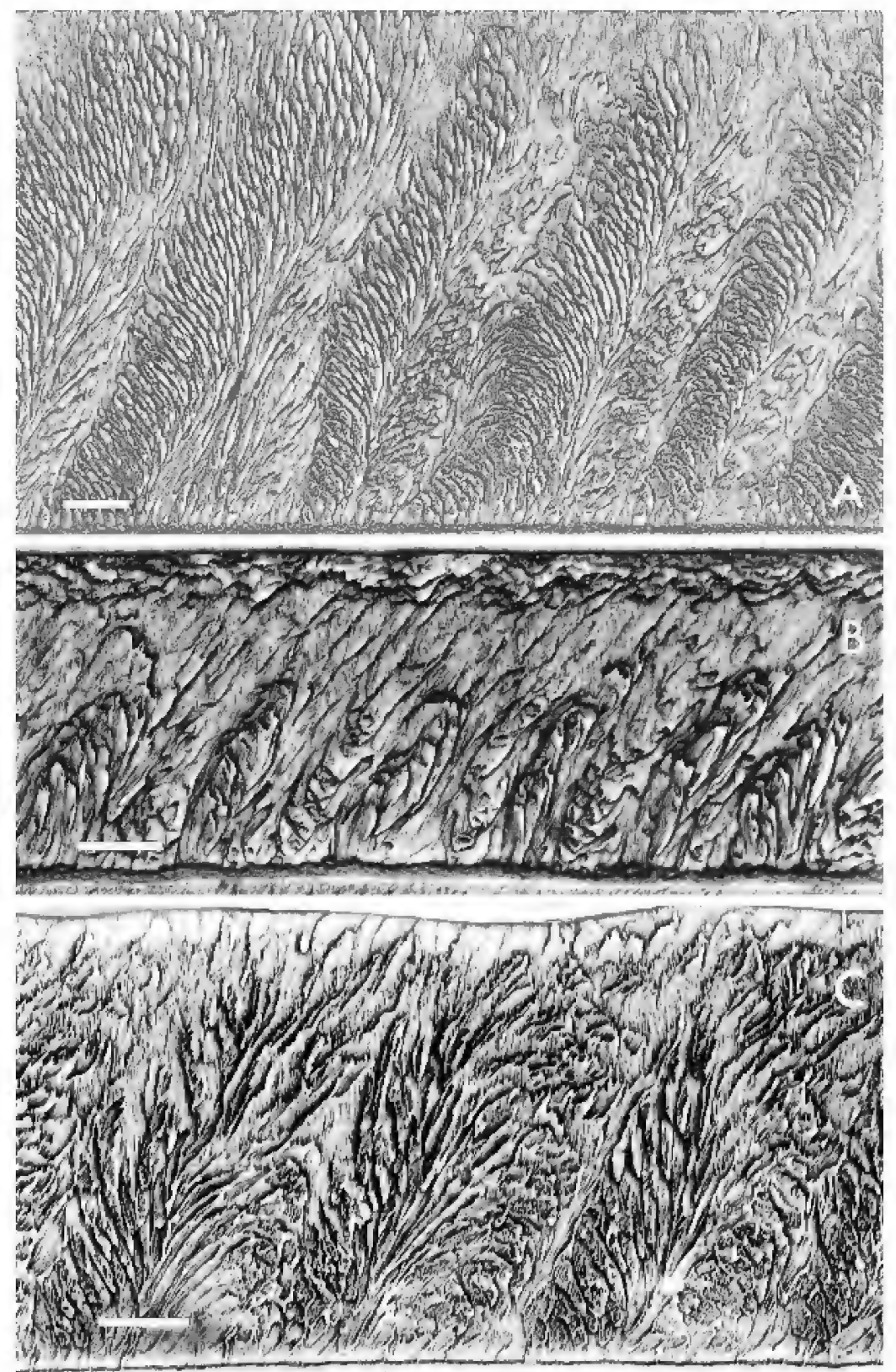

Fig. 13. Microstructures of longitudinal sections of lower incisors of tsaganomyids. A. Tsaganomys altaicus. B. Cyclomylus lohensis. C. Coelodontomys asiaticus, new genus and species. Scale $=20 \mu \mathrm{m}$.

rosomys Shevyreva (1972) a synonym of Tsaganomys. It seems that Morosomys represents a taxon distinct from Tsaganomys in having brachydont cheek teeth and other features.

Wang et al. (1981) listed Tsaganomys sp. from the Yikebulage Formation based on one specimen, IVPP V 11405. Checking the original label I found that V 11405 was collected from the upper member of the Wulanbulage Formation near IVPP Loc. 78016 rather than in Loc. 78016 of the Yikebulage Formation. Thus, Tsaganomys does not occur in the Yikebulage Formation. 
TABLE 1

Measurements (mm) of Cheek Teeth of Tsaganomys altaicus

\begin{tabular}{lrrrrrc}
\hline \hline Tooth & N & Min & Max & Aver & S & V \\
\hline P4-M3, L & 29 & 11.55 & 21.40 & 16.68 & 3.01 & 9.07 \\
M1-3, L & 43 & 8.95 & 17.58 & 12.97 & 2.15 & 4.61 \\
P4, L & 34 & 2.30 & 4.80 & 3.23 & 0.65 & 0.43 \\
P4, W & 34 & 3.08 & 7.26 & 5.01 & 1.08 & 1.16 \\
M1, L & 47 & 2.50 & 5.25 & 3.91 & 0.62 & 0.39 \\
M1, W & 46 & 4.22 & 7.62 & 6.02 & 0.87 & 0.76 \\
M2, L & 46 & 2.75 & 5.30 & 3.82 & 0.59 & 0.34 \\
M2, W & 45 & 3.98 & 8.00 & 5.89 & 0.89 & 0.80 \\
M3, L & 46 & 2.50 & 5.34 & 3.80 & 0.68 & 0.46 \\
M3, W & 46 & 3.42 & 7.56 & 5.35 & 0.91 & 0.83 \\
p4-m3, L & 60 & 11.20 & 22.81 & 17.29 & 2.45 & 6.00 \\
m1-3, L & 74 & 7.85 & 17.86 & 13.02 & 2.13 & 4.53 \\
p4, L & 82 & 2.12 & 5.00 & 3.77 & 0.59 & 0.35 \\
p4, W & 82 & 3.02 & 7.87 & 5.60 & 0.99 & 0.98 \\
m1, L & 109 & 2.13 & 5.06 & 3.90 & 0.69 & 0.47 \\
m1, W & 109 & 2.72 & 8.24 & 5.80 & 0.98 & 0.96 \\
m2, L & 105 & 1.90 & 5.20 & 3.73 & 0.67 & 0.44 \\
m2, W & 105 & 2.42 & 7.37 & 5.45 & 0.95 & 0.89 \\
m3, L & 78 & 1.83 & 4.26 & 3.13 & 0.52 & 0.27 \\
m3, W & 78 & 2.44 & 7.10 & 4.56 & 0.90 & 0.80 \\
\hline
\end{tabular}

\section{Cyclomylus Matthew and Granger, 1923}

Cyclomylus Matthew and Granger, 1923:5.

Pseudotsaganomys Vinogradov and Gambaryan, 1952:18.

Sepulkomys Shevyreva, 1972:139.

Tsaganomys, Bryant and McKenna, 1995 (partim): 5-16. McKenna and Bell, 1997 (partim): 191.

TyPE SPECIES: Cyclomylus lohensis Matthew and Granger, 1923.

INCLUDED SPECIES: Cyclomylus intermedius, new species, and $C$. biforatus, new species.

GEOLOGICAL RANGE: Early Oligocene.

GeOgraphic Distribution: North China, Mongolia, and Kazakhstan.

EMENDED Diagnosis: Small- to mediumsized tsaganomyids; antepremolar crest absent, small oval infraorbital foramen with nearly vertical major axis, almost perpendicular to anterior margin of ventral surface of anterior zygomatic root; P4 growing from below upper incisor capsule, p4 from above lower incisor; cheek teeth unilaterally hypsodont with closed roots, short dentine part and long pulp cavity with a flat or concave top, with core showing on worn occlusal surface; on unworn or slightly worn occlusal surface, cusps and lophs prominent, four lophs, enamel relatively thick, with cement on walls; lower cheek teeth with distinct metalophid I, hypertrophic hypoconid and posterolingually oblique external valley; $\mathrm{p} 4$ oval in occlusal view, with narrow trigonid, metaconid more developed than protoconid, and no metalophid I.

Discussion: Matthew and Granger (1923) distinguished Cyclomylus from Tsaganomys based on its smaller size and less hypsodont cheek teeth that have closed roots. Vinogradov and Gambaryan (1952) described a new genus, Pseudotsaganomys, based on material from Kazakhstan and Mongolia. They mentioned that Pseudotsaganomys differed from Tsaganomys in having closed roots and from Cyclomylus in having a broad skull and lacking dP3. However, the holotype of Cyclomylus lohensis (AMNH 19096) is crushed laterally and has no dP3. It is difficult to know whether dP3 is present or not based on the adult specimen. It seems there is no significant difference between Pseudotsaganomys and Cyclomylus.

Shevyreva (1972) described a new genus, Sepulkomys, from Hsanda Gol, Mongolia. She considered the presence of a P3 as a feature distinctive from the other tsaganomyids. I agree with Bryant and McKenna (1995) that the holotype of Sepulkomys eboretus (PIN 475-50) is a young individual, in which the teeth that Shevyreva interpreted as $\mathrm{p} 3$ and $\mathrm{p} 4$ are really $\mathrm{dP} 3$ and $\mathrm{dP} 4$. Thus Sepulkomys is similar to Cyclomylus in dental formula. According to her figure (Shevyreva, 1972: fig. 4), it is identical with Cyclomylus in occlusal pattern. It appears that Pseudotsaganomys and Sepulkomys are junior synonyms of Cyclomylus.

\section{Cyclomylus lohensis Matthew and Granger, 1923}

Figures 13B, 15-19; table 2

Cyclomylus lohensis Matthew and Granger, 1923 (partim): 5.

Pseudotsaganomys turgaicus Vinogradov and Gambaryan, 1952: 20-22, figs. 7-10. NEW SYNONYMY. 
Cyclomylus mashkovae Shevyreva, 1994: 112, fig. 1c, d, e, f. NEW SYNONYMY.

Tsaganomys altaicus (partim), Bryant and McKenna, 1995: 5-16, fig. 10B. NEW SYNONYMY.

Holotype: A skull, badly preserved (AMNH 19096), from Hsanda Gol Formation, lower red strata, Loh, Tsagan Nor Basin, Mongolia.

REFERRED SPECIMENS: IVPP V 1145611467, V 11543; AMNH 84545; PIN 1401$178,478-3,478-13,1442-95,414-\mathrm{m} / 47-1$, 2979/912, 2979/910 and 2979/1342.

GEOLOGICAL RANGE: Early Oligocene (Wulanbulage Formation, Hsanda Gol Formation, and Buran Formation).

GeOGRAPHIC Distribution: Qianlishan District (IVPP Locs. 79010 [V 11457], 79015 [IVPP V 11458], 79016 [V 11459], other locality [V 11456]) and Saint Jacques (IVPP Locs. 77045 [V 11460], 77049 [V 11461], 77049.2 [V 11462], 77049.5 [V 11463], 77049.7 [V 11464], 77049.8 [V 11465], 77050.b [V 11466] and 78020 [V 11467]), Nei Mongol, China; Tsagan Nor Basin (V 11543 and other specimens in AMNH), Mongolia; and Chelkar-Teniz, Chaybulak-Dzhamangora watershed and Turgai, Kazakhstan.

EMENDED Diagnosis: Single infraorbital foramen; upper cheek teeth growing from below posterior part of upper incisor and lower cheek teeth from above lower incisor; cheek teeth relatively low unilaterally hypsodont, low height difference between enamel on sides of teeth, with rather thick enamel and relatively well-developed cusps and lophs; upper cheek teeth with three closed roots; lowers with two; fourth premolar larger than molars; lower incisor having relatively thin enamel, with relatively thick PE, nearly $40 \%$ of total thickness of enamel, and with nearly $30^{\circ}$ inclination of prisms, and PI having nearly $30^{\circ}$ inclined HSB including 3-4 prisms.

DESCRIPTION: The infraorbital foramen is small and oval and its vertical major axis is almost perpendicular to the anterior margin of the ventral surface of the anterior zygomatic root. The temporal fossae are large. The sagittal crest is distinct with a prominent anterior process. The upper incisor extends to above M1-2. The angle between the dorsal surface of the posterior part of the upper incisor alveolus and the occlusal surface of the cheek teeth is near $60^{\circ}$. P4 is ventral to the upper incisor. Because the skull of the holotype is crushed laterally, it is not clear whether the antepremolar crest is present or not. The mandible is similar to that of Tsaganomys. It is hystricognathous. The mental foramen is below the posterior part of the diastema. The masseteric fossa is large and reaches below $\mathrm{m} 2$. The lower masseteric crest is weak and almost parallel to the lower margin of the angular process. There is a small, distinct fossa before the masseteric fossa. On the lingual side of the large angular process the fossa for the pterygoid muscle is large and deep. The lower incisor extends below the lower cheek teeth and ends in the condyloid process.

The cheek teeth are relatively low, unilaterally hypsodont. On the upper cheek teeth the lingual crown is higher than the buccal one, whereas on the lower teeth the posterobuccal crown is higher than anterolingual one. In young individuals when the cheek teeth are not worn the root is open. However, in those teeth that are slightly worn but still preserve the occlusal pattern, the roots are closed (AMNH 19096, 85545; IVPP V $11456,11457,11460)$. The upper molars have three closed roots: a large root lingually and two small roots buccally. The lower cheek teeth have two: a small anterior and a large posterior root. The interval of eruption of the cheek teeth is rather short. While the first and second molars still retain the occlusal pattern, both the third molar and fourth premolar erupt. Thus, when the individual is young (IVPP V 11543, AMNH 19096 and 84545 ), the occlusal pattern can be seen on the whole cheek tooth row from the fourth premolar to third molar at the same time.

On the occlusal surface the enamel is relatively thick. The cheek teeth are tetralophodont. The relatively well-developed occlusal pattern, high crests and deep basins, can last a long time during wear. However, the pattern does not extend so deep as in other hypsodont forms, such as Ctenodactylinae and Arvicolidae. When heavily worn the occlusal pattern is lost and the occlusal surface of the cheek teeth is smooth, concave, usually with a core of secondary dentine, and bordered by a higher margin. The core is generally similar to the occlusal form of the teeth in con- 

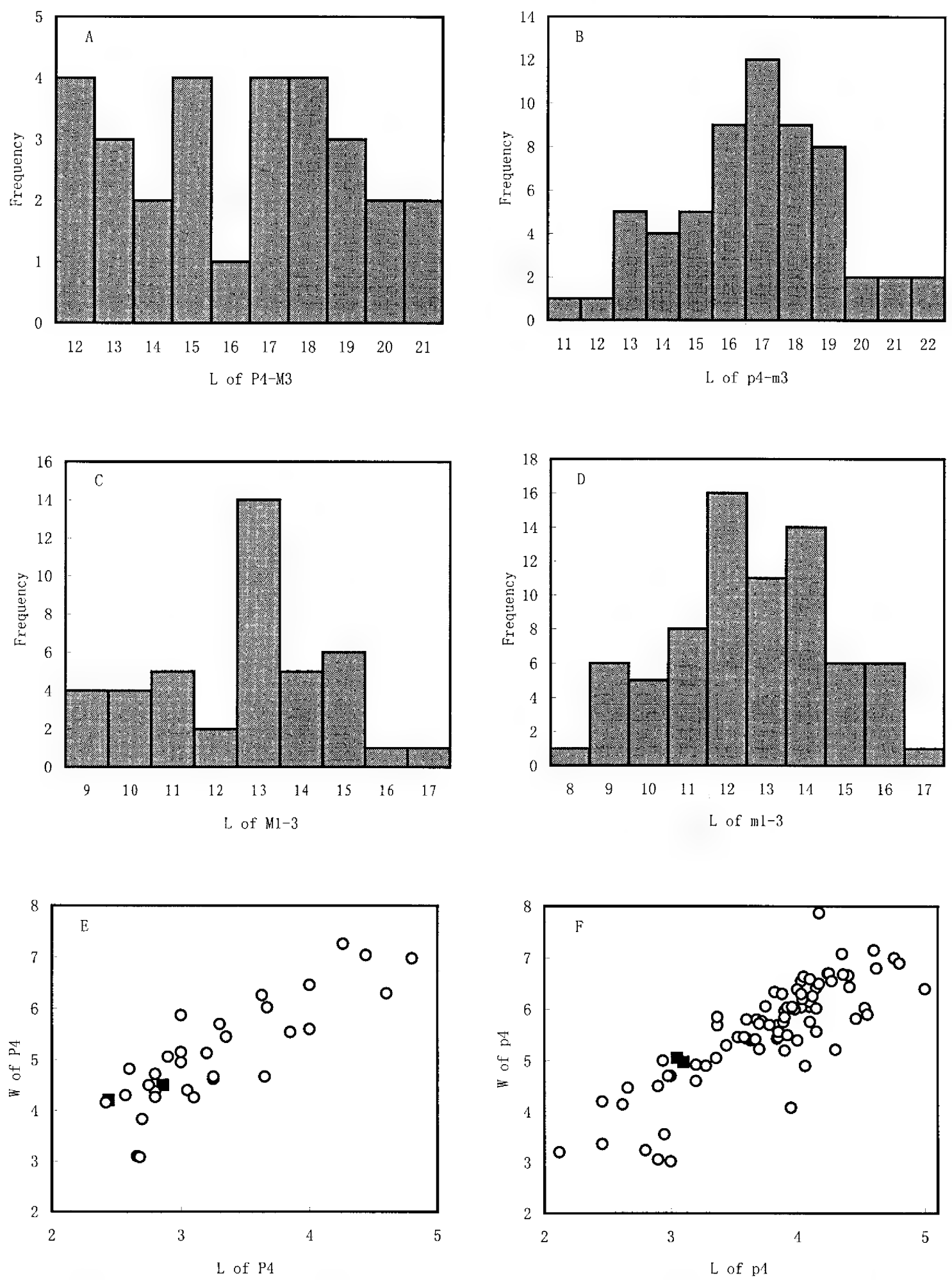

Fig. 14. Dental measurements of Tsaganomys altaicus specimens. A, B. Histograms of measurements of length of cheek tooth rows. C, D. Histograms of measurements of length of molar rows. EL. Scatterplot of measurements of length and width of cheek teeth. Solid squares represent the holotype (AMNH 19019), and open circles represent other specimens. 

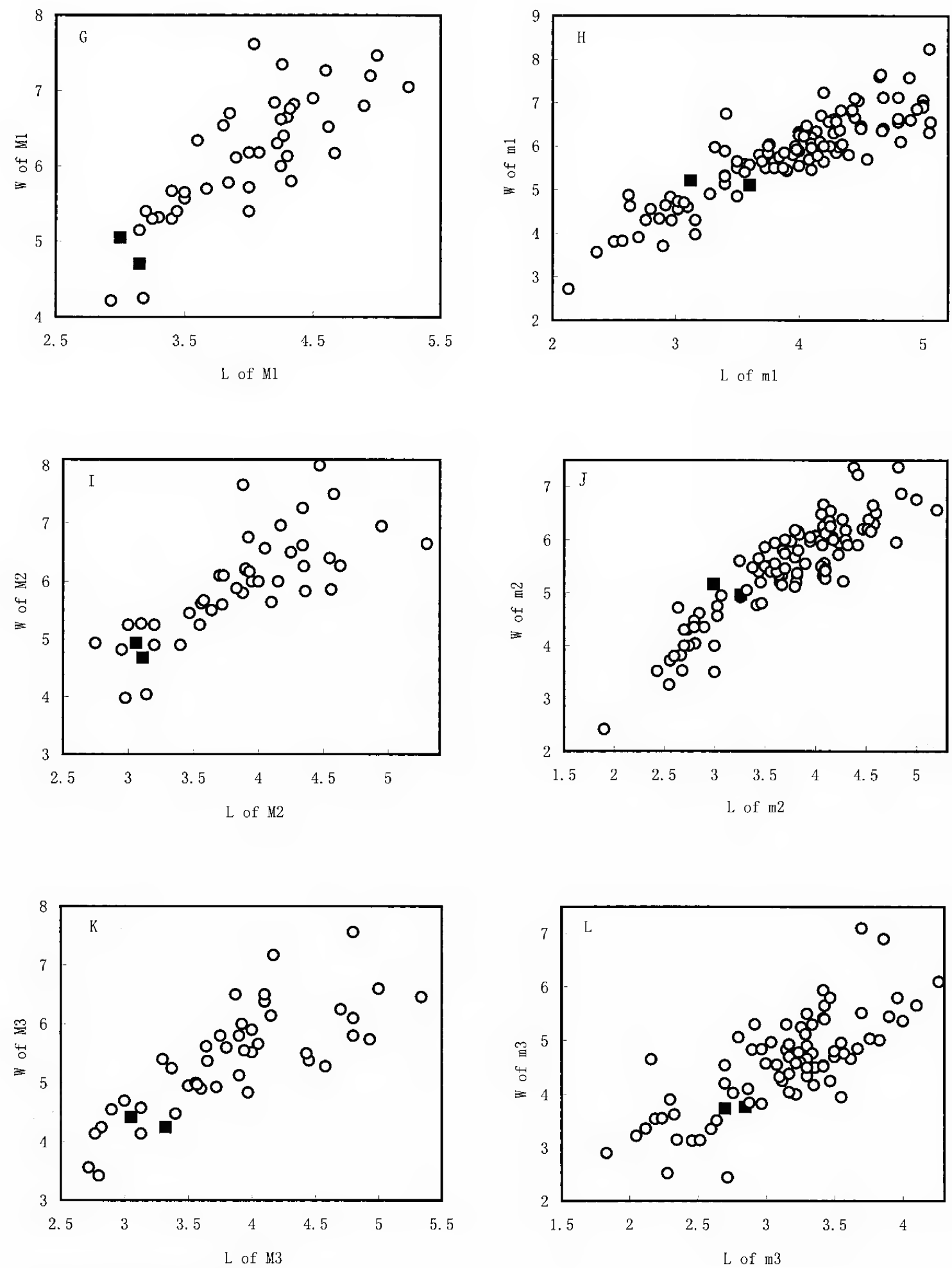

Fig. 14. Continued. 

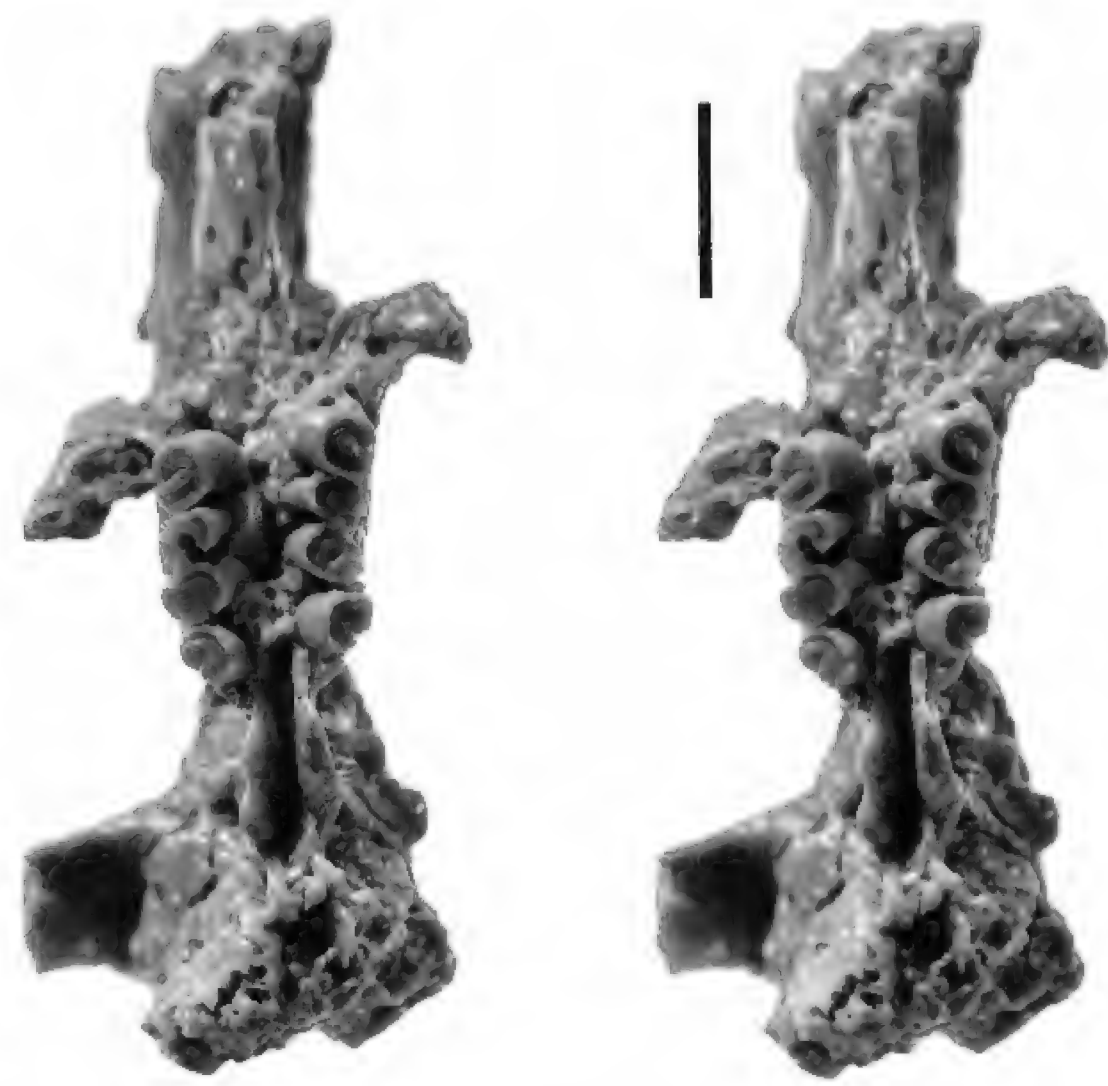

Fig. 15. Ventral view of skull of Cyclomylus lohensis (AMNH 19096, holotype) (in stereo). Scale $=1 \mathrm{~cm}$.

tour and slightly higher than the dentine around it. The dentine part is rather short in height. The pulp cavity is deep, with a flat or concave top and side walls parallel to the side walls of the tooth. The primary dentine seems to stop growing early. As the primary dentine is worn away, the secondary dentine is deposited, always forming a core.

On upper cheek teeth the four transverse lophs are almost equally developed. The protoloph and metaloph are nearly parallel to each other and join with the large protocone with wear. The anteroloph and posteroloph are convergent toward the protocone and form a continuous crescentic crest. Three buccal transverse valleys are deep and dammed by a slightly higher buccal edge, forming closed basins with wear. On more worn teeth the middle valley is the longest and the posterior one is the smallest (M1 of AMNH 84545). On slightly worn or unworn teeth, the posterior valley is large and separated by a longitudinal crest into two basins: the buccal one is deeper than the lingual one (M2 of AMNH 84545). On M3 of AMNH 84545 there are some accessory cusps and lophs in the posterior valley.

The $\mathrm{p} 4$ is quite different from that of $T_{s a-}$ ganomys. It is oval in occlusal view and longer than wide and has a small, narrow trigonid. The metaconid and protoconid are prominent and close to each other. The metastylid is distinct. The metalophid II is short and low. The metalophid I is absent. The trigonid basin is small and open anteriorly. The talonid is much wider than the trigonid. The entoconid is prominent and separated from the metaconid by a notch. The hypertrophic hypoconid is the largest of the main cusps and extends anterobuccally. The posterolophid is well developed and reaches the entoconid. The top of the entoconid is separat- 

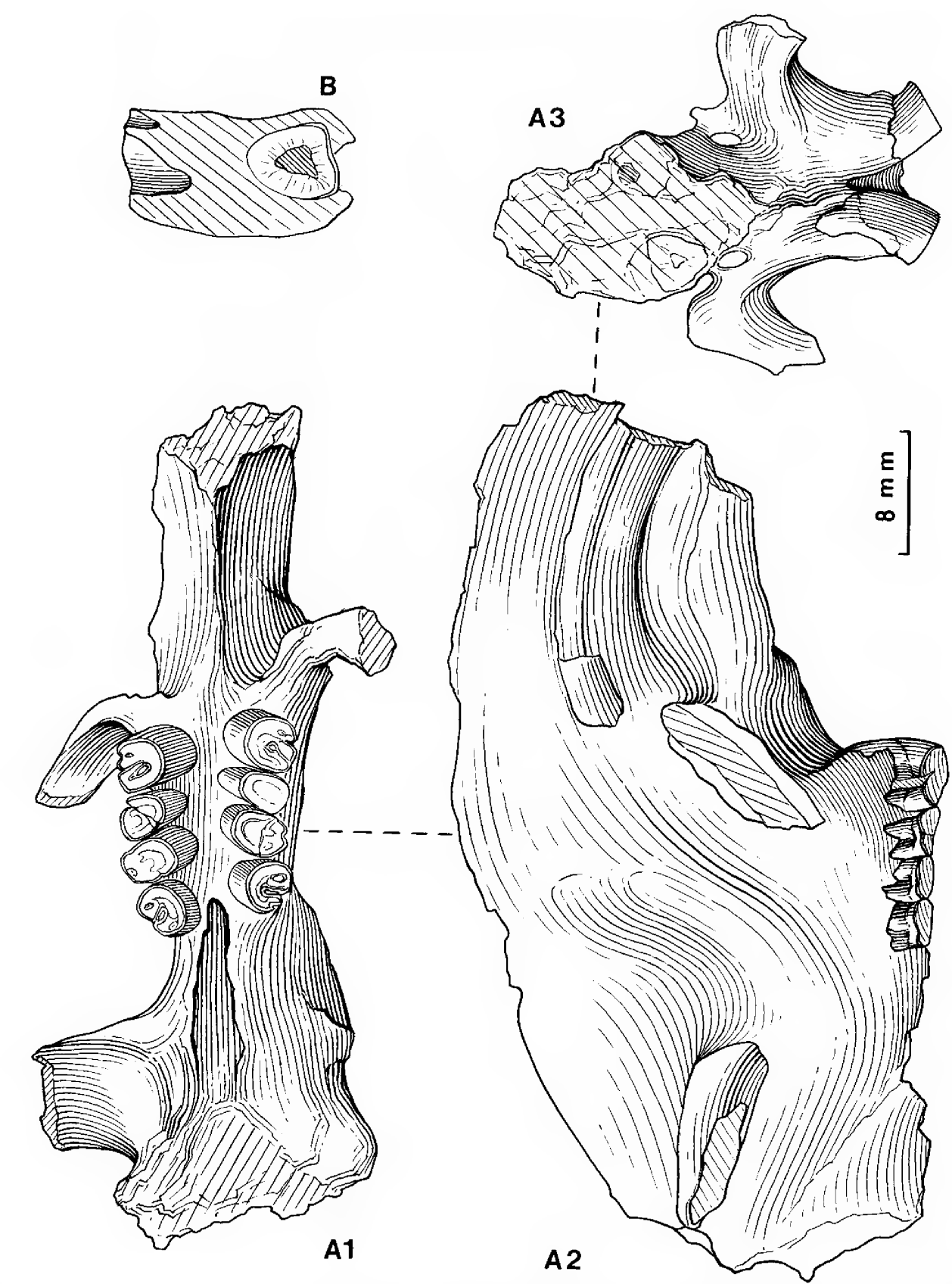

Fig. 16. Cyclomylus lohensis. A. Skull of AMNH 19096 (holotype). A1. Ventral view. A2. Right lateral view. A3. Anterior view. B. Anterior view of transverse section along p4 of right lower jaw (IVPP V 11458) showing the relation between $\mathrm{p} 4$ (alveolus) and i2.

ed from the posterolophid by a shallow groove. The straight ectolophid joins the protoconid with the hypoconid or hypolophid. The hypolophid is slender, low, and complete or incomplete. The lingual middle valley is broad. The hypoflexid is strongly oblique posterolingually and persists longer with wear than do other valleys.

The lower molars are four crested. Unlike p4 the metalophid I and II are better devel- 

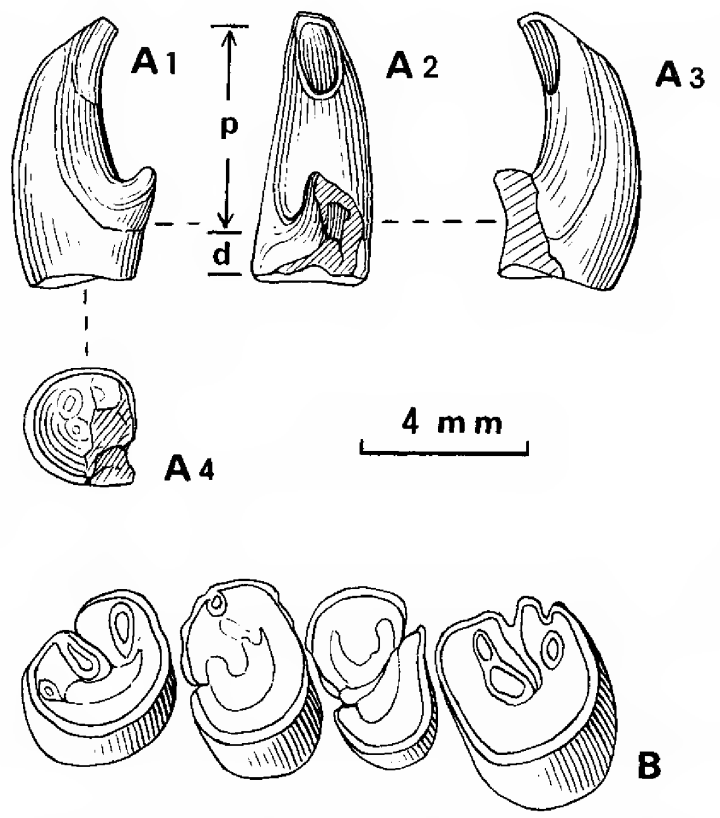

Fig. 17. Cheek teeth of Cyclomylus lohensis. A. Right M1/2 (IVPP V 11457). A1. Posterior view. A2. Buccal view. A3. Anterior view. A4. Occlusal view. B. Occlusal view of right P4-M3 of AMNH 19096 (holotype). See figure 10 for abbreviations.

oped and long. The prominent protoconid and metaconid are subequal and separated widely. The trigonid basin is a large, oval, closed basin. The hypolophid is slender and usually complete. No distinct entoconid is seen. The hypertrophic hypoconid is the largest cusp and extends anterobuccally. The posterolophid is well developed. In the lingual valleys the middle valley is the largest and opens lingually. The posterior valley is a closed basin. The hypoflexid is oblique posterolingually and remains later with wear than do the lingual valleys.

The Dp4 is molariform and similar to lower molars, except that it is longer in proportion and there is a prominent anteroconid.

As in Tsaganomys altaicus, the incisor is nearly triangular in cross section and with or without longitudinal ridges on the labial surface of the enamel. The enamel has a multiserial microstructure. However, as described by Martin (1992), and unlike Tsaganomys altaicus, the enamel is rather thin. The total enamel thickness is only about $80 \mu \mathrm{m}$. However, the PE is relatively thick, near $40 \%$ of the total enamel thickness, and the prisms of the PE have an inclination of near $30^{\circ}$. The HSB, composed of 3-4 prisms, have an inclination of near $30^{\circ}$ relative to the EDJ.

Dimensions: See table 2.

Discussion: Matthew and Granger (1923) briefly described Cyclomylus lohensis in their diagnosis without giving figures and measurements. This has led to great confusion in the classification of the tsaganomyids. Some paleontologists have expressed their uncertainty about their identification of the tsaganomyids (Vinogradov and Gambaryan, 1952; Kowalski, 1974). It is difficult for me to comment on the specimens of these paleontologists as no figures and plates are given or the specimens or casts are unavailable for personal observation.

Bryant and McKenna (1995) considered Cyclomylus lohensis as a junior synonym of Tsaganomys altaicus. A closer comparison of the two holotypes and other specimens reveals that Cylomylus lohensis differs from Tsaganomys altaicus in some skull and tooth morphology.

First, Matthew and Granger (1923: 3-5) mentioned that in $T$. altaicus the cheek teeth were very hypsodont, continuously growing, and without closed roots at any observed stage of wear; and in C. lohensis the cheek teeth were less hypsodont and the roots closed when fully grown. In the holotype of T. altaicus (AMNH 19019) the cheek teeth have lost their occlusal pattern, but the enamel still extends to the base and the roots are still open. In contrast, in the holotype of $C$. lohensis (AMNH 19096) the upper cheek teeth have three closed roots, a large lingual one and two small buccal ones, and their occlusal surfaces more or less retain lophs and valleys. Obviously, the difference in crown height of the two taxa is not age related. Correspondingly, in hypsodont Tsaganomys the upper cheek teeth extend medial to the posterior part of the upper incisor and the lower cheek teeth buccal to the lower incisor, whereas in less hypsodont Cyclomylus lohensis the uppers grow from below the upper incisor and the lowers from above the lower incisor.

Second, in $T$. altaicus the dentine part of the cheek teeth is much more developed, the pulp cavity is relatively short and with a 
pointed apex, and the ratio of the height of the dentine part of pulp cavity of the check teeth is much higher than that in Cyclomylus, for which the dentine part is much shorter than the pulp cavity. In addition, the pulp cavity in Cyclomylus has a flat or concave top with sides nearly parallel to the side walls of the crown (figs. 10, 17).

Third, the cheek teeth of Tsaganomys have much thinner enamel on the occlusal surface, much weaker expression of the cusps and lophs, and no hypertrophied hypoconid. After being worn, the occlusal surface is concave and smooth, without a core of secondary dentine in Tsaganomys, whereas in $\mathrm{Cy}$ clomylus there is a core on the surface. In addition, in Tsaganomys $\mathrm{p} 4$ is nearly square in occlusal view and has a low metalophid I, a long metalophid II, and a wide trigonid. In Cyclomylus the $\mathrm{p} 4$ is oval and longer than wide, lacks a metalophid I, but has a weak, short metalophid II and a very narrow trigonid basin.

Fourth, in Tsaganomys the major axis of the oval infraorbital foramen is nearly horizontal and almost parallel to anterior margin of the ventral surface of the anterior zygomatic root, whereas in Cyclomylus it is nearly vertical and almost perpendicular to the anterior margin of the ventral surface of the anterior zygomatic root.

Fifth, the microstructure of the incisor enamel in the two forms differs, although both have multiserial microstructure. In Tsaganomys the PE is relatively thin, its ratio to total enamel thickness is very low, its prisms have no inclination, and its HSB include more prisms but with less inclination. In Cyclomylus the PE is relatively thick, both the HSB and prisms of $\mathrm{PE}$ are inclined nearly at $30^{\circ}$ with the EDJ, and the HSB include fewer prisms.

The above arguments seem convincing enough to validate Cyclomylus lohensis as a separate taxon.

Pseudotsaganomys turgaicus Vinogradov and Gambaryan (1952) is identical with $C y$ clomylus lohensis in cheek tooth morphology. Its cheek teeth are lower crowned, covered by thicker enamel, with closed roots, more prominent cusps and lophs, and hypertrophied hypoconid. Pseudotsaganomys turgaicus may be a junior synonym of $C$. lohensis. Possibly P. mongolicus is also a junior synonym of $C$. lohensis, judging by the authors' original description. However, the authors did not figure any teeth, and I am uncertain about the status of $P$. mongolicus. Likewise, Cyclomylus mashkovae Shevyreva (1994) from Kazakhstan is likely a junior synonym of $C$. lohensis, based on the identical cheek tooth morphology.

\section{Cyclomylus intermedius, new species}

Figures 20-23; table 3

Cyclomylus lohensis, Young and Chow, 1956: 448, 449, fig. 1. Shevyreva, 1974b: 52-56, figs. 1a, b. NEW SYNONYMY.

Tsaganomys altaicus (partim), Bryant and $\mathrm{Mc}-$ Kenna, 1995: 5-16, fig. 11C. NEW SYNONYMY.

HolotyPE: A right lower jaw with i2, p4m3 (IVPP V 823), from Qingshuiying Formation, Qingshuiying, Lingwu, Ningxia, China, figured by Young and Chow, 1956: fig. 1 .

REFERRED SPECIMENS: IVPP V 1145311455; AMNH 81235, 82183, 85543; PIN 475-3883 and 475 .

GeOlogical Range: Early Oligocene (Wulanbulage Formation, Qingshuiying Formation and Hsanda Gol Formation).

GEOGRAPHIC Distribution: Qingshuiying, Lingwu of Ningxia, Saint Jacques (IVPP Loc. 77046 [IVPP V 11453]) and Qianlishan District (IVPP Locs. 78018 [V 11454] and 79011 [11455]) of Nei Mongol, China; and Tsagan Nor Basin, Mongolia.

DiAGNOSIs: Moderately unilaterally hypsodont Cyclomylus, height difference between shortest and highest enamel on walls of each cheek tooth is large, lower molars growing buccal to lower incisor, fourth premolar larger than molars in size, upper cheek teeth with three closed roots, and lowers with two.

Eтymology: Intermedius, Latin, intermediate.

DESCRIPTION: The mental foramen is anterior to $\mathrm{p} 4$. The $\mathrm{p} 4$ extends above lower incisor, but molars are slightly buccal to lower incisor. The lower incisor is triangular in cross section with a flat labial side. The enamel is thin, and the labial surface has no longitudinal ridge.

Cheek teeth are moderately unilaterally hypsodont and more or less covered by ce- 

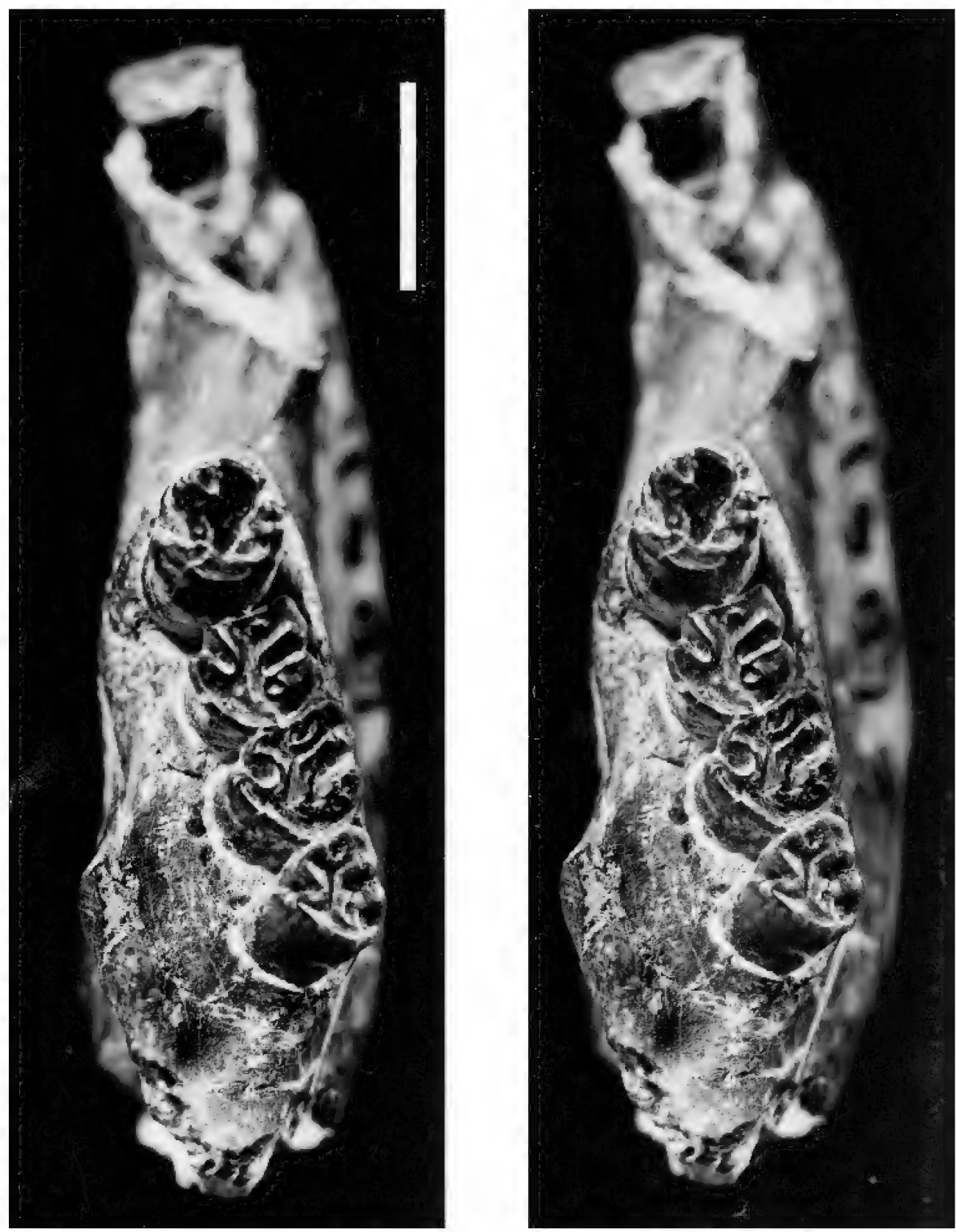

Fig. 18. Occlusal view of left lower jaw with i2, p4-m3 of Cyclomylus lohensis (IVPP V 11543) (in stereo). Scale $=5 \mathrm{~mm}$.

ment. The crown is higher than that of $C$. lohensis and lower than in $C$. biforatus. The interval of the eruption of the cheek teeth is longer than in $C$. lohensis. By the time of eruption of the third molar and fourth premolar, the occlusal pattern of the first and second molars have been worn away. The dentine part is very low. The pulp cavity is well developed and nearly cylindrical, with its side walls parallel to the side walls of the tooth, a nearly flat or concave top, and a slightly constricted base. 


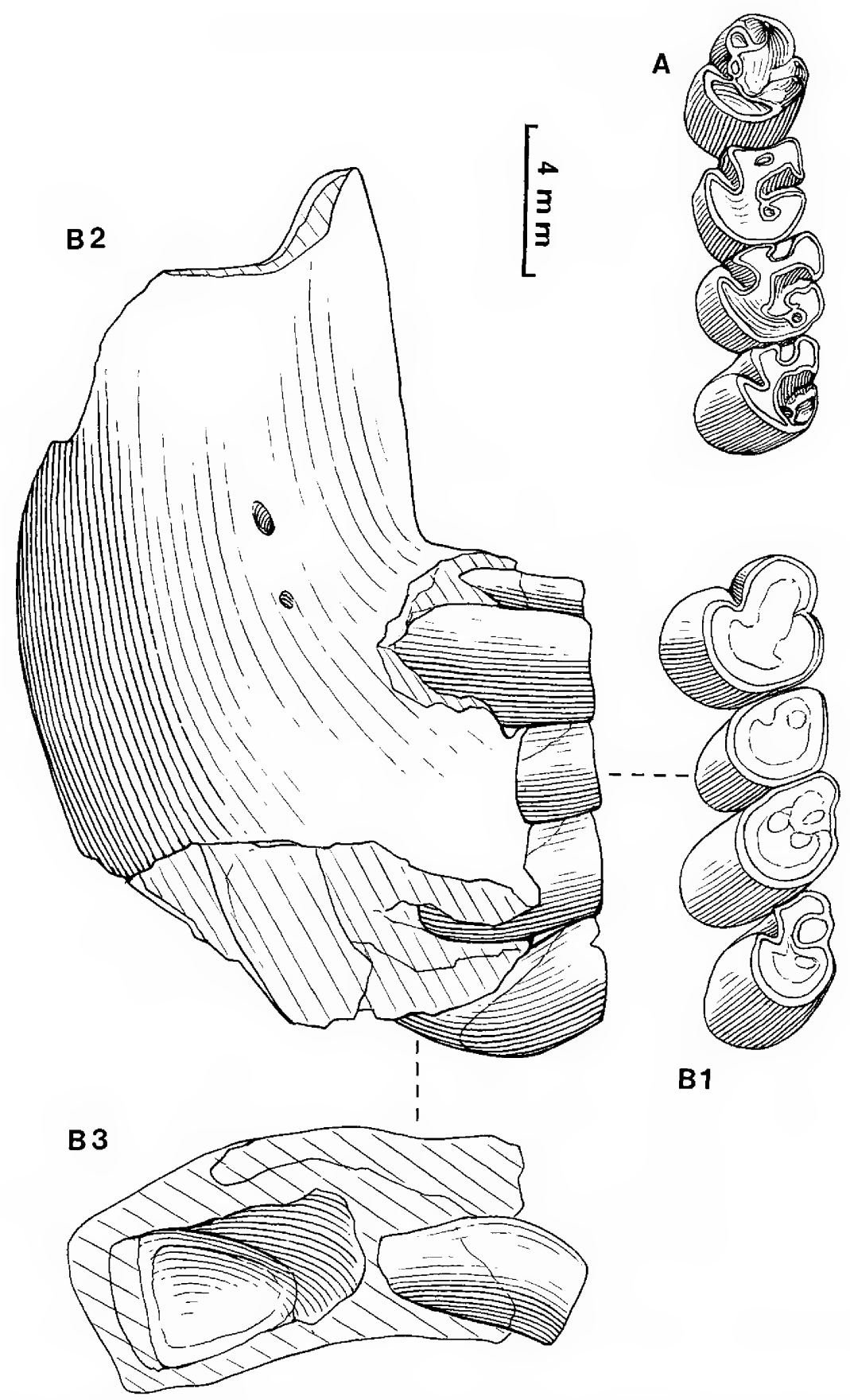

Fig. 19. Cyclomylus lohensis A. Occlusal view of left p4-m3 (IVPP V 11543). B. Left lower jaw with i2, p4-m3 (IVPP V 11456). B1. Occlusal view. B2. Buccal view. B3. Posterior view showing the relation between $\mathrm{i} 2$ and $\mathrm{m} 3$. 


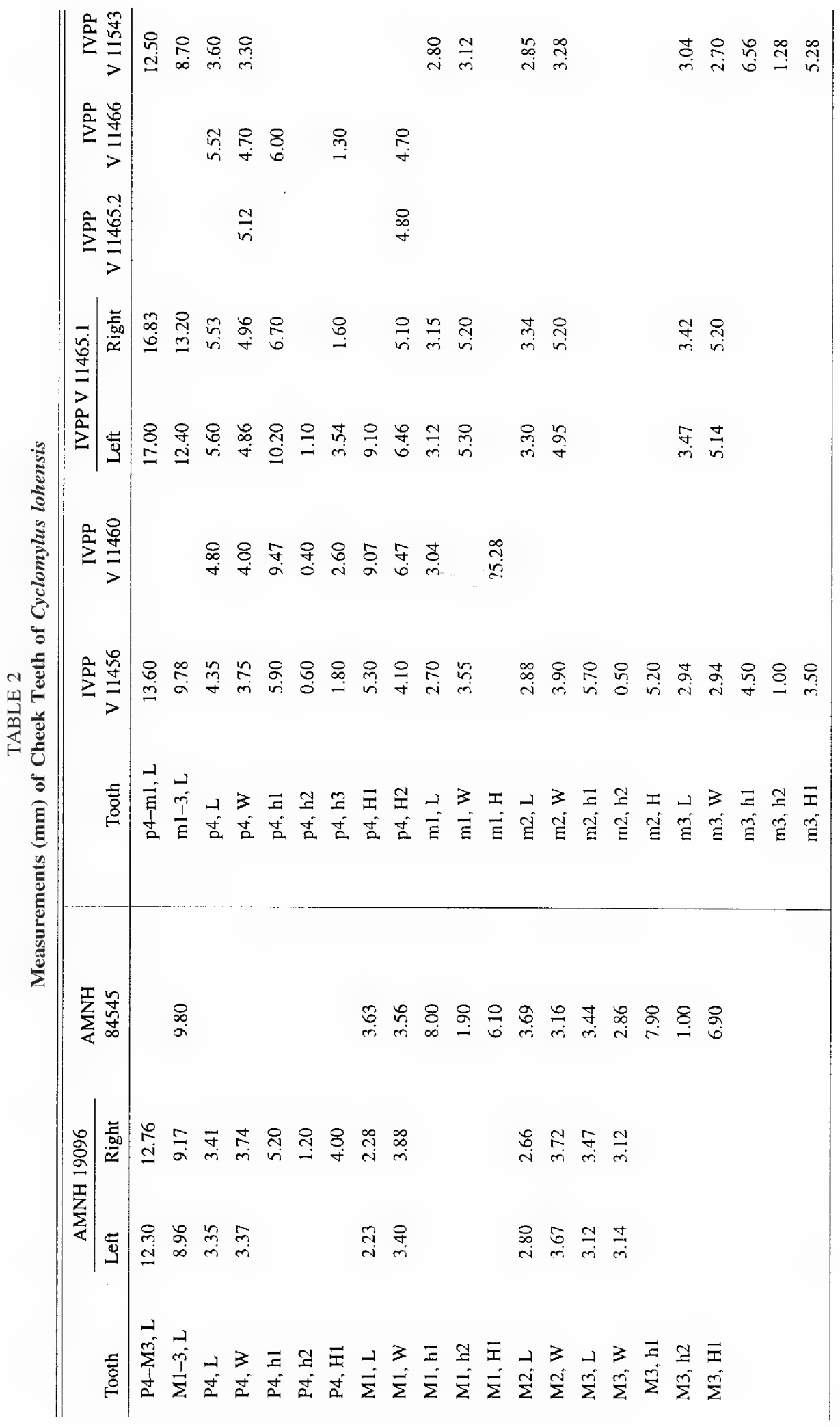




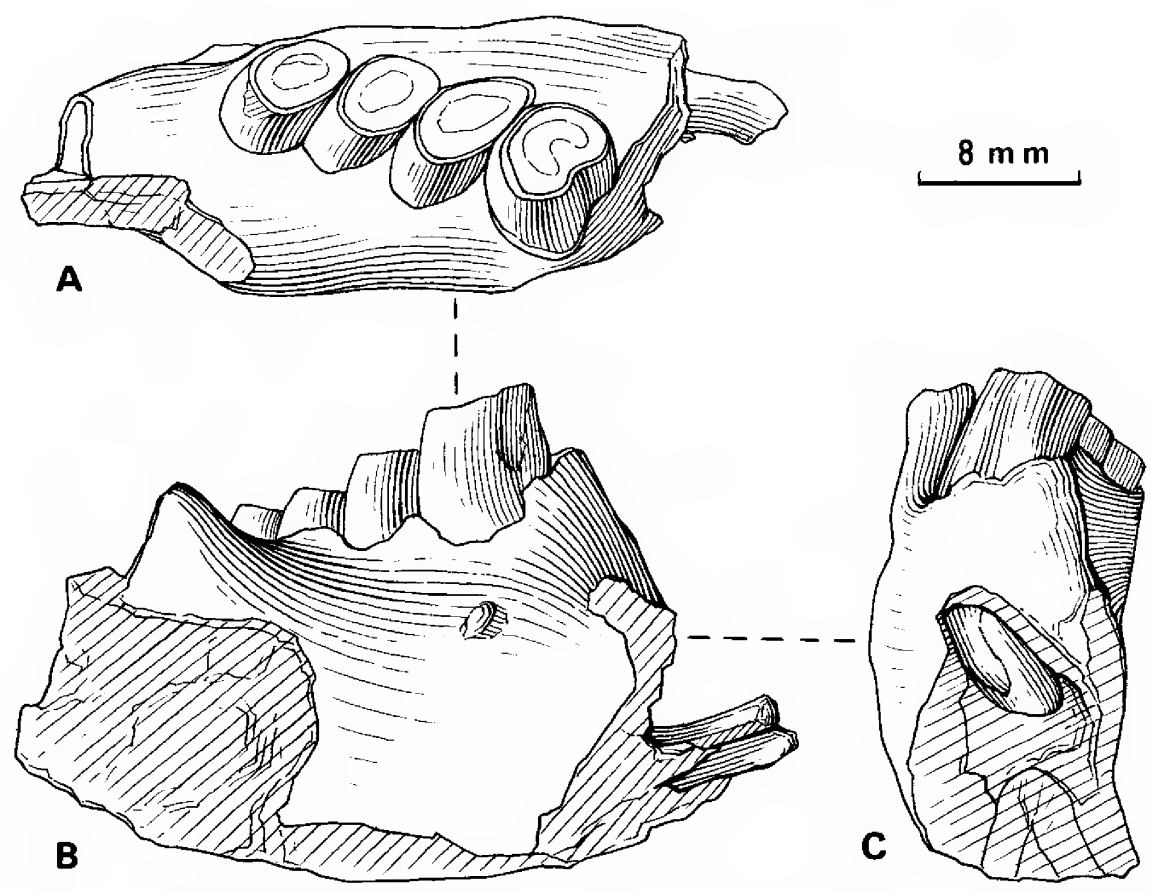

Fig. 20. Right lower jaw with i2, p4-m3 of Cyclomylus intermedius, new species (IVPP V 823, holotype). A. Occlusal view. B. Buccal view. C. Anterior view showing the relation between i2 and p4.

In most of the upper cheek teeth the occlusal surface is concave, with a more or less clearly expressed secondary dentine core in the center. The core is usually oval. On one slightly worn M1/2 (= M1 or M2, IVPP V 11454.1) the occlusal pattern is dis-
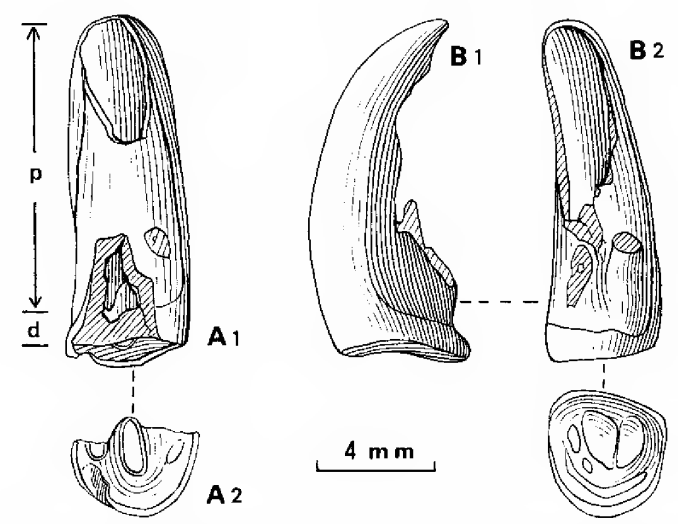

B 3

Fig. 21. Cheek teeth of Cyclomylus intermedius, new species. A. Right M1/2 (IVPP V 11454.1). A1. Buccal view. A2. Occlusal view. B. Right M1/2 (IVPP V 11454.3). B1. Posterior view. B2. Buccal view. B3. Occlusal view. See figure 10 for abbreviations. cernible: four lophs and three valleys (fig. 21A). The anterior valley is almost worn out, leaving only a small oval depression. The middle valley is the deepest and large and extends into the pulp cavity. The posterior valley is partly preserved. The protocone is large and separated from the lingual part of the posteroloph by a small groove. The dentine part is about $2 \mathrm{~mm}$ in height (from occlusal surface to top of pulp cavity). As in $C$. lohensis the upper cheek teeth have three closed roots, one large lingual and two small buccal ones.

The lower cheek teeth are oval in occlusal view and have two closed roots: a small anterior one and a large posterior one. The p4 is larger than lower molars, with a larger anterior root. The occlusal surface has a distinct core when worn, with its shape depending on the stage of wear. It is usually oval in shape. On worn p4 of IVPP V 823, it is crescent. On unworn or slightly worn cheek teeth the occlusal pattern can be preserved.

The p4 is oval in occlusal view, with a very narrow anterior part and a broad posterior part. As in Cyclomylus lohensis, the 

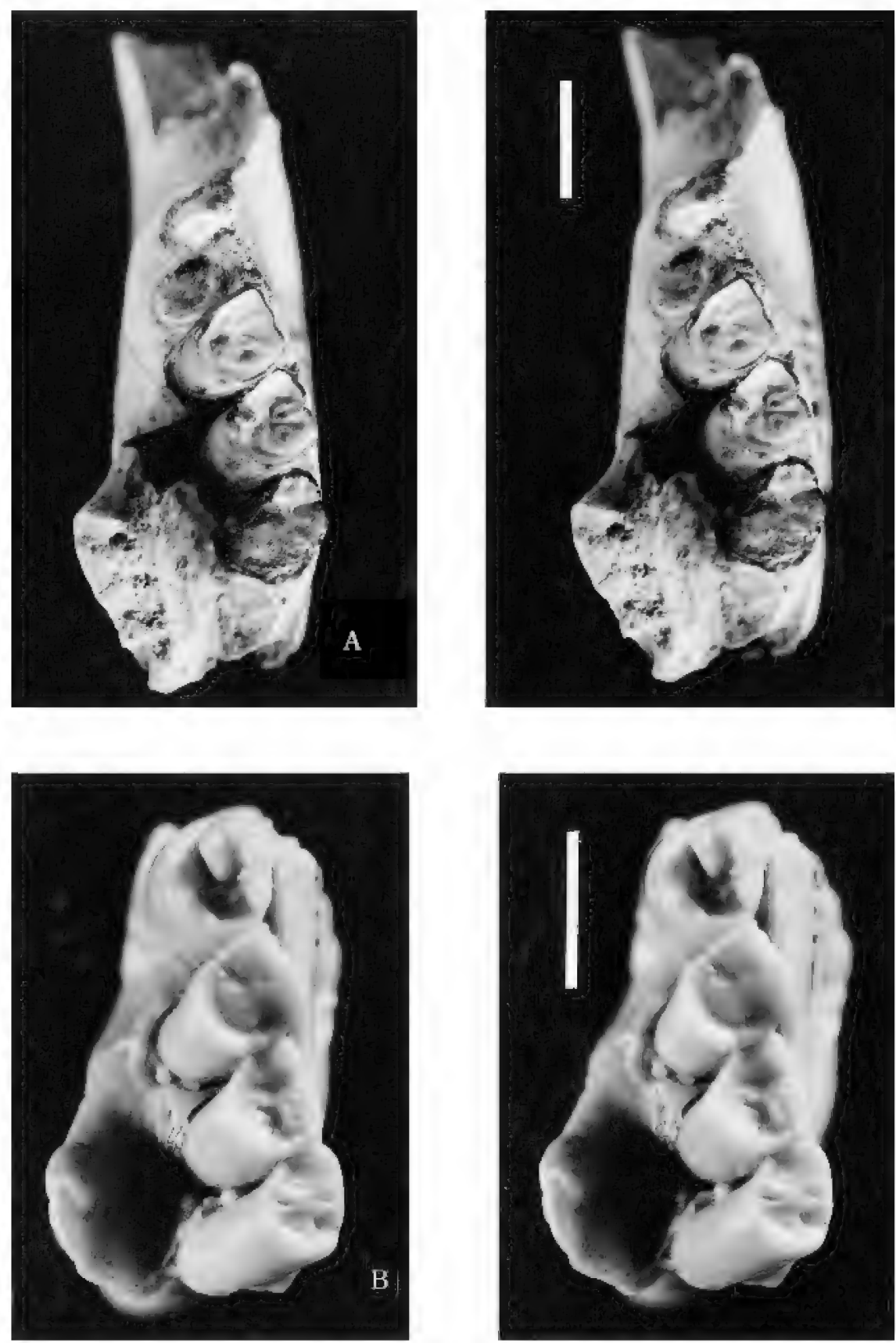

Fig. 22. Occlusal view of lower jaw of Cyclomylus intermedius, new species (in stereo). A. Left lower jaw with i2, m1-3 (IVPP V 11455). B. Left lower jaw with p4-m3 (AMNH 85543). Scale $=5$ $\mathrm{mm}$.

protoconid and metaconid are close to each other and united by a very short metalophid II. The trigonid basin is a very narrow fissure opening anteriorly. The metalophid I is ab- sent. The hypertrophic hypoconid extends anterobuccally. The ectolophid is low and short. The short hypolophid is complete and joins the hypoconid. The strong posterolo- 

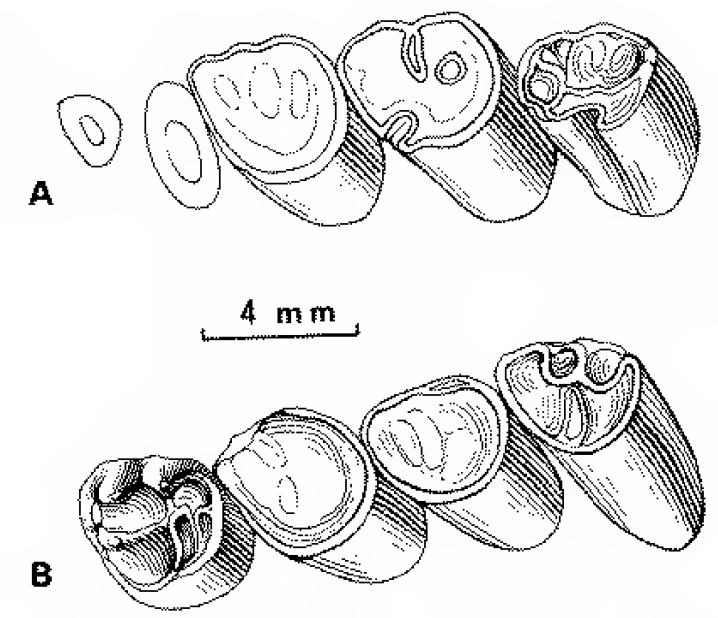

Fig. 23. Occlusal view of cheek teeth of $C y$ clomylus intermedius, new species. A. $\mathrm{m} 1-3$ (IVPP V 11455). B. p4-m3 (AMNH 85543).

phid is separated from the large entoconid by a shallow notch. The middle valley opens lingually. The posterior valley is broad and holds accessory crests in it. The hypoflexid is oblique posterolingually.

In IVPP V 11455 the occlusal surface of $\mathrm{m} 1$ is almost totally obliterated, that of the $\mathrm{m} 2$ is partly preserved: four transverse lophids and three valleys. The anterior valley is vestigial, the middle one is long transversely and open lingually, and the posterior one is a round basin. The hypoconid is hypertrophic and extends anteriorly. The hypoflexid shifts anteriorly and is strongly oblique posterolingually.

The $\mathrm{m} 3$ is similar to $\mathrm{p} 4$, but the trigonid is wider and has a distinct metalophid I and longer, prominent metalophid II. The protoconid and metaconid are of nearly equal size. The trigonid basin is wide and closed. The hypolophid may be complete or incomplete. The middle valley is open lingually until worn heavily. The closed posterior valley is about the same size as the middle valley. The hypoconid does not extend as anteriorly as in 4 . The hypoflexid is slightly oblique and does not shift much anteriorly.

The lower incisor is triangular in cross section and has a flat labial side. The enamel is thin, and the labial surface has distinct or indistinct longitudinal ridges.

Dimensions: Upper cheek teeth $(\mathrm{L} \times \mathrm{W} \times$
$\mathrm{H} 1[=\mathrm{h} 1-\mathrm{h} 2]$, in mm): M1/2 (V 11454.1), $4.1 \times ? \times ?(\mathrm{~h} 1=11.1) ; \mathrm{LM} 1 / 2(\mathrm{~V}$ 11453.6), $3.14 \times 3.3 \times 8.8(=9.8-1)$; RM3 (V 11454.2), $3.95 \times 4.1 \times 9.85(10.25$ - 0.4); and LM3 (V 11454.3), $3.73 \times 4.1 \times$ $10.96(=11.46-0.5)$. See table 3 for lower cheek teeth.

COMPARISON: Cyclomylus intermedius is an intermediate form between $C$. lohensis and $C$. biforatus in tooth morphology. It differs from $C$. biforatus in having a single infraorbital foramen, three roots on upper teeth, and two roots on lowers. The crown is higher than in $C$. lohensis. The height difference of the enamel is larger than in C. lohensis, nearly twice that of the latter. For example, in $C$. intermedius the height difference on p4 is $11.34 \mathrm{~mm}$, whereas in C. lohensis it varies from $4 \mathrm{~mm}$ to $6.4 \mathrm{~mm}$ (see tables 2 and 3 ). In addition, the lower molars extend buccal to lower incisor, whereas in $C$. lohensis they are above the lower incisor. The eruption intervals of the cheek teeth are longer than in $C$. lohensis.

\section{Cyclomylus biforatus, new species}

Figures 24-27; table 4

HolotyPE: An incomplete skull (IVPP V 11442), from IVPP Loc. 77046, Saint Jacques, Nei Mongol, China.

REFERRED SPECIMENS: IVPP V 11441 , 11443-11452.

GeOlogical Range: Late early Oligocene (upper member of Wulanbulage Formation).

GeOGRAPHIC Distribution: Saint Jacques (IVPP Locs. 77045 [V 11441], 77046 [V 11442, 11443], 77046 [white bed II] [V 11444], 77047 [V 11445], 77049.2 [V 11446], 77049.3 [V 11447] and other locality [V 11448]) and Qianlishan District (IVPP Locs. 78018 [79] [V 11449], 78018 [upper part] [V 11450], 78019 [V 11451] and 79016 [V 11452]), Nei Mongol, China.

DiAGNOSIS: Infraorbital foramen is separated into two foramina; cheek teeth high crowned with great unilateral hypsodonty and with only one main, closed root and without small roots; M1-2 originate medial to upper incisor.

ETYMOLOGY: Biforatus, Latin, double holes. The name indicates that the infraorbital foramen into two foramina. 
TABLE 3

Measurements (mm) of Lower Cheek Teeth of Cyclomylus intermedius, new species

\begin{tabular}{lrrrrrrr}
\hline \hline & IVPP & IVPP V 11455 & \multicolumn{3}{c}{ AMNH } \\
\cline { 6 - 7 } \cline { 5 - 6 } Tooth & V 823** & Left & Right & 81235 & 82183 & 85543 \\
\hline p4-m3, L & 18.00 & & & 18.15 & 17.56 & 14.60 \\
m1-3, L & 13.60 & 11.84 & 12.00 & 12.96 & 11.40 \\
p4, L & 5.34 & & & 5.55 & 4.96 & 3.72 \\
p4, W & 4.96 & & & 4.85 & 4.40 & 3.66 \\
p4, h1 & 14.80 & & & 14.90 & & \\
p4, h2 & & & & 0.40 & & \\
p4, h3 & 3.40 & & & 3.00 & & \\
p4, H1 & & & & 14.50 & & \\
p4, H2 & 11.40 & & & 11.90 & 11.20 & \\
m1, L & 3.80 & 3.50 & & & 4.85 & 4.20 \\
m1, W & 5.90 & 4.50 & 3.72 & 3.90 & 3.34 \\
m2, L & 3.95 & 3.75 & 3.72 & 5.80 & 4.67 & 3.76 \\
m2, W & 5.20 & 4.30 & 4.20 & 4.16 & 4.33 & 3.35 \\
m3, L & 3.74 & 3.42 & & 4.65 & 4.36 & 3.75 \\
m3, W & 4.86 & 3.70 & 3.72 & 3.80 & 3.18 \\
m3, h1 & & 6.60 & & & 10.00 & 7.55 \\
m3, h2 & & & & & 1.10 & \\
m3, H1 & & & & & 8.90 & \\
\hline
\end{tabular}

* Holotype.

DESCRIPTION: The rostrum is slender and long. The anterior end of the zygomatic arch is formed by a broad vertical maxillary root. On the ventral side there is a scar for the masseteric muscle. The infraorbital foramen is small and oval in shape. The major axis is nearly vertical and perpendicular to the anterior margin of the ventral surface of the anterior zygomatic root. One of the particular features is that the infraorbital foramen is separated by a small bony plate into two foramina. Between $\mathrm{P} 4$ and the incisive foramen no indication of antepremolar crest is present. The two cheek tooth rows are nearly parallel to each other. The upper incisor extends lateral to $\mathrm{M} 1-2$. The P4 grows from below the posterior part of the upper incisor alveolus, and the M1-2 grow medial to the upper incisor. The lower cheek teeth grow from above the lower incisor.

The cheek teeth are highly crowned with great unilateral hypsodonty and have only one main closed root and thick cement on walls. The occlusal surface is oval in shape, having a core when worn. As in other $C y$ clomylus, the dentine part is very short and the pulp cavity is well developed, cylindrical in form, and with a flat or concave top.

In this species only the upper incisor is known. As in other tsaganomyids, it is triangular in cross section. Its labial surface is flat with longitudinal ridges.

DimENSIONS: See table 4.

COMPARISON: Cyclomylus biforatus differs from $C$. lohensis and $C$. intermedius in infraorbital foramen being separated into two foramina and cheek teeth being higher crowned and having only one closed root.

\section{Coelodontomys, new genus}

Tsaganomys Matthew and Granger, 1923 (partim). Vinogradov and Gambaryan, 1952 (partim).

Shevyreva, 1974a. Bryant and McKenna, 1995 (partim). McKenna and Bell, 1997 (partim).

Cyclomylus Matthew and Granger, 1923 (partim). NEW SYNONYMY.

TyPE SPECIES: Coelodontomys asiaticus, new and only known species.

GeOLOGICAL RANGE: late early Oligocene.

Geographic Distribution: North China, Mongolia, and Kazakhstan.

ETYMOLOGY: Coelodontomys, Greek; koilos, hollow; odontos, tooth; and mys, mouse. The name indicates that the cheek teeth have developed pulp cavity.

DiAGNOSIS: Medium-sized tsaganomyid, nasal extending slightly posteriorly, with nasal-frontal suture in one line with premaxillary-frontal suture; small oval infraorbital foramen with nearly vertical major axis, almost perpendicular to anterior margin of ventral surface of anterior zygomatic root; left and right antepremolar crests convergent forward but not merging; premaxillary-maxillary suture intersects the two antepremolar crests; angle between dorsal surface of posterior part of upper incisor alveolus and occlusal surface of cheek teeth near $60^{\circ}$; $\mathrm{P} 4$ concave buccally, passing by ventral and reaching buccal side of upper incisor; upper molars extending to orbital region passing by upper incisor on the medial side; lower cheek teeth concave medially or anteromedially; p4 extends from above lower incisor, but lower molars buccal to lower incisor; cheek teeth strongly unilarterally hypsodont, with open roots, very short dentine part, well-developed cylindrical pulp cavity, and covered by ce- 
ment; enamel on occlusal surface slightly thick, occlusal pattern lost early and usually with core when worn; lower cheek teeth with hypertrophic hypoconid, oval p4 with narrow trigonid; PE of lower incisor enamel thin, with near $30^{\circ}$ inclined prisms; HSB inclined at nearly $30^{\circ}$ and composed of $4-5$ prisms.

\section{Coelodontomys asiaticus, new genus and species}

Figures 13C, 28-31; table 5 .

Tsaganomys altaicus Matthew and Granger, 1923 (partim): 2-4, figs. 1 (partim), 2 (partim), 3, 4A. Vinogradov and Gambaryan, 1952 (partim): 23, 24. Bryant and McKenna, 1995 (partim): 5-16, figs. 3 (partim), 4, 5, 10A, 11A. Shevyreva, 1974a: 46, figs. 1v, g, 6, 7, 8. NEW SYNONYMY.

Cyclomylus lohensis Matthew and Granger, 1923 (partim): 5. NEW SYNONYMY.

Tsaganomys sp. Emry et al. 1998: 308-310, fig. 8B. NEW SYNONYMY.

Holotype: A nearly complete skull (AMNH 21675), from Hsanda Gol Formation, Field. no. 531, Grand Canyon, north of Tsagan Nor, Mongolia, figured by Bryant and McKenna, 1995: figure 4. (Note that this figure is actual size. The scale is incorrect.)

REFERRED SPECIMENS: IVPP V 1142711440; AMNH 19021-19025, 19028, 19029, 19033-19035, 19038, 19099, 21659, 21676$21678,21691,22085,56625,81219,81221$, $81222,81235,81273,81335,81347,81396$, $81397,81468,81469,81472,81482,81484$, 81485, 81990A, 81993, 81995-81998, 82251, $82255,82266,82271,82278-82281,82284$, $82400,83502-83504,83506,83507,83521$, $83541,83548-83554,83556,83557,83559-$ $83561,83565,83579,83583,83589,83599$, 83601-83604, 83611-83614, 83616-83620, $83625,83627,83628,83630-83632,83635$, $83642,83645,83648,84329-84331,84333-$ $84340,84342,84344-84346,84497-84500$, 84502-84504, 84506, 84507, 84509, 84511, $84512,84514,84515,84518-84521,84523$, $84526,84535,84546,85183,85185-85188$, $85194,85239,85242,85244,85245,85248$, $85254,85259,85262,85267-85269,85274$, $85277-85281,85287,85318,85538,85544$, 85738, 85741, 85743, 85745; PIN 475-3878, 47540; and K35(15)/425.

GEOLOGICAL RANGE: Late early Oligocene (upper member of Wulanbulage Formation, upper part of Ulantatal Formation, Hsanda Gol Formation and Buran Formation).

GeOGRAPHIC Distribution: Saint Jacques (IVPP Locs. 77045 [IVPP V 11427], 77046 [V 11428], 77047 [V 11429], 77049 [V 11430, V 11431], 77049.1 [V 11432], 77049.2 [V 11433], 77049.3 [V 11434], 77049.7 [V 11435], 78020 [V 11436]), Qianlishan District (IVPP Loc. 78018: V 11437), Ulantatal (V 11438) of Nei Mongol, China; Grand Canyon and other localities of Tsagan Nor Basin, Mongolia (V 11439, V 11440, and other specimens in $\mathrm{AMNH}$ ); and $\mathrm{K} 15$, Podorpzhnik, Zaysan Basin, Kazakhstan [K35(15)/425].

DiAgnosis: As for genus.

ETyMology: Asiaticus, Latin, Asian.

DESCRIPTION: Bryant and McKenna (1995) carefully described Tsaganomys altaicus but, unfortunately, based their description on a mixture of specimens, some of which are referred to Tsaganomys (AMNH 19037), Cyclomylus (AMNH 81927, 82183, 84545), and others to Coelodontomys (AMNH 21675, 19021, and 19023), respectively, in the present paper. Their description of the skull is mainly based on AMNH 21675 and 19021. These two specimens are now referred to Coelodontomys asiaticus, of which AMNH 21675 is the holotype. To some extent, what they described is the skull of Coelodontomys. A few additional remarks are given below.

Taken as a whole, the skull of Coelodontomys is similar to that of Tsaganomys. However, there are some important differences between them. In Coelodontomys the range of variation in size is not as large as in $T s a-$ ganomys. It is usually medium sized. The nasals extend more posteriorly than in Tsaganomys. The nasal-frontal suture is nearly straight or convex posteriorly and almost in one line with the premaxillary-frontal suture. As in Tsaganomys the temporal fossae are large and the distinct temporal crests arise from the prominent anterior process medial to the orbit and turn posteromedially to merge into the sagittal crest, which, in turn, meets the occipital crest. On the dorsal view the narrowest part of the skull is in the postorbital constriction area rather than in the interobital constriction. The strong zygoma is much arched outward.

The antepremolar crests from $\mathrm{P} 4$ to the in- 

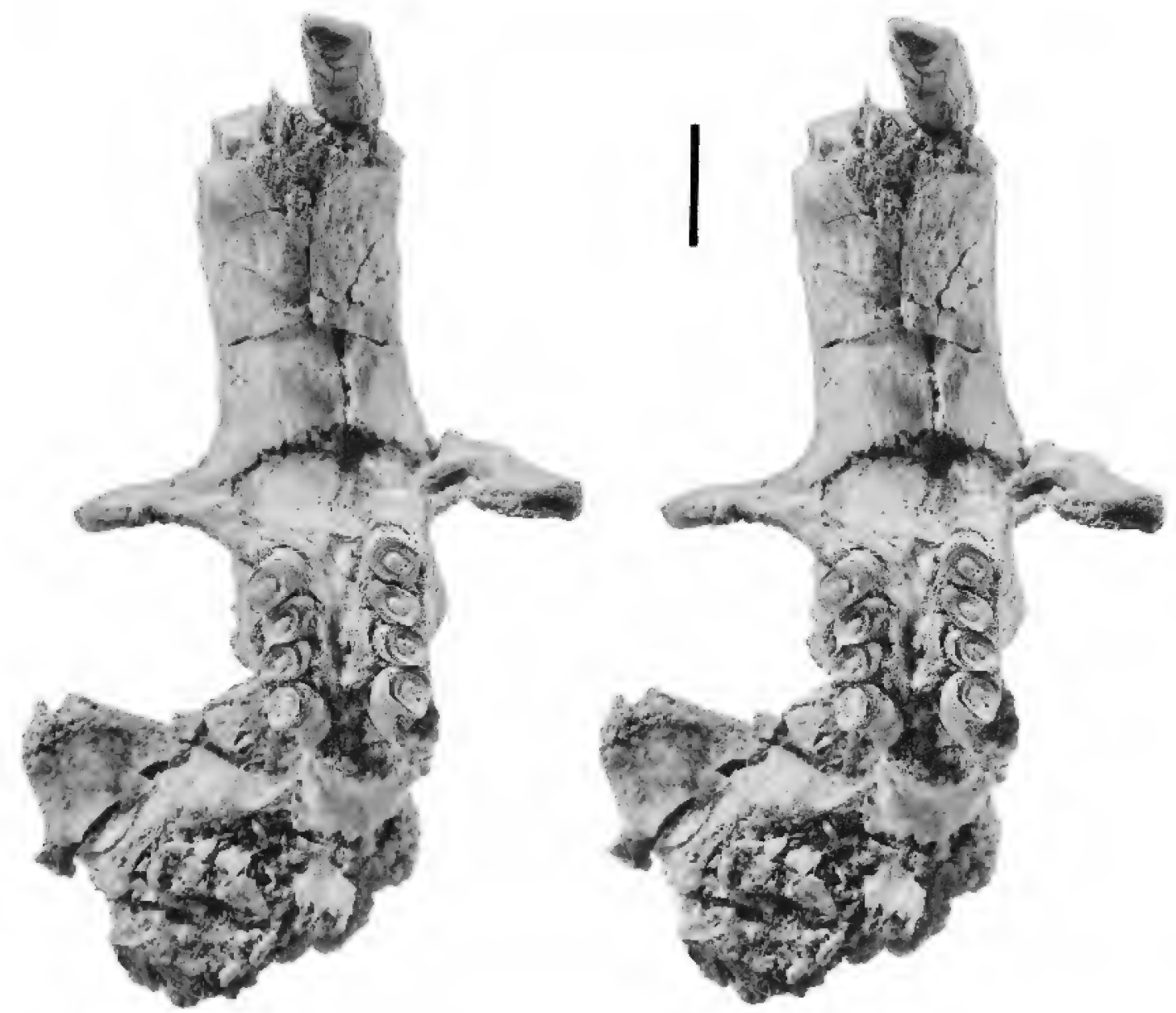

Fig. 24. Ventral view of skull of Cyclomylus biforatus, new species (IVPP V 11442, holotype) (in stereo). Scale $=1 \mathrm{~cm}$.

cisive foramen are nearly straight, are convergent toward the incisive foramen, but do not merge. The premaxillary-maxillary suture crosses the two crests. In anterior view the small oval infraorbital foramen is slightly inclined, with a nearly vertical major axis that is almost perpendicular to the anterior margin of the ventral surface of the anterior zygomatic root. The pterygoid fossa is small, shallow, and not perforated.

As in Tsaganomys the pocket formed by lachrymal, jugal, and maxillary is interpreted here as the eye socket. The orbit is very small. The procumbent upper incisor extends backward to the buccal side of the M1-2. The dorsal line of the posterior part of the upper incisor alveolus and the occlusal sur- face of the upper cheek teeth form an angle of nearly $60^{\circ}$, which is larger than in Tsaganomys. The upper molars extend to the orbital area, passing by the medial side of the upper incisor. Unlike in Tsaganomys, however, P4 is strongly concave buccally, passing ventrally to reach the buccal side of the upper incisor (fig. 28).

The mandible is similar to that to Tsaganomys, and the lower cheek teeth are concave lingually or anterolingually. The lower molars originate buccal to the lower incisor. However, $\mathrm{p} 4$ grows from above the lower incisor, which is similar to that of Cyclomylus but different from that of Tsaganomys.

The cheek teeth, as in Tsaganomys, are cylindrical, strongly unilaterally hypsodont, 


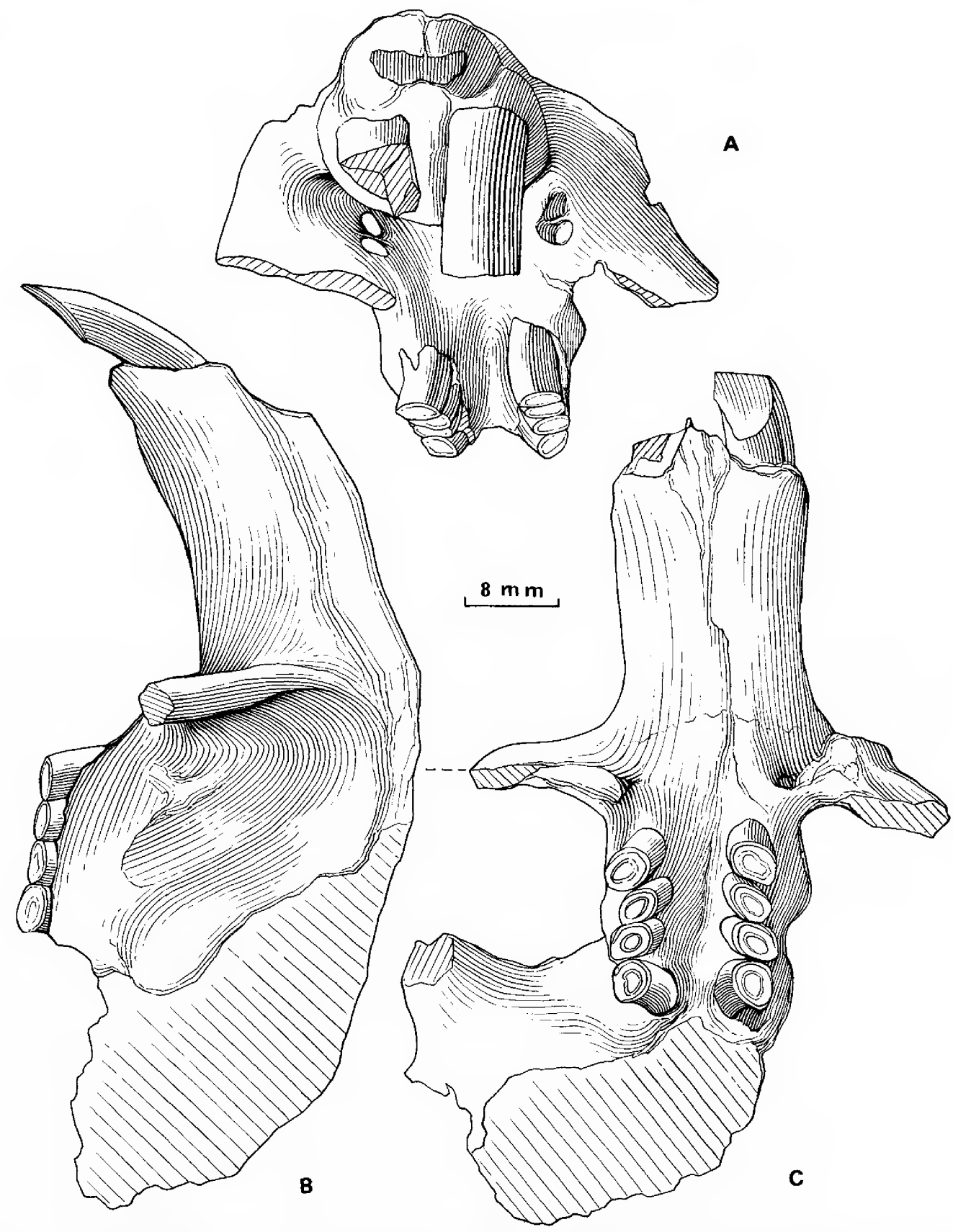

Fig. 25. Skull of Cyclomylus biforatus, new species (IVPP V 11442, holotype). A. Anterior view. B. Left lateral view. C. Ventral view.

and with open roots. The enamel, extending from occlusal surface to the base, covers the anterolingual side on the upper cheek teeth but the posterobuccal side on the lowers. There is always cement covering the side walls. On the occlusal surface the enamel is thicker than in Tsaganomys but thinner than in Cyclomylus. With wear the occlusal pattern is lost early; the occlusal surface becomes smooth and concave and usually has 

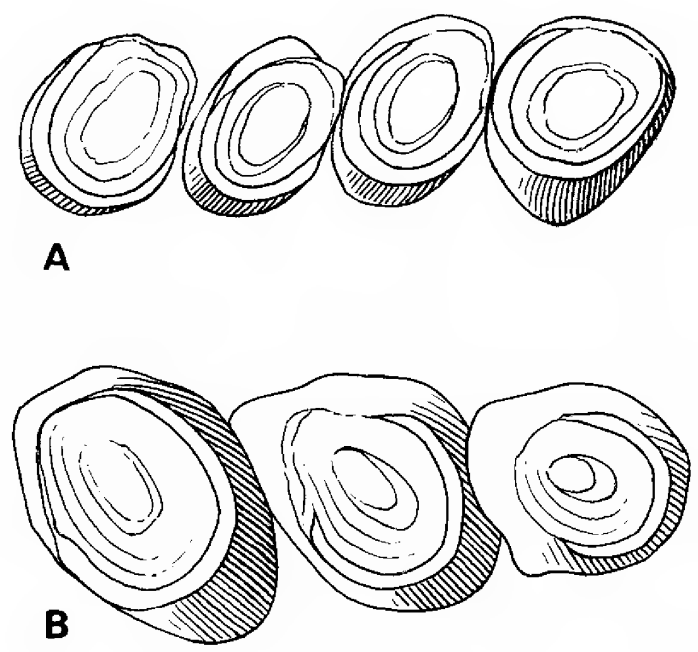

$4 \mathrm{~m} \mathrm{~m}$

Fig. 26. Occlusal view of cheek teeth of $C y$ clomylus biforatus, new species A. Left P4-M3 (IVPP V 11442, holotype). B. Left m1-3 (IVPP V 11447).

a core, which is slightly convex and usually similar to the contour of the tooth in shape. Different from Tsaganomys but similar to Cyclomylus, the dentine part is very short in height and the pulp cavity is well developed. The ratio of the dentine part to the pulp cavity is very small, even smaller than in Cyclomylus. The primary dentine seems to stop growing early. As the primary dentine is worn away, the void is replaced by the secondary dentine, which forms a core. The pulp cavity is usually cylindrical in shape, with its walls parallel to those of the tooth and with a flat or concave top.

The occlusal pattern is more similar to that of Cyclomylus than Tsaganomys. It is weaker than in the former, with more slender crests and shallower valleys. The cheek teeth are four crested. The p4 is oval in occlusal view, with a very narrow trigonid. The protoconid and metaconid are close to each other, and the metalophid II is very short. The metalophid $I$ is absent. The trigonid basin forms a very narrow fissure opening anteriorly. The hypertrophic hypoconid is the largest of the main cusps, extending anterobuccally. The hypolophid is weak. The molars are similar to $\mathrm{p} 4$ but with a wider trigonid.

As in Tsaganomys, the incisors are trian-

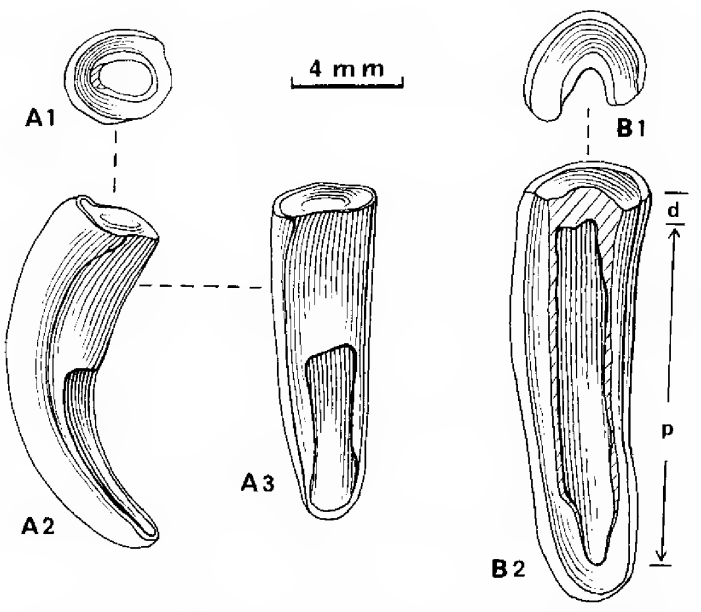

Fig. 27. Cheek teeth of Cyclomylus biforatus, new species. A. Left upper molar (IVPP V 11443.1). A1. Occlusal view. A2. Posterior view. A3. Buccal view. B. Buccal view of logitudinal section of right upper molar (IVPP V 11443.2). See figure 10 for abbreviations.

gular in cross section, with distinct or indistinct longitudinal ridges on the labial surface. The incisor enamel is multiserial with relatively thin PE; its ratio to total enamel thickness is near $17 \%$. Its total enamel thickness is near $110-139 \mu \mathrm{m}$, thinner than in Tsaganomys. The HSB is composed of 4-5 prisms and has $25-30^{\circ}$ inclination. The inclination of the prisms of PE is near $30^{\circ}$.

DiMENSIONS: See table 5.

Discussion: While describing Tsagano-

TABLE 4

Measurements (mm) of Cheek Teeth of Cyclomylus biforatus, new species

\begin{tabular}{lrrllc}
\hline \hline & \multicolumn{2}{c}{ IVPP V 11442} & & IVPP \\
\cline { 2 - 3 } Tooth & Left & Right & & Tooth & V 11447 \\
\hline P4-M3, L & 14.60 & 13.35 & m1-3, L & 15.30 \\
M1-3, L & 11.00 & 10.20 & m1, L & 4.80 \\
P4, L & 3.45 & 3.40 & m1, W & 6.00 \\
P4, W & 4.28 & 4.20 & m2, L & 5.20 \\
M1, L & 2.95 & 2.95 & m2, W & 6.00 \\
M1, W & 4.14 & 4.20 & $\mathrm{~m} 3, \mathrm{~L}$ & 4.84 \\
M2, L & 3.30 & 3.30 & $\mathrm{~m} 3, \mathrm{~W}$ & 5.34 \\
M2, W & 4.37 & 4.12 & & \\
M3, L & 4.05 & 4.05 & & \\
M3, W & 4.07 & 3.96 & & \\
\hline
\end{tabular}



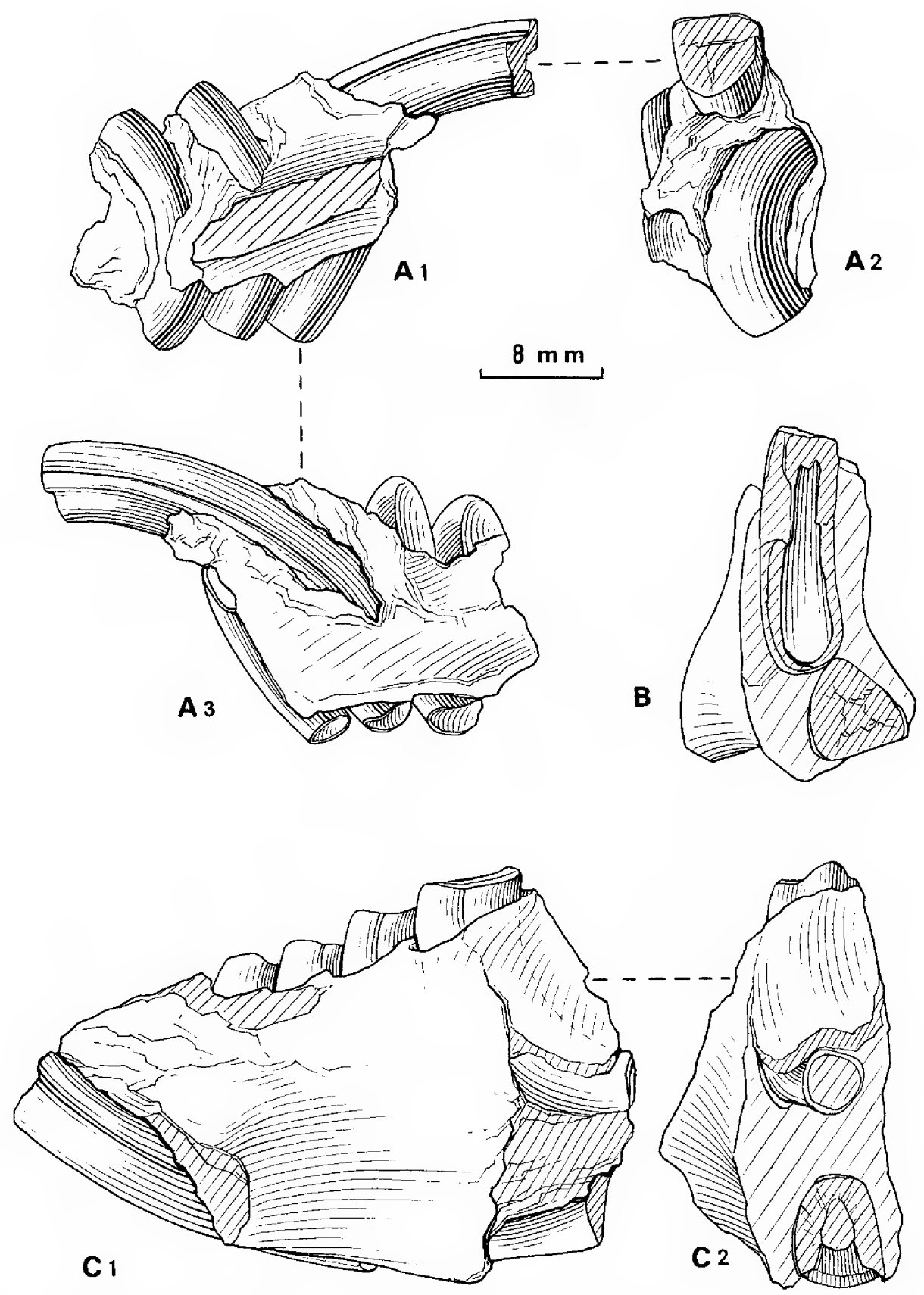

Fig. 28. Coelodontomys asiaticus, new genus and species, showing the relations between incisors and cheek teeth. A. Left upper jaw with I2, P4-M2 (AMNH 85277). A1. Medial view. A2. Anterior view. A3. Buccal view. B. Anterior view of transverse section across p4 of right lower jaw (IVPP V 11434). C. Right lower jaw with i2, p4-m3 (AMNH 83521). C1. Buccal view. C2. Anterior view. 

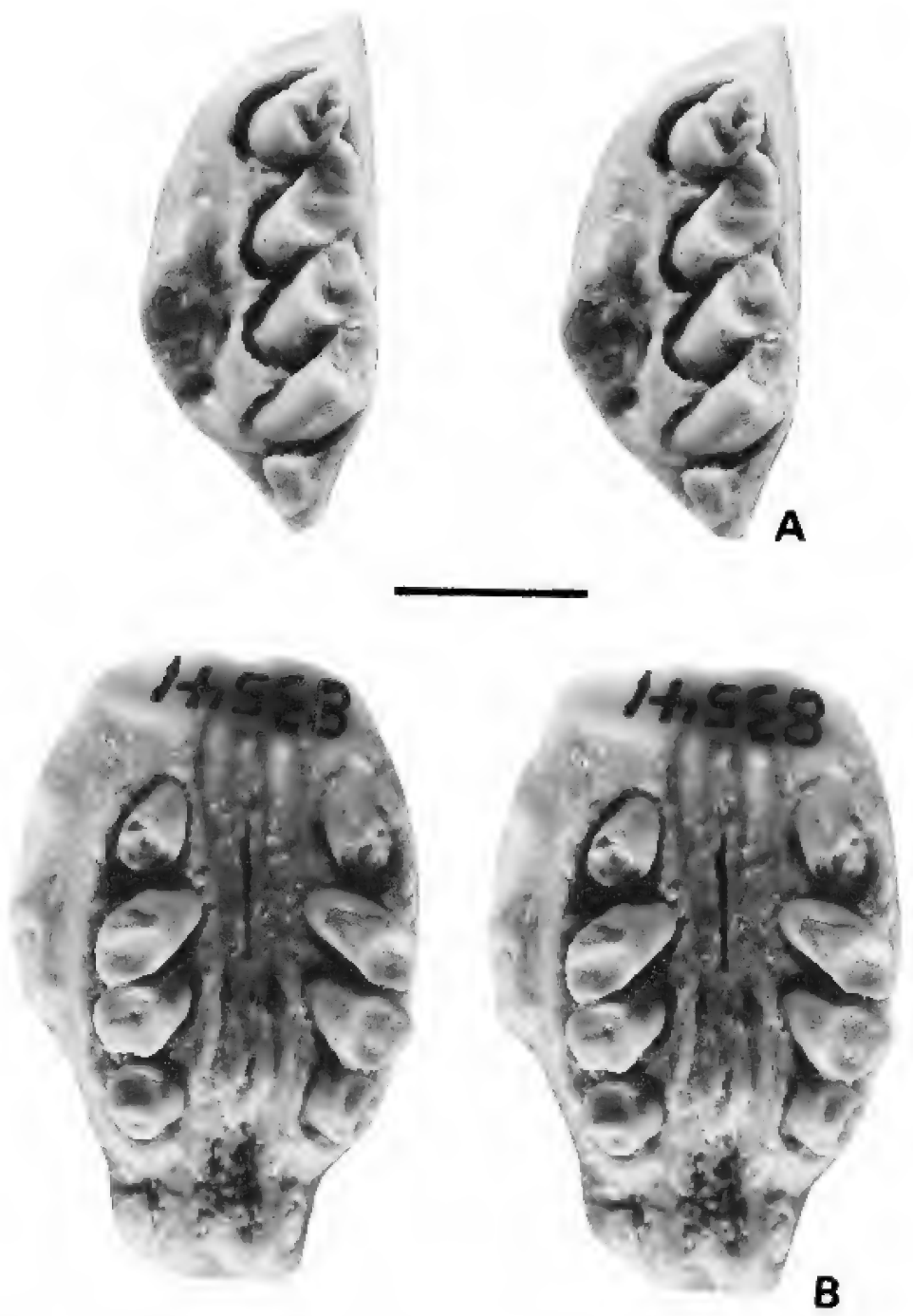

Fig. 29. Coelodontomys asiaticus, new genus and species A. Occlusal view of left lower jaw with p4-m3 (AMNH 84344). B. Occlusal view of upper jaw with left and right P4-M3 (AMNH 83541) (in stereo). Scale $=1 \mathrm{~cm}$.

mys altaicus, Matthew and Granger (1923) mixed the specimens presently referable to both Tsaganomys altaicus and Coelodontomys asiaticus. Of their paratypes only AMNH 19020 and 19037 belong to T. altaicus. The other specimens, including AMNH 19029, 19033, and 19038 (I have not seen AMNH 19030), belong to Coelodontomys asiaticus. Figure 1 of Matthew and Granger (1923) is a reconstructed skull based on both $T$. altaicus (holotype, AMNH 19019) and C. asiaticus (AMNH 19021 and 19033). Their figures 3 and 4 showed the specimens belonging to $C$. asiaticus. As mentioned above, Shevyreva (1972, 1974a) distinguished two forms among the strong hypsodont tsaganomyids. Unfortunately Beatomus bisus is a synonym of Tsaganomys altaicus, and her Tsaganomys altaicus is actually Coelodontomys asiaticus. Bryant and McKenna (1995) lumped all the known tsaganomyid taxa into one species Tsaganomys altaicus. However, Coelodontomys is generically different not only from Cyclomylus but also from Tsaganomys. The differences are listed in the table 6. 


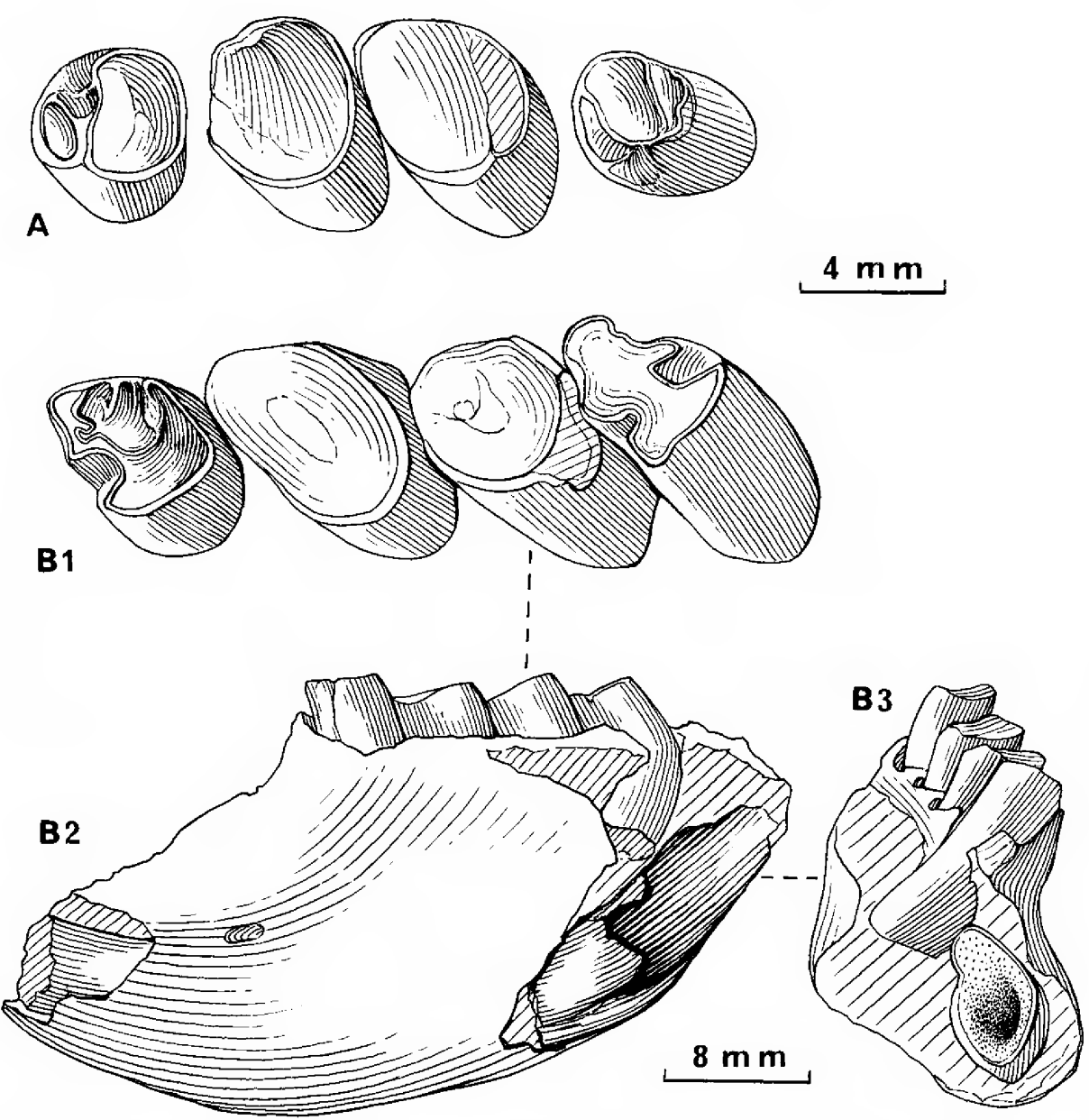

Fig. 30. Coelodontomys asiaticus, new genus and species. A. Occlusal view of right P4-M3 (AMNH 83541). B. Left lower jaw with i2, p4-m3 (AMNH 84344). B1. Occlusal view. B2. Buccal view. B3. Posterior view.

\section{DISCUSSION}

The Structure of Cheek Teeth of the TSAGANOMYIDAE

The cheek teeth of the Tsaganomyidae are all unilaterally hypsodont, and the occlusal pattern is lost early in wear. However, the tooth structure of Tsaganomys is quite different from that of Cyclomylus and Coelodontomys. In Tsaganomys the dentine part is well developed, always deeper than the pulp cavity in height. The primary dentine grew continuously with the growth of the tooth. With wear, the occlusal surface became smooth, lacking a core of secondary dentine. Therefore, it is made totally of primary dentine. In Cyclomylus and Coelodontomys the dentine part is short, but the pulp cavity is well developed and high. As the tooth aged, it does not seem the primary dentine grew continuously as in Tsaganomys, but the pulp cavity grew higher and higher and the tooth walls became thin. This kind of tooth seems physically weak, even if it is very high crowned. When considerably worn, the short primary dentine in the center of the tooth was lost, and the pulp cavity became uncovered on the occlusal surface so that a hole can be seen extending from the surface to the pulp cavity in some teeth. To reinforce the tooth secondary dentine filled this hole, forming a core.

\section{P3 Or dP3 of Tsaganomyidae}

In the diagnosis of Tsaganomys, Matthew and Granger (1923: 2-4) mentioned that the 


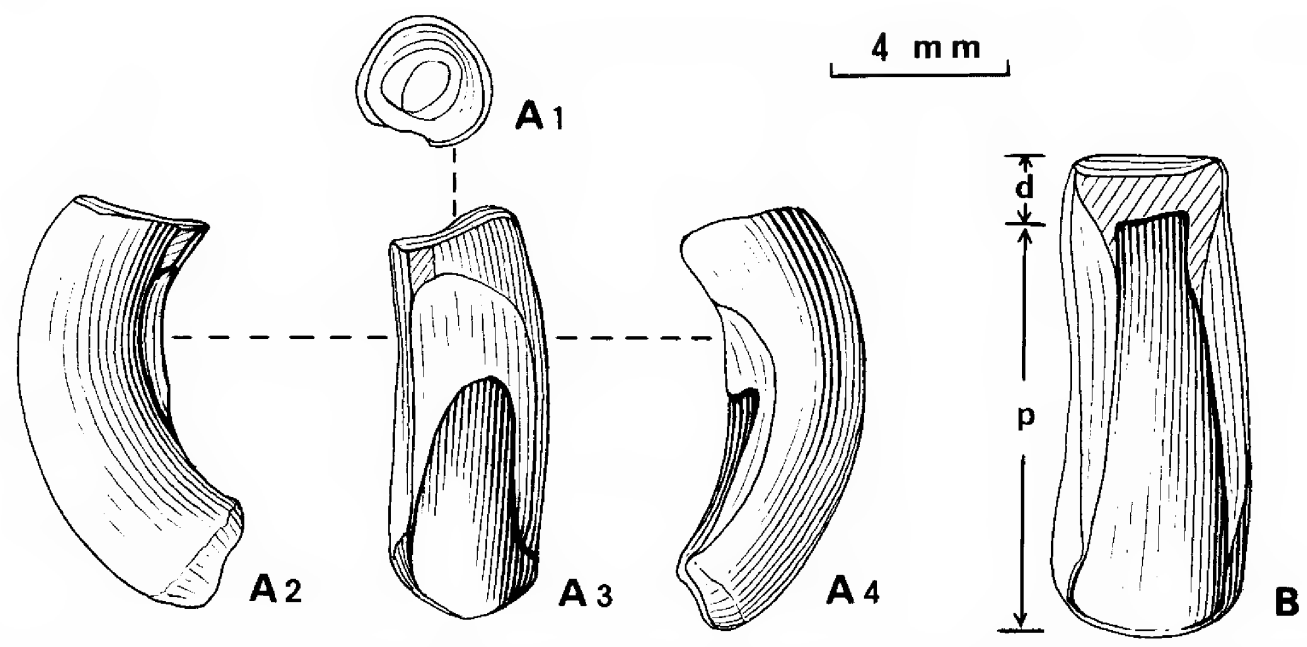

Fig. 31. Cheek teeth of Coelodontomys asiaticus, new genus and species. A. Right upper molar (IVPP V 11428). A1. Occlusal view. A2. Anterior view. A3. Buccal view. A4. Posterior view. B. Buccal view of longitudinal section of cheek tooth (IVPP V 11433). Abreviation as in figure 10.

TABLE 5

Measurements (mm) of Cheek Teeth of Coelodontomys asiaticus, new genus and species

\begin{tabular}{lcrrrrc} 
Tooth & N & Min & \multicolumn{1}{c}{ Max } & Aver & S & V \\
\hline P4-M3, L & 19 & 15.30 & 24.46 & 18.70 & 2.44 & 5.94 \\
M1-3, L & 20 & 11.68 & 20.03 & 14.20 & 2.12 & 4.48 \\
P4, L & 19 & 3.24 & 5.20 & 4.03 & 0.61 & 0.37 \\
P4, W & 19 & 3.30 & 6.15 & 4.89 & 0.97 & 0.94 \\
M1, L & 21 & 3.12 & 5.46 & 3.97 & 0.57 & 0.32 \\
M1, W & 20 & 4.10 & 7.34 & 5.65 & 0.73 & 0.54 \\
M2, L & 21 & 3.66 & 4.94 & 4.30 & 0.39 & 0.15 \\
M2, W & 21 & 4.40 & 6.60 & 5.56 & 0.66 & 0.43 \\
M3, L & 19 & 3.74 & 6.10 & 4.63 & 0.65 & 0.43 \\
M3, W & 19 & 3.40 & 6.40 & 4.79 & 0.85 & 0.72 \\
p4-m3, L & 10 & 16.05 & 25.07 & 20.14 & 2.92 & 8.53 \\
m1-3, L & 11 & 11.90 & 18.83 & 14.98 & 2.12 & 4.51 \\
p4, L & 12 & 4.06 & 5.50 & 4.57 & 0.48 & 0.23 \\
p4, W & 12 & 4.63 & 6.57 & 5.55 & 0.77 & 0.60 \\
m1, L & 13 & 3.46 & 5.60 & 4.23 & 0.67 & 0.46 \\
m1, W & 13 & 4.90 & 7.17 & 5.97 & 0.77 & 0.59 \\
m2, L & 12 & 3.78 & 5.50 & 4.24 & 0.54 & 0.29 \\
m2, W & 12 & 4.50 & 6.14 & 5.32 & 0.57 & 0.33 \\
m3, L & 10 & 3.35 & 4.34 & 3.69 & 0.32 & 0.10 \\
m3, W & 10 & 4.20 & 5.95 & 4.88 & 0.64 & 0.41 \\
\hline & & & & & &
\end{tabular}

dental formula of the cheek teeth was $4 / 4$ and $\mathrm{dP} 3$ and $\mathrm{dP} 4$ were present. In the diagnosis of Cyclomylus lohensis they stated (1923: 5), "The permanent premolar is preceded by a minute, simple dP3 and a large round molariform dP4, as in Tsaganomys." Obviously they thought that in both Tsaganomys and Cyclomylus two upper deciduous teeth, dP3 and $\mathrm{dP} 4$, were replaced by only one premolar, P4, and P3 was never present. In his diagnosis of the Tsaganomyinae Wood (1974: 50) mentioned "milk teeth dP3-4/dp4; permanent cheek teeth reduced to P4/p4, M1-3/ m1-3)." Later, however, misinterpretations of dP3 as P3 by some paleontologists have led the classification of the tsaganomyids into confusion. Shevyreva (1972) considered the presence of $\mathrm{P} 3$ one of the main features of her new genus, Sepulkomys, because she thought dP3 and dP4 of PIN 475-50 as P3 and P4. Kowalski (1974: 159) even thought that Cyclomylus lohensis had a P3. This was accepted as the main feature of Cyclomylus lohensis distinct from Tsaganomys by Huang (1993). Bryant and McKenna (1995: 8) mentioned that "the tooth in question is actually 
TABLE 6

Comparison of Characters among Tsaganomys, Cyclomylus, and Coelodontomys

\begin{tabular}{|c|c|c|c|}
\hline Character & Tsaganomys & Cyclomylus & Coelodontomys \\
\hline Nasal-frontal suture & $\begin{array}{l}\text { More anterior to pre- } \\
\text { maxillary-frontal suture }\end{array}$ & & $\begin{array}{l}\text { Nearly in one line with pre- } \\
\text { maxillary-frontal suture }\end{array}$ \\
\hline $\begin{array}{l}\text { Left and right antepremolar } \\
\text { crests }\end{array}$ & $\begin{array}{l}\text { Curved and merge into one } \\
\text { before reaching incisive } \\
\text { foramen }\end{array}$ & Absent & $\begin{array}{l}\text { Nearly straight, convergent } \\
\text { anteriorly, but not merging } \\
\text { into one }\end{array}$ \\
\hline $\begin{array}{l}\text { Major axis of infraorbital } \\
\text { foramen }\end{array}$ & $\begin{array}{l}\text { Nearly horizontal, almost } \\
\text { parallel with ventral surface } \\
\text { of anterior zygomatic root }\end{array}$ & $\begin{array}{l}\text { Nearly vertical, almost } \\
\text { perpendicular to ventral } \\
\text { surface of anterior zygo- } \\
\text { matic root }\end{array}$ & $\begin{array}{l}\text { Nearly vertical, almost } \\
\text { perpendicular to ventral } \\
\text { surface of anterior } \\
\text { zygomatic root }\end{array}$ \\
\hline $\begin{array}{l}\text { Angle between dorsal } \\
\text { margin of posterior part of } \\
\text { I } 2 \text { alveolus and occlusal } \\
\text { surface of cheek teeth }\end{array}$ & Near $40^{\circ}$ & Near $60^{\circ}$ & Near $60^{\circ}$ \\
\hline Relation between P4 and I2 & P4 extends medial to I2 & P4 extends below 12 & $\begin{array}{l}\text { P4 extends buccoventral } \\
\text { to } 12\end{array}$ \\
\hline Relation between p4 and i2 & p4 grows buccal to $\mathrm{i} 2$ & p4 grows above i2 & p4 grows above i2 \\
\hline Cheek teeth & $\begin{array}{l}\text { Strongly unilaterally hypso- } \\
\text { dont, with open roots }\end{array}$ & $\begin{array}{l}\text { Unilaterally hypsodont, } \\
\text { with closed roots }\end{array}$ & $\begin{array}{l}\text { Strongly unilaterally hypso- } \\
\text { dont, with open roots }\end{array}$ \\
\hline Dentine part & Well developed & Reduced & Reduced \\
\hline Pulp cavity & $\begin{array}{l}\text { Relatively short, nearly } \\
\text { conic, with pointed apex }\end{array}$ & $\begin{array}{l}\text { Well developed, nearly } \\
\text { conic, decreased to base, } \\
\text { with flat or concave top }\end{array}$ & $\begin{array}{l}\text { Well developed, nearly } \\
\text { cylindrical, with flat or } \\
\text { concave top }\end{array}$ \\
\hline Enamel on occlusal surface & Very thin & Thick & Thin \\
\hline Occlusal pattern & Very weak & Prominent & Distinct \\
\hline Core & Absent & Present & Present \\
\hline Lower cheek teeth & Concave anterolingually & Slightly concave lingually & $\begin{array}{l}\text { Concave lingually or } \\
\text { anterolingually }\end{array}$ \\
\hline Hypoconid & Not hypertrophic & Hypertrophic & Hypertrophic \\
\hline Hypoflexid & Nearly transverse & Oblique & Oblique \\
\hline p4 on occlusal view & $\begin{array}{l}\text { Nearly square, with wide } \\
\text { trigonid }\end{array}$ & $\begin{array}{l}\text { Oval, with very narrow } \\
\text { trigonid }\end{array}$ & $\begin{array}{l}\text { Oval, with very narrow } \\
\text { trigonid }\end{array}$ \\
\hline $\begin{array}{l}\text { Protoconid and metaconid } \\
\text { on p4 }\end{array}$ & $\begin{array}{l}\text { Separated widely by } \\
\text { long metalophid II }\end{array}$ & $\begin{array}{l}\text { Close to each other, with } \\
\text { short metalophid II }\end{array}$ & $\begin{array}{l}\text { Close to each other, with } \\
\text { short metalophid II }\end{array}$ \\
\hline Metalophid I of p4 & Present but low & Absent & Absent \\
\hline Trigonid basin of $\mathrm{p} 4$ & Wide and short & Narrow & Very narrow fissure \\
\hline Total enamel thickness of i2 & $170-185 \mu \mathrm{m}$ & Near $80 \mu \mathrm{m}$ & $110-139 \mu \mathrm{m}$ \\
\hline $\begin{array}{l}\text { PE/total enamel thickness } \\
\text { of i } 2\end{array}$ & Near $10 \%$ & Near $40 \%$ & Near $17 \%$ \\
\hline $\begin{array}{l}\text { Inclination of prisms of } \\
\text { PE of i2 }\end{array}$ & $0^{\circ}$ & Near $30^{\circ}$ & Near $30^{\circ}$ \\
\hline Inclination of HSB & $20-30^{\circ}$ & Near $30^{\circ}$ & $25-30^{\circ}$ \\
\hline Number of prisms per HSB & $5-7$ & $3-4$ & $4-5$ \\
\hline
\end{tabular}


a dP3 that is lost early in life and not replaced." They came to the same conclusion as Matthew and Granger (1923). As far as I know the specimens, which preserved dP3 (see Bryant and McKenna: 19, table 2), belong to either Cyclomylus or Coelodontomys. So far no specimen of Tsaganomys altaicus preserving dP3 has ever been found. In $C y$ clomylus and Coelodontomys dP3 occurred but it was lost early in life and was not replaced, whereas in Tsaganomys it is uncertain whether dP3 was present or not.

\section{Analysis of Some Features of Skull and MANDible of THE TSAGANOMYIDAE}

Vinogradov and Gambaryan (1952) analyzed the masticator muscle and the muscle of the anterior limb of the tsaganomyids. Some supplementary analysis is given below. The Tsaganomyidae have many particular features, which can indicate something about their ecology and relationships with other rodents. These features are

(1) protrogomorphous skull with small infraorbital foramen, which is not the passage for the masseter muscle;

(2) temporal fossa tremendous, sagittal and occipital crests very prominent, with pronounced anterior process;

(3) zygomatic arch very robust and strongly flared laterally, with rough area for masseteric muscle on the ventral surface;

(4) jugal enlarged and extending anteriorly to meet the premaxilla;

(5) pterygoid fossa small, shallow, not perforated;

(6) glenoid fossa broad, short, and shallow;

(7) hystricognathous mandible with large, flared, but not very much posteriorly extended angular process;

(8) coronoid process high;

(9) condyloid process with wide, short, triangularly convex articular surface;

(10) postcondyle expansion absent;

(11) masseteric fossa large and deep, with weak upper and lower masseteric crests;

(12) small fossa present anterior to the masseteric fossa;

(13) lower margin of angular process is rough;

(14) distinct longitudinal crest separating medial fossa from flat lower part on the lingual side of angular process;

(15) occlusal surface of cheek tooth row with steplike profile; and

(16) cheek teeth cylindrical, unilaterally hypsodont, with occlusal pattern lost early in wear, and the worn occlusal surface concave bordered by high margin.

Among these features, character (2) and (8) indicate that the tsaganomyid temporal muscle was voluminous. The anterior process of the sagittal crest is interpreted as the anterior origin of the temporal muscle. It is situated anterior to $\mathrm{P} 4$ in position, and a distinct anteroventral crest is present posteromedial to the orbit. These features indicate that the temporal muscle had a well-developed orbital part in the tsaganomyids. The primary function of this muscle was to close the jaw. This voluminous temporal muscle may have been correlated with the specialized mode of life in the tsaganomyids, characterized by digging and crushing rather than by propalinally chewing food.

Probably the extremely large temporal muscle needed a very large space. Therefore the zygoma forms a strong laterally convex arch. To strengthen the zygoma the jugal is enlarged and extends anteriorly to meet the premaxillary. Corresponding to the strongly laterally convex zygoma, the angular process of the lower jaw becomes very large and flared. This is apparently associated with the strongly convex zygoma.

Character (1) indicates that the masseter muscle did not pass through the infraorbital foramen. The small pocket formed by the jugal, lachrymal, and maxillary is the eye socket rather than a depression for the attachment of the anterior part of the masseter muscle. As in other protrogomorphs, the masseter medialis of the Tsaganomyidae was not elongate forward and its origin did not shift forward. It may have originated from the medial side of zygoma and inserted on the masseteric fossa of the lower jaw. It was strong and pulled the lower jaw in almost a vertical direction. Generally, the horizontally lying posterior part of masseter lateralis profundus is often associated with the posterior expansion of the mandible (= postcondyloid process) (Woods, 1972). However, character (10) indicates that the masseter lateralis in 
the tsaganomyids was not as elongated and did not lie as horizontally as in hystricomorphs but was short, strong, and mainly vertically directed.

As in the Hystricognathi there is a groove between the angular process and the lower incisor alveolus for the masseter superficialis in the Tsaganomyidae. However, character (14) indicates that the groove was restricted by a distinct longitudinal crest, which may represent the upper margin of the insertion of the pars reflexa of the superficial masseter. As so interpreted, the insertion of this part of masseter muscle was low and restricted on the flat lower part and rough ventral margin of the angular process.

According to Woods (1972) the elongated and horizontally lying masseteric muscle is an important component of the propalinal masticatory apparatus of the rodents. Its function is to force the lower jaw anteriorly in propalinal chewing. In the tsaganomyids the main function of the masseter muscle was nearly vertical, and the muscles were mainly associated with crushing and transversely chewing rather than with anteroposterior movement of the lower jaw.

The pterygoid muscles are important components of the rodent jaw musculature. To accommodate the propalinal movement the pterygoid muscles increase in length and lie in a more horizontal plane. This is accomplished by the movement of the origin of the internal pterygoid muscle deep into the pterygoid fossa, through movement of the insertion of the internal pterygoid muscle distally onto the posteriorly extended angle of the mandible, and by movement of the insertion of external pterygoid muscle onto the postcondyloid process. As a result, the pterygoid fossa becomes enlarged or even open into the orbit or braincase, and a prominent postcondyloid process is present. In the tsaganomyids, however, characters (5), (10) and (13) indicate that as in other protrogomorphs their pterygoid muscles did not increase in length and did not lie horizontally (Wood, 1965). Obviously the main function of these muscles in the tsaganomyids was to pull the lower jaw mediad and serve a transverse motion in chewing food.

In rodents a greater anteroposterior shift of the lower jaw is allowed by the elongation of the glenoid fossa and condyloid process in an anteroposterior direction. However, the condition of the tsaganomyids is contrary (see characters [6] and [9]). This indicates that the mouth of the animal could open very widely and the mandible could move rather freely in different directions, but the propalinal movement was limited.

The flatness of the worn cheek tooth surface in many rodents is an indication that the animal chews propalinally. In the tsaganomyids the steplike occlusal surface of the cheek tooth row, character (15), obviously hindered the propalinal chewing of the lower jaw when the upper and lower cheek teeth came into contact.

It seems that the tsaganomyids were adapted for a fossorial mode of life. They had a low, broad skull with a narrow rostrum and strong and procumbent incisors and could open their mouth widely. The well-developed temporal muscle and the short, vertically oriented masseter and pterygoid muscles could close the mouth quickly. They may have dug with their lower jaw and crushed and chewed food transversely rather than propalinally. In addition, their tooth morphology (character [16]) is similar to some of the edentates. Possibly they had similar feeding habits, adapted to feed on insects and worms.

\section{Phylogenetic Relationships Among the Genera of THE TSAganomyidaE}

The Tsaganomyidae comprises five species in three genera. Among the genera, Cyclomylus seems the most primitive. Tsaganomys and Coelodontomys, sharing highcrowned, unilaterally hypsodont cheek teeth, have been confused for a long time. However, tooth structure, occlusal pattern, and the relation between the incisor and the forth premolar are quite different between them. On the contrary, Cyclomylus and Coelodontomys have a closer relationships than either do with Tsaganomys. They share such derived features as an infraorbital foramen with a nearly vertical major axis, a larger angle between the dorsal surface of the posterior part of upper incisor alveolus and the occlusal surface of the cheek teeth, cheek teeth having a reduced dentine part, a well-devel- 
oped pulp cavity, a secondary dentine core, and incisor enamel having inclined prisms of PE. Although the cheek teeth of Tsaganomys and Coelodontomys have a similar evolutionary tendency, becoming strongly unilaterally hypsodont, their evolutionary direction is quite different. In Tsaganomys the dentine grows continuously with tooth growth and the premolar growth mimics that of the molars: $\mathrm{P} 4$ reaches the medial side of $\mathrm{I} 2$ and $\mathrm{p} 4$ extends to buccal side of i2 as do the lower molars. In Coelodontomys, when cheek teeth grow the pulp cavity grows but the dentine part stops growing. The premolars proceed in a different path from the molars: $\mathrm{P} 4$ passes by the ventral side of 12 , reaches the buccal side of $I 2$, and is separated from the upper molars by the posterior part of the upper incisor, and p4 extends to dorsal side of the incisors, not to the buccal side as do the lower molars. Obviously, Tsaganomys and Coelodontomys represent two different lineages initially. The cylindrical, strongly unilaterally hypsodont cheek teeth common to both $T s a$ ganomys and Coelodontomys are the result of parallel evolution. Therefore, Coelodontomys and Cyclomylus may form a sister group to Tsaganomys. Within Cyclomylus, $C$. lohensis is the most primitive species, whereas $C$. biforatus is the most advanced, with $C$. intermedius lying in between.

\section{Biostratigraphic Distribution OF THE TSAGANOMYIDAE}

The Tsaganomyidae ranged through a very short geological time in central Asia (from early Oligocene through early late Oligocene, perhaps to early Miocene). They are index fossils for the Asian Oligocene. With their relationships now resolved, the geological range of the genera and species of the Tsaganomyidae becomes clear (fig. 32). The most primitive taxon, Cyclomylus lohensis, appeared in the early early Oligocene. Cyclomylus intermedius made its first appearance in early early Oligocene as well but may be slightly later than $C$. lohensis. Cyclomylus lohensis made its first appearance in the 13th level of the Wulanbulage Formation (IVPP Loc. 79010 and the 4th level of section $\mathrm{XIIIH}$ ), whereas $C$. intermedius appears in the 16th level, just below the boundary of the upper and lower members of Wulanbulage Formation. Cyclomylus biforatus and Coelodontomys asiaticus were restricted to late early Oligocene. Tsaganomys altaicus made its first appearance in late early Oligocene. By the early late Oligocene Cyclomylus and Coelodontomys were extinct, and only Tsaganomys survived. The cheek tooth structure may be one of the major reasons why Tsaganomys survived longer than did Coelodontomys and Cyclomylus. The cheek teeth of Tsaganomys were stronger than those of Coelodontomys and Cyclomylus and could have lasted longer in life.

\section{RELATIONSHIPS OF TSAGANOMYIDAE WITH OTHER RODENTS}

The relationships of the Tsaganomyidae with other rodents have long posed a puzzling problem. There have been four different hypotheses: (1) the tsaganomyids were an Asian ancestor of the bathyergids, without relation to cylindrodontids (Matthew and Granger, 1923; Landry, 1957); (2) the tsaganomyids were derived from the cylindrodontids, and the relation with bathyergids is obscure (Burke, 1935, 1936; Wood, 1937, 1970, 1974); (3) the bathyergids originated from the tsaganomyids, which, in turn, were derived from Asian cylindrodontids (Wood, 1980, 1985; Patterson and Wood, 1982); and (4) Tsaganomys and Hystricognathi form a sister group to the Ctenodactylidae (Bryant and McKenna, 1995).

RELATIONSHIP BETWEen THE TSAgANOMYIDAE AND BATHYERGIDAE: Matthew and Granger (1923) considered the tsaganomyids as the fossil record of the Bathyergidae and put them in a separate subfamily of the Bathyergidae. They suggested that Tsaganomys might be the Asiatic ancestor of the Bathyergidae. Landry (1957) agreed with them and further thought the tsaganomyids to be more closely related to bathyergids and put them in the Bathyerginae with Bathyergus. The main similarities he mentioned between these taxa are protrogomorphy, hystricognathy, and hypsodonty. However, Landry (1957: 73) was very careful when he said, "Tsaganomys should be reexamined to see if the pterygoid fossa communicates with the orbit in this genus. Its incisors should be sec- 


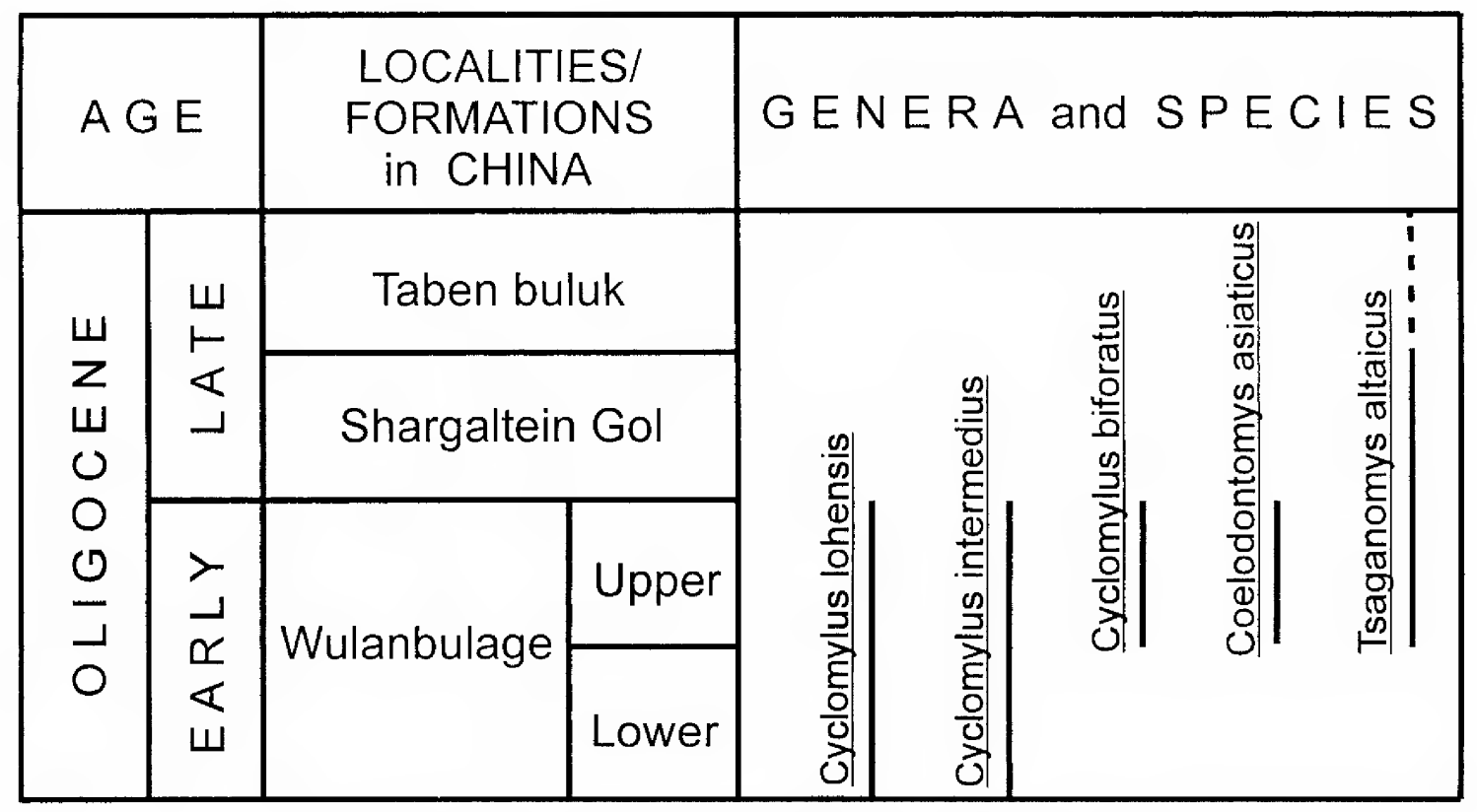

Fig. 32. Biochronologic distribution of the Tsaganomyidae.

tioned to check the pattern of the enamel prisms, and, if necessary, its tympanic bullae should be opened to see whether the malleus and incus are fused." Now it is evident that in the tsaganomyids the pterygoid fossa is small and not open into the orbit, and the malleus and incus are not fused. These derived traits of Bathyergidae are absent in Tsaganomyidae. In addition, the Tsaganomyidae have more different derived features than the Bathyergidae, including horizontal position of fenestra ovalis, partly covered stepedial muscle origin, as well as other features (see Parent, 1993, and Bryant and McKenna, 1995: table 4). The protrogomorphy of the Bathyergidae has been showed to be secondary (Maier and Schrenk, 1987). Obviously the tsaganomyids and bathyergids do not have a close relationship.

RELATIONSHIP BETWEEN THE TSAGANOMYIDAE AND CylindrodontidaE: Burke (1935, 1936) first pointed out the possible relationship between the tsaganomyids and Ardynomys. Wood (1937, 1970, 1974, 1980) agreed with Burke that the tsaganomyids were derived from Ardynomys and formally put the tsaganomyids in the Cylindrodontidae. This viewpoint was widely accepted (Simpson, 1945; Vinogradov and Gambaryan, 1952;
Mellett, 1968; Shevyreva, 1971, 1972, 1974a, 1974b, 1994; Kowalski, 1974; Huang, 1993). The similarities of the skull between the two taxa were listed as follows: an antorbital crest, widely expanded zygomatic region, oval infraorbital foramen, and the extension of the base of the incisor into the orbit (Burke, 1936, Wood, 1970, 1974). Bryant and McKenna (1995) analyzed the similarities and differences between the two taxa in more detail. I agree with them that the similarities mentioned above are superficial or plesiomorphous. The occlusal pattern of the cheek teeth of the Tsaganomyidae is strikingly similar to that of some cylindrodonts. However, the microstructure of the incisor of the Tsaganomyidae is different from that of the Cylindrodontidae. In the Tsaganomyidae it is multiserial, whereas in the Cylindrodontidae (Cylindrodon and Ardynomys) it is uniserial (Wahlert, 1968: 15; Martin, 1992: 43). According to presently available data, the Tsaganomyidae and Cylindrodontidae developed in different directions.

Relationships AMONG THE TSAgANOMYIDAe, Hystricognathi, and CtenodactyloIDEA: Bryant and McKenna (1995) suggested that the Ctenodactylidae is the sister taxon to the Hystricognathiformes, including Tsaganomys and Hystricognathi. They stated that 
"in addition to the morphological characters from our analysis, this relationship is supported by embryological (Luckett, 1985), reproductive and chromosomal (George, 1985), and dental characters (Hussain et al., 1978; Jaeger et al., 1985; Flynn et al., 1986)." (Bryant and McKenna, 1995: 34).

It is necessary to point out that the analysis of the authors mentioned above on the relationship of the Ctenodactylidae with the Hystricognathi did not include the tsaganomyids. Luckett (1985: 269) pointed out the difficulties involved in corroborating any hypotheses for the affinities of Sciuridae, Aplodontidae, Castoridae, Anomaluridae, Pedetidae, and Ctenodactylidae with either of Hystricognathi and Myomorpha, based on the available developmental data. Wang (1997b) stated that the evidence from the fossils is not enough to support the sister group hypothesis of the Ctenodactyloidea with the Hystricognathi. The dental characters used in the works of some authors (Hussain et al., 1978, Jaeger et al., 1985, and Flynn et al., 1986) were based on isolated cheek teeth of the Chapattimyidae and Protophiomys, whose status is still problematic. In addition, all the other ctenodactyloids have a sciurognathous mandible, and we have not seen any material in the Ctenodactyloidea showing the change from the sciurognathy to hystricognathy.

No matter whether the relationship between the ctenodactyloids and the Hystricognathi is as close as hypothesized by the authors mentioned above, it is difficult to corroborate the affinities of the Tsaganomyidae with these two taxa because the Tsaganomyidae lack the derived features common to these taxa, including hystricomorphous skull, large and deep pterygoid fossa, well-developed lower masseteric crest, fused malleus and incus, large and anteriorly expanded malleus head, proximal fusion of the tibia and fibula, and large hypocone on the upper cheek teeth. On the other hand, the Tsaganomyidae have derived features of their own (autapomorphies), such as voluminous temporal fossa, prominent sagittal and occipital crests, robust and strongly convex laterally zygomatic arch with well-developed jugal, which meets the premaxillary to form a plate with the lachrymal, high ascending ramus with high coronoid process, triangularly convex surface of condyloid process, and absence of a hypocone on upper cheek teeth. The Tsaganomyidae also have short masseter and pterygoid muscles, well-developed temporal muscle, and steplike occlusal surface of the cheek tooth row. These features of the Tsaganomyidae can be associated with crushing and chewing food transversely. On the contrary, in the Hystricognathi and the Ctenodactyloidea the masseter and pterygoid muscles are elongated and the temporal muscle is very much reduced. These features are associated with propalinal chewing (Landry, 1957; Woods, 1972). Obviously the Tsaganomyidae evolved in an evolutionary direction distinct from both the Ctenodactyloidea and Hystricognathi.

The sister group hypothesis of the Tsaganomyidae with the Hystricognathi suggested by Bryant and McKenna (1995) was based on such derived features as hystricognathous mandible, reduced lachrymal, and multiserial enamel microstructure. As mentioned above the orbital wing of the lachrymal of the Tsaganomyidae is wide. As for the multiserial enamel, it evidently evolved at least twice in the Ctenodactyloidea (Martin, 1992), and in the Tsaganomyidae the enamel structure of Cyclomylus represents a primitive stage of the multiserial structure. Possibly the multiserial enamel microstructure arose independently in the Tsaganomyidae and the Hystricognathi.

The hystricognathous lower jaw is an important character for classification in Rodentia. Although the tsaganomyids and Hystricognathi share the hystricognathous mandible, the two taxa are different in the form of the angular process. In the Hystricognathi the lower masseteric crest is well developed, the coronoid process is reduced, the condyloid process is narrow and long, the postcondyloid process is usually present, and the angular process usually extends posteriorly with the insertion of pars reflexa of the superficial masseter high up near and posterior to the condyle (Woods, 1972: 124). All these features of the Hystricognathi are associated with propalinal chewing (Woods, 1972; Landry, 1957).

However, the characters in the tsaganomyids are different: the angular process is 
large, strongly flared, and extends ventrally rather than posteriorly; the lower masseteric crest is weak; the coronoid process is high; the articular surface of the condyloid process is wide, triangularly convex, and without postcondyloid process; and the insertion of pars reflexa of masseter superficialis is low. The Tsaganomyidae did not develop propalinal chewing but mainly crushed and chewed food transversely. Obviously the laterally flared angular process in the Tsaganomyidae is due to the strongly laterally convex zygoma forced by the strong temporal muscle. Therefore, the origin of the hystricognathous mandible of the Tsaganomyidae is independent from the typical hystricognathous mandible of the Hystricognathi. For simplicity's sake, I tentatively call it tsaganomyid-type hystricognathous mandible.

It seems that the Tsaganomyidae represent a quite independent lineage. Up to now no other rodents have been shown to have a close relationship with it. Thus, I temporarily consider the Tsaganomyidae as Rodentia incertae sedis.

\section{CONCLUSIONS}

(1) Cyclomylus lohensis is not a junior synonym of Tsaganomys altaicus but a valid genus and species. The concept of Tsaganomys altaicus of some authors includes at least two taxa: Tsaganomys altaicus and Coelodontomys asiaticus, new genus and species. Altogether the Tsaganomyidae comprises three genera and five species: Tsaganomys altaicus, Cyclomylus lohensis, C. intermedius, new species, $C$. biforatus new species, and Coelodontomys asiaticus, new genus and species.

(2) Among the Tsaganomyidae Cyclomylus lohensis is the most primitive genus and species. Cyclomylus and Coelodontomys represent one lineage and form a sister group to Tsaganomys.

(3) The Tsaganomyidae are suggested to have had a fossorial habit with a diet of insects and worms. The mandible of the Tsaganomyidae has a large flared angular process. It is associated with crushing and chewing food transversely and represents a special type of mandible distinct from the typical hystricognathous mandible of the Hystricognathi.

(4) Biostratigraphic distribution of the Tsaganomyidae shows that Cyclomylus lohensis appeared earliest in the early early Oligocene. Cyclomylus intermedius appeared in early early Oligocene but a little later than C. lohensis. Cyclomylus biforatus and Coelodontomys asiaticus were limited to the late early Oligocene. Tsaganomys altaicus appeared also in late early Oligocene, but survived into the early late Oligocene (perhaps into early Miocene). After that the Tsaganomyidae disappeared in Asia.

(5) The Tsaganomyidae represent a special independent evolutionary group in the Rodentia and have nothing to do with other known rodents based on the present available data.

\section{ACKNOWLEDGMENTS}

It would have been impossible for me to finish this work had I not had the opportunity to observe so large a portion of the tsaganomyid collection of the Asiatic Expedition held in the AMNH. I wish to express my deep appreciation to Dr. R. H. Tedford of AMNH for kindly inviting me to visit the AMNH, his encouragement and manifold help during my stay in New York, and for assistance in improving my written English. I owe a great deal to Dr. M. C. McKenna of the AMNH for his permission to make casts and his loan of specimens to me, and to Drs. X.-m. Wang, J. Meng, and K.-q. Gao of the AMNH for their help during my stay in New York and work on this paper. I am deeply gratful to Profs. Z.-x. Qiu, C.-k. Li, S.-h. Zheng, W.-y. Wu, X.-s. Huang, Z.-d. Qiu, and Y.-s. Tong of IVPP and Prof. R.-y. Li of Beijing Stomatological Hospital for their stimulating discussion, from which some of the ideas expressed in this paper were developed. Many thanks to Mr. E. Pederson of the AMNH for his excellent skill in preparation of some specimens and some casts, Prof. W.-1. Sheng of IVPP for his good illustrations, Mr. J. Zhang for his photographs, and Mrs. L. Ouyang for preparing the SEM photomicrographs of the incisors. I express my heartfelt thanks to two reviewers for their helpful reviews. This project was supported 
by NSF of China (Nos. 49472083 and 49872011) and my travel was supported by the Carter Fund of the AMNH.

\section{REFERENCES}

Bohlin, B.

1937. Oberoligozäne Säugetiere aus dem Shargaltein-Tal (western Kansu). Palaeontol. Sin. n. ser. C 3: 66 pp.

Bryant, J. D., and M. C. McKenna

1995. Cranial anatomy and phylogenetic position of Tsaganomys altaicus (Mammalia: Rodentia) from the Hsanda Gol Formation (Oligocene), Mongolia. Am. Mus. Novitates 3156: 42 PP.

Burke, J. J.

1935. Pseudocylindrodon, a new rodent genus from the Pipestone Springs Oligocene of Montana. Ann. Carnegie Mus. 25: 1-4.

1936. Ardynomys and Desmatolagus in the North American Oligocene. Ibid. 135154.

Emry, R. J., and W. W. Korth

1996. 19. Cylindrodontidae. In D. R. Prothero and R. J. Emry (eds.), The terrestrial Eocene-Oligocene transition in North America: 399-416. New York: Cambridge Univ. Press.

Emry, R. J., S. G. Lucas, L. Tyutkova, and B.-y. Wang

1998. The Ergilian-Shandgolian (EoceneOligocene) transition in the Zaysan Basin, Kazakstan. In K. C. Beard and M. R. Dawson (eds.), Dawn of the age of mammals in Asia. Bull. Carnegie Mus. Nat. Hist. 34: 298-312.

Flynn, L. J., L. L. Jacobs, and I. U. Cheema

1986. Baluchimyinae, a new ctenodactyloid rodent subfamily from the Miocene of Baluchistan. Am. Mus. Novitates 2841: $58 \mathrm{pp}$.

George, W.

1985. Reproductive and chromosomal characters of ctenodactylids as a key to their evolutionary relationships. In $\mathrm{W}$. P. Luckett and J.-L. Hartenberger (eds.), Evolutionary relationships among rodents - a multidisciplinary analysis: 453-474. New York: Plenum Press.

Huang, X.-s.

1993. Cylindrodontidae (Rodentia, Mammalia) from the Middle Oligocene of Ulantatal, Nei Mongol. Vertebr. PalAsiat. 31(1): 33-43. [in Chinese, English Summary]
Hussain, S. T., H. de Bruijn, and J. M. Leinders

1978. Middle Eocene rodents from the Kala Chitta Range (Punjab, Pakistan). Proc. K. Ned. Akad. Wet. ser. B 81(1): 74112.

Jaeger, J.-J., C. Denys, and B. Coiffait

1985. New Phiomorpha and Anomaluridae from the late Eocene of north-west Africa: phylogenetic implications. In W. P. Luckett and J.-L. Hartenberger (eds.), Evolutionary relationships among rodents - a multidisciplinary analysis: 567-588. New York: Plenum Press.

Kowalski, K.

1974. Results of the Polish-Mongolian paleontological expeditions. P. V. Middle Oligocene rodents from Mongolia. Palaeontol. Pol. 30: 147-178.

Landry, S. O., Jr.

1957. The interrelationships of the new and old world hystricomorph rodents. Univ. California Publ. Zool. 56(1): 118 pp.

Luckett, W. P.

1985. Superordinal and intraordinal affinities of rodents: developmental evidence from the dentition and placentation. In W. P. Luckett and J.-L. Hartenberger (eds.), Evolutionary relationships among rodents-a multidisciplinary analysis: 227-276. New York: Plenum Press.

Maier, W., and F. Schrenk

1987. The hystricomorphy of the Bathyergidae, as determined from ontogenetic evidence. Z. Säugetierkd. 52(3): 156164.

Martin, T.

1992. Schmelzmikrostruktur in den Inzisiven alt- und neuweltlicher hystricognather Nagetiere. Palaeovertebr. Mèm. Extra.: 168 pp.

Matthew, W. D., and W. Granger

1923. New Bathyergidae from the Oligocene of Mongolia. Am. Mus. Novitates 101: $5 \mathrm{pp}$.

McKenna, M. C., and S. K. Bell

1997. Classification of mammals above the species level. New York: Columbia Univ. Press, 631 pp.

Mellett, J. S.

1968. The Oligocene Hsanda Gol Formation, Mongolia: A revised faunal list. Am. Mus. Novitates 2318: 16 pp.

Parent, J.-P.

1993. Contribution de l'étude de la région auditive à la recherche des affinités systématiques du genre Tsaganomys (Mat- 
thew et Granger 1923). C. R. Acad. Sci. Ser. II: 316: 843-846.

Patterson, B., and A. E. Wood

1982. Rodents from the Deseadan Oligocene of Bolivia and the relationships of the Caviomorpha. Bull. Mus. Comp. Zool. 149(7): 371-543.

Qiu, Z.-X., and Z.-g. Gu

1988. A new locality yielding mid-Tertiary mammals near Lanzhou, Gansu. Vertebr. PalAsiat. 26(3): 198-213. [in Chi-

Schaub, S. nese, English summary]

1958. Simplicidentata ( $=$ Rodentia). In J. Piveteau (ed.), Traité de paléontologie 6(2): 659-818. Paris: Masson.

Shevyreva, N. S.

1971. K voprosu o sistematicheskom polozhenii "Tsaganomys altaicus" (Mammalia, Rodentia). Byull. Mosk. O-va. Ispt. Prir. Otd. Geol. 46(6): 144 pp. [in Russian]

1972. Novye gryzuny iz Paleogena Mongolii i Kazakhstana. Palaeontol. Z. 3: 134145. [in Russian]

1974a. About taxonomic place of Tsaganomys altaicus. Based on analysis of molar teeth microstructures of several species in family Cylindrodontidae (Rodentia, Mammalia). In N. N. Kamarenko et al. (eds.), Mesozoic and Cenozoic Faunas and Biostratigraphy of Mongolia. The Joint Soviet-Mongolian Paleontological Expedition, Transaction, 1: 46-59. Moscow: Nauka Press. [in Russian]

1974b. Historical development of some rodents of the suborder Sciuromorpha in Asia. Paleontol. J. 1974(1): 90-100. [in Russian]

1994. New rodents (Rodentia, Mammalia) from the Lower Oligocene of the Zaysan Depression (Eastern Kazakhstan). Ibid. 28(4): 111-126. [in Russian, English abstract]

Simpson, G. G.

1945. The principles of classification and a classification of mammals. Bull. Am. Mus. Nat. Hist. 85: 350 pp.

Teilhard de Chardin, P.

1926. Description de mammifères tertiaires de Chine et de Mongolie. Ann. Paléontol. 15: 1-52.

Teilhard de Chardin, P., and P. Leroy

1942. Chinesis fossil mammals. Inst. Géobiol. Pékin (8): $142 \mathrm{pp}$.

Vinogradov, B. S., and P. P. Gambaryan

1952. Oligotsenovyie tsilindrodontyi Mongolii i Kazakhstana (Cylindrodontidae,
Glires, Mammalia). Tr. Paleontol. Inst. Akad. Nauk SSSR 41: 13-42. [in Russian]

Wahlert, J. H.

1968. Variabilities of rodent incisor enamel as viewed in thin section, and the microstructure of the enamel in fossil and recent rodent groups. Breviora 309: 1-18.

Wang, B.-y.

1997a. Chronological sequence and subdivision of the Chinese Oligocene mammalian faunas. J. Stratigr. 21(3): 183191. [in Chinese, English abstract]

1997b. The mid-Tertiary Ctenodactylidae (Rodentia, Mammalia) of eastern and central Asia. Bull. Am. Mus. Nat. Hist. 234: $88 \mathrm{pp}$.

Wang, B.-y. J. Chang, X.-j. Meng, and J.-r. Chen

1981. Stratigraphy of the upper and middle Oligocene of Qianlishan District, Nei Mongol (Inner Mongolia). Vertebr. PalAsiat. 19(1): 26-34. [in Chinese, English summary]

Wilson, R. W.

1949. Early Tertiary rodents of North America. Carnegie Inst. Washington Publ. 584: $67-164$.

Wood, A. E.

1937. The mammalian fauna of the White River Oligocene. Part II. Rodentia. Trans. Am. Philos. Soc. n. ser. 28, p. 2: 269 pp.

1955. A revised classification of the rodents. J. Mammal. 36(2): 165-187.

1962. The early Tertiary rodents of the family Paramyidae. Trans. Am. Philos. Soc. n. ser. 52 p.1: 261 pp.

1965. Grades and clades among rodents. Evolution 19(1): 115-130.

1970. The early Oligocene rodent Ardynomys (Family Cylindrodontidae) from Mongolia and Montana. Am. Mus. Novitates 2418: 18 pp.

1974. Early Tertiary vertebrate faunas Vieja Group Trans-Pecos Texas: Rodentia. Texas Memorial Mus. Bull. 21: 1-112.

1980. The Oligocene rodents of North America. Trans. Am. Philos. Soc. 70 p. 5: 68 pp.

1985. The relationships, origin and dispersal of the hystricognathous rodents. In W. P. Luckett and J.-L. Hartenberger (eds.), Evolutionary relationships among rodents - a multidisciplinary analysis: 475-513. New York: Plenum Press. 
Wood, A. E., and R. W. Wilson

1936. A suggested nomenclature for cusps of cheek teeth of rodents. J. Paleontol. 10(5): 388-391.

Woods, C. A.

1972. Comparative myology of jaw, hyoid, and pectoral appendicular regions of new and old world hystricomorph ro- dents. Bull. Am. Mus. Nat. Hist. 147(3): 117-198.

Young, C. C., and M. M. Chow

1956. Some Oligocene mammals from Lingwu, N. Kansu. Acta Palaeontol. Sin. 4(4): 447-459. [in Chinese, English abstract] 

Recent issues of the Novitates may be purchased from the Museum. Lists of back issues of the Novitates and Bulletin published during the last five years are available at World Wide Web site http://nimidi.amnh.org. Or address mail orders to: American Museum of Natural History Library, Central Park West at 79th St., New York, NY 10024. TEL: (212) 769-5545. FAX: (212) 7695009. E-MAIL: scipubs@amnh.org

(a) This paper meets the requirements of ANSI/NISO Z39.48-1992 (Permanence of Paper). 